\section{Pacific Northwest}

National Laboratory

Operated by Battelle for the

U.S. Department of Energy

\title{
The Feasibility of Using an Ultrasonic Fish Tracking System in the Tailrace of Lower Granite Dam in 2002
}

\author{
D M Faber \\ MA Weiland \\ T J Carlson \\ KM Cash(a) \\ SA Zimmerman(b)
}

(a) U.S. Geological Survey Biological Resources Division, Cook, Washington

(b) Mevatec, Inc., North Bonneville, Washington

DRAFT FINAL REPORT

September 2003
Prepared for the U.S. Army Corps of Engineers

Portland District, Portland, Oregon under a Related Services Agreement with the U.S. Department of Energy Contract DE-AC06-76RLO1830 


\title{
DISCLAIMER
}

This report was prepared as an account of work sponsored by an agency of the United States Government. Neither the United States Government nor any agency thereof, nor Battelle Memorial Institute, nor any of their employees, makes any warranty, express or implied, or assumes any legal liability or responsibility for the accuracy, completeness, or usefulness of any information, apparatus, product, or process disclosed, or represents that its use would not infringe privately owned rights. Reference herein to any specific commercial product, process, or service by trade name, trademark, manufacturer, or otherwise does not necessarily constitute or imply its endorsement, recommendation, or favoring by the United States Government or any agency thereof, or Battelle Memorial Institute. The views and opinions of authors expressed herein do not necessarily state or reflect those of the United States Government or any agency thereof.

\author{
PACIFIC NORTHWEST NATIONAL LABORATORY \\ operated by \\ BATTELLE \\ for the \\ UNITED STATES DEPARTMENT OF ENERGY
}

under Contract DE-AC06-76RL01830

Printed in the United States of America

Available to DOE and DOE contractors from the

Office of Scientific and Technical Information,

P.O. Box 62, Oak Ridge, TN 37831-0062;

ph: (865) 576-8401

fax: (865) 576-5728

email: reports@adonis.osti.gov

\begin{abstract}
Available to the public from the National Technical Information Service, U.S. Department of Commerce, 5285 Port Royal Rd., Springfield, VA 22161 ph: (800) 553-6847 fax: (703) 605-6900

email: orders@ntis.fedworld.gov

online ordering: http://www.ntis.gov/ordering.htm
\end{abstract}

This document was printed on recycled paper.

$(8 / 00)$ 


\title{
The Feasibility of Using an Ultrasonic Fish Tracking System in the Tailrace of Lower Granite Dam in 2002
}

\author{
D. M. Faber \\ M. A. Weiland \\ T. J. Carlson \\ K. M. Cash ${ }^{(a)}$ \\ S. A. Zimmerman ${ }^{(b)}$ \\ DRAFT FINAL REPORT
}

September 10, 2003

Prepared for the U.S. Army Corps of Engineers

Portland District, Portland, O regon

under a Related Services Agreement

with the U.S. Department of Energy

Contract DE-AC06-76RLO 1830

Pacific Northwest National Laboratory

P.O. Box 999

Richland, WA 99352

(a) U.S. Geological Survey Biological Resources Division, Cook, Washington

(b) Mevatec, Inc., North Bonneville, Washington 



\section{Executive Summary}

In spring 2002, the Pacific Northwest National Laboratory (PNNL) conducted a study for the U.S. Army Corps of Engineers (the Corps) - Portland District to assess the feasibility of using ultrasonic fish tracking in the untested environment of a hydroelectric dam tailrace. If fish tracking were determined to be feasible, we would track the movement of juvenile hatchery chinook (Oncorhynchus tshawytscha), juvenile hatchery steelhead (O. mykiss), and juvenile wild steelhead (O. mykiss) and relate their movement to dam operations. The majority of fish to be tracked were released as part of a separate study conducted by the Biological Resources Division of the U.S. Geological Survey (BRD), which was investigating the movement of juvenile salmon in the forebay of Lower Granite Dam in relation to Removable Spillway Weir (RSW) testing. The two studies took place consecutively from April 14 to June 7, 2002.

To determine the feasibility of using an ultrasonic fish tracking system to track juvenile salmon in a tailrace environment, we set up an array of 16 hydrophones in a 90,000 $\mathrm{m}^{2}$ square in the tailrace at Lower Granite Dam. We determined that using an ultrasonic fish tracking system (UFTS) in the tailrace of Lower Granite Dam was feasible for investigating the behavior of juvenile salmon in that environment. However, the resolution of behavioral information was coarser than we had anticipated; thus, we have presented alternative methods for future use of ultrasonic fish tracking in this environment. The alternative methods, which are described in detail in this report, will provide better behavioral information when using the UFTS in the tailrace environment.

The methods that we used for our feasibility study were sufficient to address research objectives and provided one-dimensional tracking information from tagged fish (up to $75 \mathrm{~m}$ resolution). The effective ranges of the tags were less than anticipated, so spatial resolution of fish position was poor. The low hydrophone detection ranges for tagged fish were due to the presence of noise and entrained air from spill. It is possible that positions of fish could be resolved to within one meter (two dimensions [2D]) if a hydrophone array were adequately spaced to account for the reduction in tag ranges due to the high air entrainment in the spill environment. It is feasible that four hydrophones spaced within a 7-m square could resolve a 2D fish position in highly turbulent flow where air entrainment is high, or within a 34-m square where flow is dynamic and the array is located adjacent to an area where air entrainment is high, such as a spillway. Irrespective of the coarseness of the behavioral data that we collected, valuable information was acquired on the movements of juvenile salmon with respect to the dam operations at Lower Granite Dam.

We determined that juvenile steelhead (wild and hatchery) were delayed when a large eddy was present downstream of the powerhouse. This eddy was formed by relatively high spill discharges and low powerhouse discharges. Computational flow model results confirmed this trend.

To investigate the relationship between dam operations and juvenile salmon egress timing, we divided the research period into four separate flow treatments: 1) high powerhouse and spillway discharge; 2) low powerhouse and spillway discharge; 3) high powerhouse and low spillway discharge; and 4) and low powerhouse and high spillway discharge. The threshold separating high and low discharge was the median powerhouse $(\mathrm{Q}=54 \mathrm{kcfs})$ and spillway $(\mathrm{Q}=24 \mathrm{kcfs})$ hourly discharge values. 
Our results showed that juvenile steelhead were delayed within the tailrace during the low powerhouse (< $54 \mathrm{kcfs}$ ) - high spill (> $24 \mathrm{kcfs}$ )tailrace condition. Previous studies have observed that juvenile salmon are disoriented after dam passage, impairing their avoidance response to predators. Our flow model also showed that the low powerhouse-high spill flow treatment created large eddies and slack water areas conditions more suitable to predatory activity by piscivorous fishes such as the northern pikeminnow (Ptychocheilus oregonensis) than did two of the other three tailrace treatments tested. The compounded effects of delay, expansion of habitat suitable for predators, and disorientation of juvenile salmon likely increased the opportunity for predation of juvenile steelhead during the low powerhouse-high spill tailrace treatment more that during the other three treatments tested.

Juvenile spring chinook were more variable in their behavior than the juvenile steelhead with respect to dam operations and were not significantly delayed for any one tailrace condition. There were also no significant differences observed in the residence times of juvenile salmon when comparing daytime or nighttime passage.

The greatest challenge with ultrasonic fish tracking in the tailrace of a hydroelectric facility is the maintenance of the sensitive hydrophone array in the dynamic flow environment of a dam tailrace. High spill discharge regimes exacerbate the problem but, if the equipment can be maintained in place, ultrasonic fish tracking can be very effective for describing the movement patterns of juvenile salmon with respect to their surrounding environment. Tracking of juvenile salmonids can also be applied to survivorship studies, where inferences on predation mortality and predatory pressure are linked to habitat selection. A future study that takes advantage of these findings and places hydrophones in areas that are isolated from direct spill will dramatically increase the detectability of tagged fish. If the telemetry data on the behavior of juvenile salmon in the immediate tailrace is needed, then placing hydrophones in greater densities with built-in redundancies may be an acceptable alternative. 


\section{Acknowledgments}

We thank the field scientists without whom this study could not have succeeded: Noah Adams and Dennis Rondorf of U.S. Geological Survey for their support during the field research portion of the study. Also from USGS, Rob Burns, John Hopkins, Theresa Nation, John Plumb, Seth Caldwell, Tyson Hatton, Ted Jones for their field support of the study. We thank the U.S. Army Corps of Engineers project support staff, Jim Holston, Richard Hammer, and Jim Cline, as well as the riggers at Lower Granite Dam, Gene Bilbrey, Earl Darst, Frank Gates, Jim Harris, Joe Hodge, Mark Poirier, and Dave Woodland. We appreciate review comments from Carl Schilt of BAE Systems, Dennis Dauble, and Terri Gilbride of Pacific Northwest National Laboratory. Finally, we are grateful to the following U.S. Army Corps of Engineers staff for their assistance and guidance: Dan Feil, Blaine Ebberts, Mike Langslay, Rock Peters, and Tim Wik. 
The Feasibility of Using an Ultrasonic Fish Tracking System in the Tailrace of Lower Granite Dam 


\section{Acronyms and Abbreviations}

\begin{tabular}{|c|c|}
\hline $3 \mathrm{D}$ & three-dimensional \\
\hline 3DAT & three-dimensional acoustic telemetry \\
\hline Baseline & an array of hydrophones used to track an ultrasonic transmitter \\
\hline BGS & Behavioral Guidance Structure (Located at Lower Granite Dam) \\
\hline $\mathrm{BiOp}$ & Biological Opinion, published by NOAA Fisheries in 2000 \\
\hline BRD & Biological Resources Division of the U.S. Geological Survey \\
\hline CBR & Columbia Basin Research, University of Washington \\
\hline CFD & computational fluid dynamics \\
\hline $\mathrm{COE}$ & U.S. Army Corps of Engineers \\
\hline $\mathrm{dB} \mathrm{re} / / 1 \mu \mathrm{Pa}$ & decibels referenced to 1 micro-Pascal \\
\hline DOP & dilution of precision \\
\hline FFT & Fast Fourier Transform \\
\hline GDOP & geometric dilution of precision \\
\hline GPS & Global Positioning System \\
\hline HDOP & horizontal dilution of precision \\
\hline HTI & Hydroacoustic Technologies Inc. \\
\hline $\mathrm{Hz}$ & Hertz or samples/second \\
\hline $\mathrm{kcfs}$ & thousand cubic feet of discharge/second \\
\hline $\mathrm{kHz}$ & kiloHertz \\
\hline LGR & Lower Granite Dam \\
\hline $\mathrm{m}$ & meters \\
\hline NOAA & National Oceanic and Atmospheric Administration \\
\hline
\end{tabular}




\begin{tabular}{|c|c|}
\hline NMFS & National Marine Fisheries Service (now known as NOAA Fisheries \\
\hline PDOP & position dilution of precision \\
\hline PNNL & Pacific Northwest National Laboratory \\
\hline PSC & Prototype Surface Collector (located at Bonneville Dam) \\
\hline RSW & Raised Spillway Weir (located at Lower Granite Dam) \\
\hline RTK-GPS & real time kinematics of Global Positioning \\
\hline $\mathrm{S}$ & seconds \\
\hline SBC & Surface Bypass Collector (located at Lower Granite Dam) \\
\hline SL & source level \\
\hline SNR & signal to noise ratio \\
\hline SPL & sound pressure level \\
\hline Transmitter & ultrasonic transmitter \\
\hline TDOP & time dilution of precision \\
\hline Trilateration & $\begin{array}{l}\text { using time of arrival differences in three (or more) receivers to } \\
\text { determine the position of a transmitting device }\end{array}$ \\
\hline Ultrasonic & high-frequency sound \\
\hline UFTS & ultrasonic fish tracking system \\
\hline USACE & U.S. Army Corps of Engineers \\
\hline USGS & U.S. Geological Survey \\
\hline UW & University of Washington \\
\hline VDOP & vertical dilution of precision \\
\hline WES & MS \\
\hline
\end{tabular}




\section{Contents}

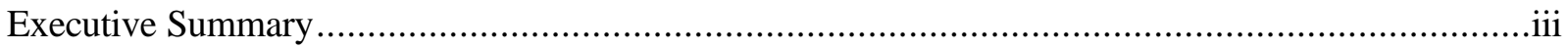

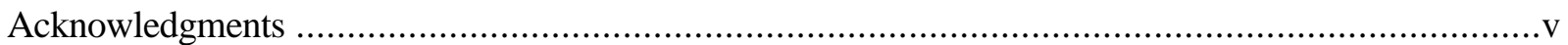

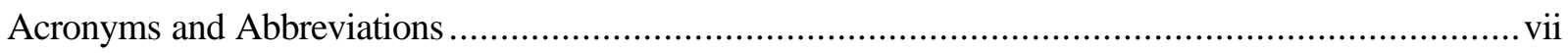

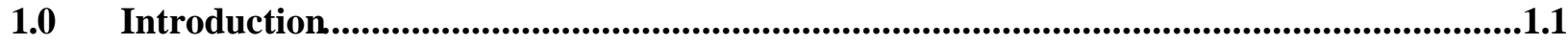

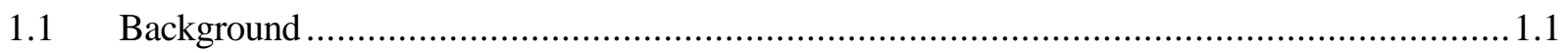

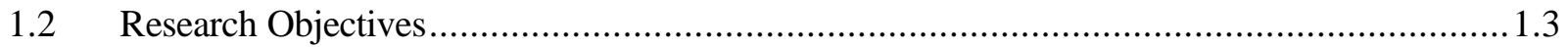

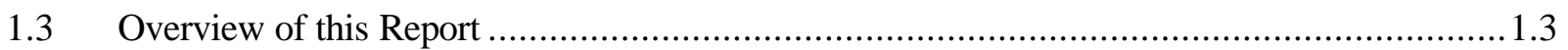

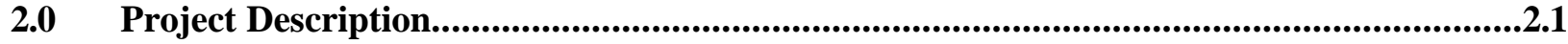

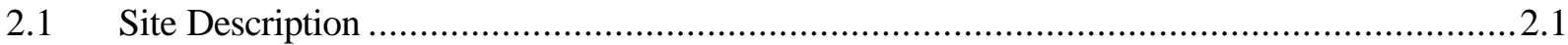

$2.2 \quad$ Pre-Deployment....................................................................................... 2.2

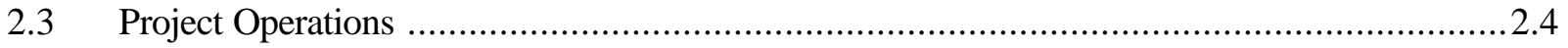

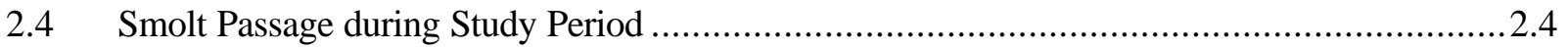

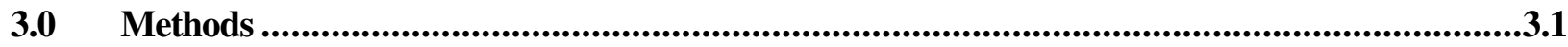

3.1 Evaluating the Level of Acoustic Noise in the Lower Granite Dam Tailrace .......................3.1

3.1.1 Measuring the Acoustic Noise Using a Spectrum Analyzer.................................... 3.1

3.1.2 Measuring the Acoustic Noise Using the UFTS ................................................. 3.2

3.2 Hydrophone Setup ........................................................................................... 3.3

3.3 Evaluating the Ultrasonic Fish Tracking System (UFTS) Performance .............................. 3.5

3.4 Tracking the Path of Juvenile Salmon and Passive Drogues.............................................. 3.6

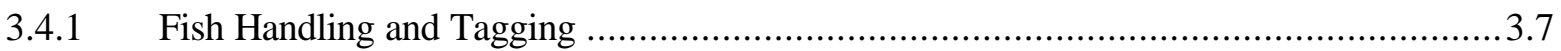

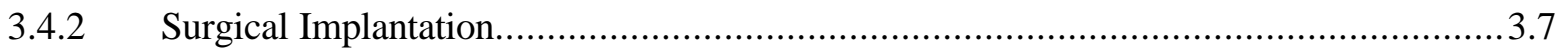

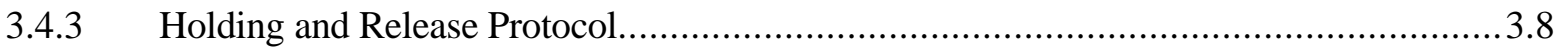

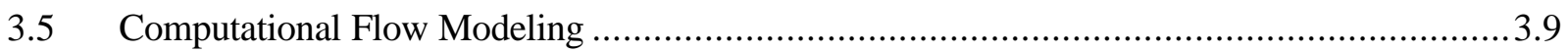

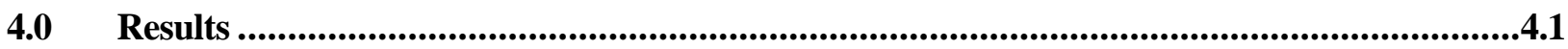

4.1 Evaluating the Acoustic Noise in Lower Granite Tailrace ............................................. 4.1

4.1.1 Noise Levels Measured Using a Spectrum Analyzer ............................................... 4.1

4.1.2 Noise Levels Measured Using the UFTS ............................................................ 4.5

$4.2 \quad$ Performance of Ultrasonic Fish Tracking System .................................................... 4.13

4.2.1 UFTS Performance by Direct Measure.................................................................. 4.13

4.2.2 UFTS Performance by Release Location ....................................................... 4.15

4.2.3 UFTS Performance by Exit Route .............................................................. 4.15

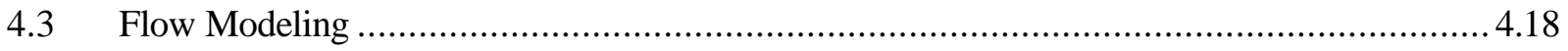

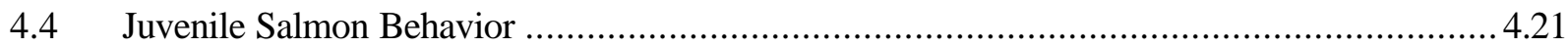

4.4.1 Juvenile Salmon and Drogues........................................................................... 4.21

4.4.2 Juvenile Salmon Released by BRD Upstream of Lower Granite Dam ...................... 4.24 


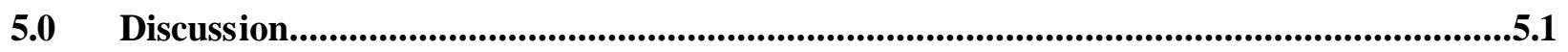

5.1 Evaluation of the Acoustic Noise in the Lower Granite Dam Tailrace...............................5.1

5.1.1 Evaluation of Acoustic Noise Using a Spectrum Analyzer..........................................5.1

5.1.2 Evaluation of Acoustic Noise Using the UFTS .............................................. 5.2

5.2 Performance of Ultrasonic Fish Tracking System................................................... 5.3

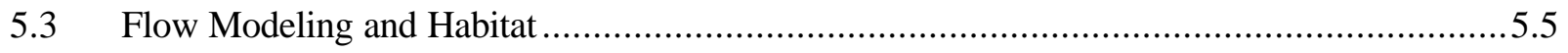

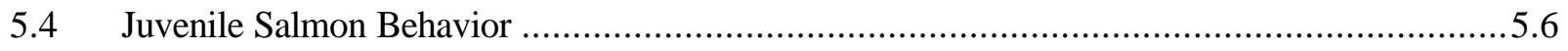

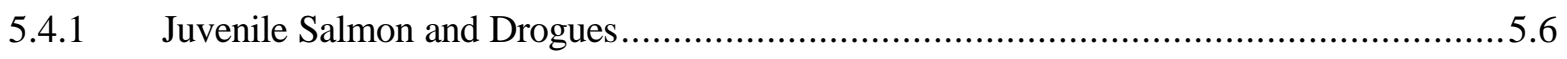

5.4.2 Juvenile Salmon Behavior after Dam Passage........................................................5.8

5.5 Recommendations for Future UFTS Deployment .................................................... 5.9

6.0 Conclusions and Recommendations ...............................................................................6.1

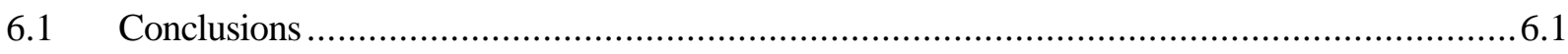

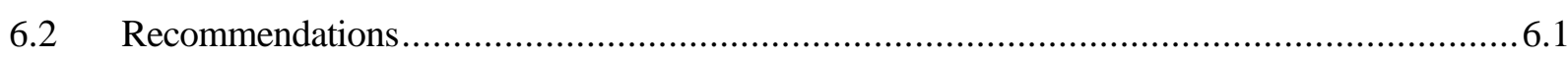

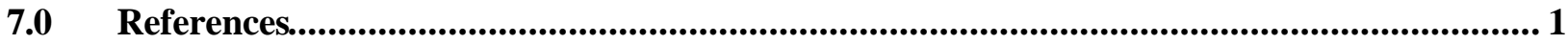

Appendix A - SAS (Statistical Analysis Software) Output for Noise Measurement Analyses.............. A.1

Appendix B - SAS (Statistical Analysis Software) Analysis O utput of Noise Amplitude ................ B.1

Appendix C - Fish Contacts by Hydrophone in the Lower G ranite D am Tailrace.......................... 1 


\section{Figures}

2.1 Northwest Map Showing the Location of Lower Granite Dam in Relation to other Columbia and Snake River Dams

2.2 Study Site Location at Lower Granite Dam.....

2.3 Modeled Horizontal Dilution of Precision (HDOP) for the Hydrophone Array Placed in Lower Granite Dam Tailrace with Assumed Tag Detection Range of $150 \mathrm{~m}$.

2.4 Discharge from Lower Granite Dam from April 17, 2002 through June 8, 2002.

2.5 Smolt Passage at the Juvenile Bypass Facility at Lower Granite Dam.

3.1 Layout of Hydrophones as Deployed in the Lower Granite Dam Tailrace..

3.2 A "Clump" Hydrophone Anchor Mount

3.3 Surgical Implantation of Ultrasonic Tag.

4.1 Average Sound Pressure Levels in the Tailrace of Lower Granite Dam in the Spring with High Spill and 5 of 6 Turbine Units Operating, and in Summer with No Spill and One Turbine Unit Operating.

4.2 Sound Pressure Levels $(\mathrm{dB})$ at the Draft Tube Exits of Turbine Units at Lower Granite Dam in Spring during High Spill with Five of Six Turbine Units Operating

4.3 Sound Pressure Levels $(\mathrm{dB})$ at $307.2 \mathrm{kHz}$ in the Tailrace of Lower Granite Dam in Spring during High Spill and When Five of Six Turbine Units Were Operating

4.4 Calculated Loss in Tag Signal Strength with Increase in Distance due only to Spherical Spreading Relative to Threshold Detection Levels Measured in the Tailrace of LGR in Both Spring and Summer.

4.5 Signalto-Noise Ratio of the Acoustic Tag Relative Noise Levels at $307.2 \mathrm{kHz}$ in the Tailrace Downstream of the Draft Tubes at Lower Granite Dam....

4.6 Median Sound Pressure Levels, and 10th and 90th Percentile Bounds, Detected at Hydrophones 1 through 8

4.7 Median Sound Pressure Levels, and 10th and 90th Percentile Bounds Detected at Hydrophones 9 through 16.

4.8 Number of Sound Pressure Detections at $307 \mathrm{kHz}$ Collected above the Threshold Level Detected at Hydrophones 1 through 8

4.9 Number of Sound Pressure Detections at $307 \mathrm{kHz}$ Collected above the Threshold Level Detected at Hydrophones 9 through 16.

4.10 Median Sound Pressure Detected by Hydrophones Relative to Spill and Generation Levels

4.11 Median Sound Pressure Detected by Hydrophones Located Downstream of the Powerhouse and the Spillway 
4.12 Median Sound Pressure Detected by Hydrophones Relative to Distance of the Hydrophone from the Dam.

4.13 Number of Sound Pressure Detections by Hydrophones Relative to Spill and Generation Levels. 4.11

4.14 Number of Sound Pressure Detections by Hydrophones Located Downstream of the Powerhouse and the Spillway

4.15 Number of Sound Pressure Detections by Hydrophones Located Downstream of the Powerhouse and the Spillway....

4.16 Detection Range of Hydrophones as Measured and Estimated with the "Ping-Around" Test during the No-Spill Tailrace Condition

4.17 Detection Ranges of Hydrophones that Were Directly Measured and Estimated during the NOAA BoOp (high spill) Tailrace Condition.

4.18 Detection Ranges of Hydrophones that Were Directly Measured and Estimated during the NOAA BiOp (high-spill) Tailrace Condition Showing only those Hydrophones still Operational on Day 30 of the Research Period

4.19 The Percentage of Fish that Were Detected in the Tailrace by Forebay Passage Route....

4.20 Modeled Flow of Lower Granite Dam Tailrace Showing Mean Water Column Speeds and Directions at Low Powerhouse-Low Spill Conditions with RSW On

4.21 Modeled Flow of Lower Granite Dam Tailrace Showing Mean Water Column Speed and Direction at Low Powerhouse-High Spill Condition with RSW On

4.22 Modeled Flow of Lower Granite Dam Tailrace Showing Mean Water Column Speed and Direction at High Powerhouse-Low Spill Condition with RSW Off

4.23 Modeled Flow of Lower Granite Dam Tailrace Showing Mean Water Column Speed and Direction at High Powerhouse-High Spill Condition with RSW On.

4.24 Median Tailrace Residence Times of Juvenile Hatchery Chinook Drogues Released into the Tailrace at Spillbays 3 and 6 or Turbine Units 2 and 4

4.25 General Movement of Fish and Drogues Released at Turbine Unit 2 ................................ 4.23

4.26 General Movement of Fish and Drogues Released at Turbine Unit 4

4.27 Movement of a Juvenile Spring Chinook in the Tailrace of Lower Granite Dam during a No-Spill Tailrace Condition

4.28 Tailrace Conditions that Were Used as Treatments to Compare the Behavior of Juvenile Salmon as They Exited the Tailrace.

4.29 Median Residence Times for all Species Categorized by Tailrace Condition .......................... 4.26

4.30 Median Residence Times of Juvenile Salmon Categorized by Tailrace Condition and Species.... 4.26

4.31 Correlation of the Tailrace Residence Times of Juvenile Wild Steelhead to Spill Discharge, Powerhouse Discharge, and the Ratio of Spill to Powerhouse Discharge

4.32 Correlation of the Tailrace Residence Times of Juvenile Hatchery Steelhead to Spill Discharge, Powerhouse Discharge, and the Ratio of Spill to Powerhouse Discharge 
4.33 Correlation of the Tailrace Residence Times of Juvenile Spring Chinook to Spill Discharge, Powerhouse Discharge, and the Ratio of Spill to Powerhouse Discharge

4.34 Median Residence Times of Juvenile Salmon Categorized by the Time Period in which They Entered the Tailrace at Lower Granite Dam

4.35 Distribution of Tailrace Conditions by the Research Period and by RSW Operation during the Research Period

4.36 Median Residence Times for Juvenile Salmon Exiting the Tailrace with the RSW On vs. RSW Off

5.1 Number of BRD-Released Juvenile Salmon that Were Detected by each Hydrophone Based on the Operational State of the RSW 


\section{Tables}

4.1 Number and Percent of Juvenile Spring Chinook and Drogue Detections by Release Site

4.2 Total Lower Granite Dam Discharge through the Spillway and Powerhouse at the Time of Juvenile Spring Chinook and Drogue Releases..................................................... 4.16

4.3 The Percentage of Fish Detected in the Tailrace by Forebay Passage Route

4.4 The Percentage of Water Velocity Habitat Bound by the Extent of the Tailrace Model for Lower Granite Dam

4.5 Descriptive Statistics for the Residence Time of Juvenile Salmon with the RSW On and RSW Off..

5.1 Estimated Detection Range and Measured Detection Range of Acoustic Tags in the Tailrace of Lower Granite and Bonneville Dam Powerhouse 2. 


\subsection{Introduction}

This report describes the testing of a commercially available ultrasonic fish tracking system in the tailrace of Lower Granite Dam. The study was conducted for the U.S. Army Corps of Engineers (COE) through the joint efforts of the Pacific Northwest National Laboratory (PNNL), at North Bonneville, Washington, and the U.S. Geological Survey Biological Resources Division (USGS BRD), at Cook, Washington. Our goal was to determine the feasibility of using ultrasonic tags and hydrophones to track juvenile salmonids in a hydroelectric dam tailrace. The tailrace for our study was defined as the downstream environment to $340 \mathrm{~m}$ from the Lower Granite Dam Spillway, where the flow was directly influenced by hydroelectric dam operations. In March 2002, we deployed a Hydroacoustic Technology Inc. (HTI) model 290 ultrasonic fish tracking system in the tailrace of Lower Granite Dam (LGR) with a complement of 16 hydrophones. If fish tracking was determined to be feasible we were to track the movement of juvenile hatchery chinook, juvenile hatchery steelhead, and juvenile wild steelhead and relate their movement to dam operations. The majority of fish to be tracked were released as part of a separate study conducted by the BRD that was investigating the movement of juvenile salmon in the forebay of LGR in relation to Removable Spillway Weir (RSW) testing. The studies were conducted consecutively from April 14 to June 7, 2002.

\section{$1.1 \quad$ Background}

In Section 9.1.2 of the Draft Biological Opinion (BiOp, 2000), the National Oceanic and Atmospheric Administration (NOAA, formerly National Marine Fisheries Service (NMFS)) has made the following recommendations to address tailrace egress of juvenile salmon and lower predation risk: 1) enhanced spill and spillway improvements to facilitate higher spill levels without exceeding dissolved gas standards, 2) improved flow management, and 3) continuation of spill at collector projects to maximize the survival of in-river migrants. The study site at Lower Granite Dam also falls under the incidental take statement (ITS) number 2.

In an effort to address the $\mathrm{BiOp}$ and to increase juvenile salmon survival during their approach, passage, and egress from hydroelectric dams, the COE has funded studies that utilize ultrasonic fish tracking systems (UFTS) to better understand juvenile salmon behavior. The objective of prior research with UFTS was to describe the response of fish to the flow fields in dam forebays and in the immediate vicinity of fish bypass entrances. An overall goal of the research was to obtain a better understanding of fish response to flow field features so that the design and operations of fish passage facilities would be optimized. UFTS are capable of resolving fish location to within one $\mathrm{m}^{3}$, many times in one second. This has enabled researchers to determine the paths of many individual juvenile salmon and to relate their combined paths to flow manipulation of the Columbia and Snake Rivers at hydroelectric dams. Miniature ultrasonic tags were surgically implanted into juvenile salmon. Each tag emits a unique code so many fish can be tracked at the same time. Detailed methods for deployment and use of UFTS have been described in Faber et al. 2001 and Cash et al. 2000. In these studies, ultrasonic fish tracking technology was used to describe the behavior of juvenile salmon on the upstream side of Bonneville and Lower Granite Dams, but the technology had not been employed in tailraces. 
In a review of John Day Dam tailrace research, Poe et al. (2001) associated powerhouse and spillway operations with delay and risk of predation in the tailrace and suggested that route-specific survivorship and predator studies would be helpful. In the spring of 2002 we installed an UFTS in the tailrace of Lower Granite Dam to determine the feasibility of using this technology in the dynamic environment of a hydroelectric dam tailrace. If the method were found to be effective then we would investigate the behavior of juvenile salmon during the time that they egress the tailrace at Lower Granite Dam. Justification for the investigation of the behavior of juvenile salmon during egress was highlighted in previous tailrace egress research, the majority of which has used radio-telemetry to describe juvenile salmon movement in the tailrace. Poe et al. (2001) observed in their synthesis of research at the tailrace of John Day Dam that "Spill patterns and operational conditions which cause smolts to have longer tailrace residence times will also concentrate smolts which may attract predators," and that "Route specific survival studies and predator monitoring studies are needed to better understand these risks." Our study provides a baseline data set on juvenile salmonids movement through the tailrace for future passage, survivorship, and predation studies.

The tailraces of Columbia and Snake River dams are of concern to fishery managers as they expose outmigrating juvenile salmon to the greatest predation risk in the Columbia River system (Ward, Peterson and Loch 1995; Beamesderfer et al. 1996; Friesen and Ward 1999; Gadomski and Hall-Griswold 1992; Gregory and Levings 1998). Predators such as the northern pikeminnow (Ptychocheilus oregonensis), walleye (Stizostedion vitreum), and small-mouth bass (Micropterus dolomieu), as well as piscivorous birds can eat juvenile salmon that are disoriented after passage through dam routes. Mesa (1994) showed that juvenile salmon avoidance of predators would be affected by multiple agitations that were designed to mimic dam passage. The juvenile salmon in Mesa's studies were lethargic for up to one hour after the agitations, which could affect the avoidance response that a juvenile salmon has after passing a dam, increasing their susceptibility to predation. Similar observations have been seen in studies by Pacific Northwest National Laboratory (PNNL 1997). Changing a dam's operation (outflow) could alleviate this risk by decreasing the available habitat for predators as well as by increasing the time that juvenile salmon have to recover from stresses incurred during dam passage.

Northern pikeminnow, a primary predator of juvenile salmon in the lower Columbia River, have specific habitat requirements. For example, water velocities over $100 \mathrm{~cm} / \mathrm{s}$ may exclude northern pikeminnow (Mesa and Olson 1993). Temperature is also a factor since fatigue was seen in northern pikeminnow at a temperature of $12^{\circ} \mathrm{C}$ before it was seen at a temperature of $18^{\circ} \mathrm{C}$ when swimming performance was tested (Mesa and Olson 1993). The difference in fatigue for northern pikeminnow may translate to greater predation risk for summer migrants such as juvenile fall chinook when the river temperatures are greater, than for the spring outmigrants when waters are cooler.

Steps have been taken by the USACE and Bonneville Power Administration to reduce predation on juvenile salmon in tailraces by initiating an active sport fishing reward program for northern pikeminnow caught by anglers in the tailraces of Columbia and Snake River dams. Northern pikeminnow predation on juvenile salmon has decreased in years since the sport reward was offered (Knutsen and Ward 1999) but a combination of sport-reward and dam operation improvements to reduce predation risk would further improve the survival of juvenile salmon.

In order to evaluate and improve survival through different dam passage routes, managers need a way to track known fish through the various routes and to determine their fates. Many smolt consumption models have been based on the numerical abundance of predators and associated prey-capture rate, prey 
distribution, and predator distribution. The models vary in the overall consumption of juvenile salmon by piscivores; they have predicted that from 1.4 million to 8.1 million fish are preyed upon as they pass through the hydropower complexes of the Columbia (Ward et al. 1995; Rieman et al. 1991). Sampling to provide data input for the models was described as labor intensive and difficult to measure due to sampling gear selectivity and the dangers associated with sampling within hydroelectric dam tailraces. Procedures for estimating the survival and reducing sample bias are the preferred methods of fishery managers, and acoustic telemetry may provide key components in the search for means to improve inriver survival estimates.

\subsection{Research Objectives}

Our objectives were to evaluate the acoustic environment of Lower Granite Dam tailrace, track the movement of tagged juvenile salmon and drogues, track juvenile salmon that were released as part of a separate BRD study, and describe juvenile salmon behavior based upon those tracks. Our detailed objectives were as follows:

1. Evaluate the level of acoustic noise in the tailrace of Lower Granite Dam with specific regard to the frequencies used by the ultrasonic fish tracking system (UFTS).

2. Evaluate the performance of an UFTS in the spillway of Lower Granite Dam and determine the detectability, precision, and accuracy of the location of ultrasonic fish tags under varied spill treatments.

3. Track the path of juvenile salmon and drogues under all spill treatments.

a. Compare the passage route of ultrasonically tagged juvenile salmon and tagged drogues released from the same locations.

b. Evaluate the passage routes of juvenile salmon by species, time of day, and entry into the tailrace.

c. Determine comparability of Lower Granite Dam spill patterns to John Day Dam spill patterns for the application of juvenile salmon egress to spill scenarios at John Day Dam.

With these objectives we addressed the following null hypotheses:

$\mathbf{H}_{\mathbf{0}}$ : Spill discharge does not influence the precision, accuracy, or tracking ability of the ultrasonic fish tracking system.

$\mathbf{H}_{\mathbf{0}}$ : Spill discharge does not influence the detection of ultrasonic fish tags.

$\mathbf{H}_{\mathbf{0}}$ : Juvenile salmon passage route is not influenced by spill pattern.

\subsection{Overview of this Report}

Chapter 2 of this report describes the site and project operations. Chapter 3 describes methods used to evaluate the acoustic noise level; hydrophone set up, and evaluation; fish tagging, releasing, and tracking; and computational flow modeling. In Chapter 4 we quantify the detectability of tags, the precision and accuracy of fish tracks, noise levels at relevant frequencies, and the detectability of tagged juvenile salmon under varied spill treatments and dam operations at Lower Granite Dam. Data acquired 
during the tests provided fish movement and movement of neutrally buoyant drogues over time. These data are compared directly to a two-dimensional computational fluid dynamic model of the Lower Granite Dam tailrace to evaluate the response of fish to spill operations. These data are compared to egress studies at Lower Granite Dam using radio telemetry as the means to track juvenile salmon. This study provides background information for future use of ultrasonic fish tracking technology in juvenile salmon egress studies, survival studies, or any other research on fish behavior in high water velocity environments. This study also provides a baseline for future predictions (models) of juvenile salmon survival through the tailrace regions of dams in order to estimate juvenile salmon mortality through specific routes and to establish possible mechanisms that influence juvenile salmon survival. Chapter 5 is a discussion of the evaluation and the performance of the UFTS and of the fish behavior observed. Chapter 6 is conclusions and recommendations. Appendixes A, B, and C show the SAS (Statistical Analysis Software) analysis output of noise amplitude (Appendix A) and number of measurements (Appendix B) by Relative Distance and Location to the Lower Granite Dam Powerhouse and Spillway, and the number of fish observations for each hydrophone located in the Lower Granite Dam tailrace (Appendix C).

The goal of this study was to determine the feasibility of tracking juvenile salmon in the tailrace of Lower Granite Dam using ultrasonic fish tracking technology. 


\subsection{Project Description}

\subsection{Site Description}

The Lower Granite Dam is the uppermost of four Lower Snake River dams located near the border of Washington and Idaho. The dam has a spillway with eight bays (numbered south to north) and a powerhouse with six turbines. The turbines are numbered 1 to 6 from south to north. Each turbine unit is divided into three intakes, identified as A, B, and C. The spillway spans $167 \mathrm{~m}$ and the Powerhouse spans $167 \mathrm{~m}$. The field portion of our study was conducted in the tailrace of Lower Granite Dam (Figures 2.1 and 2.2). The site was selected for several reasons. A tracking study was conducted to evaluate the performance of the Removable Spillway Weir (RSW) in the forebay at Lower Granite during the same time period; that study also used 3D acoustic telemetry. Using the same method, and therefore the same type of fish tags, we took advantage of releases of juvenile salmon used for forebay RSW evaluations, and tracked those fish as they entered and exited the tailrace of Lower Granite Dam.

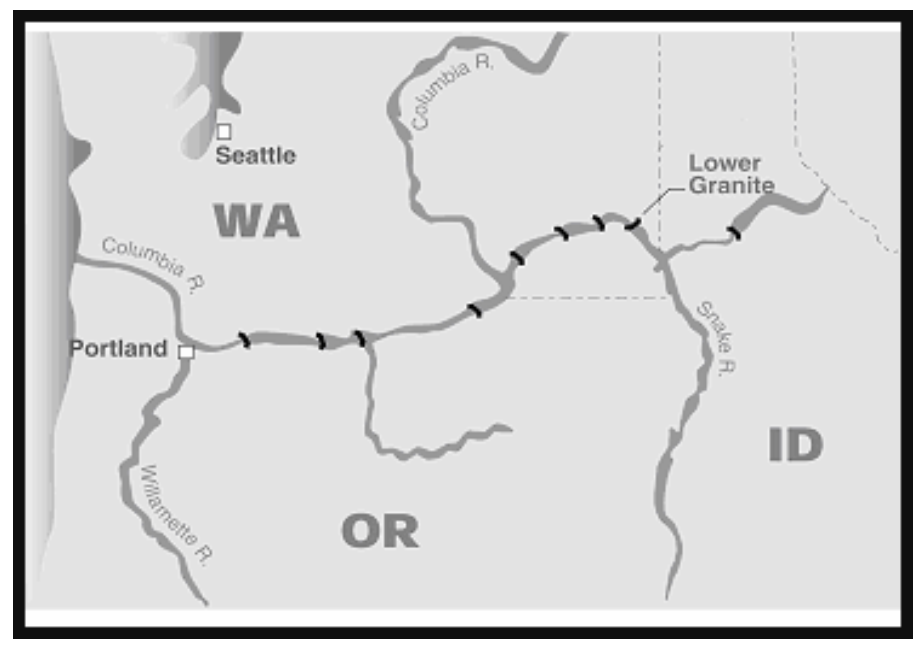

Figure 2.1. Northwest (U.S.) Map Showing the Location of Lower Granite Dam in Relation to other Columbia and Snake River Dams 


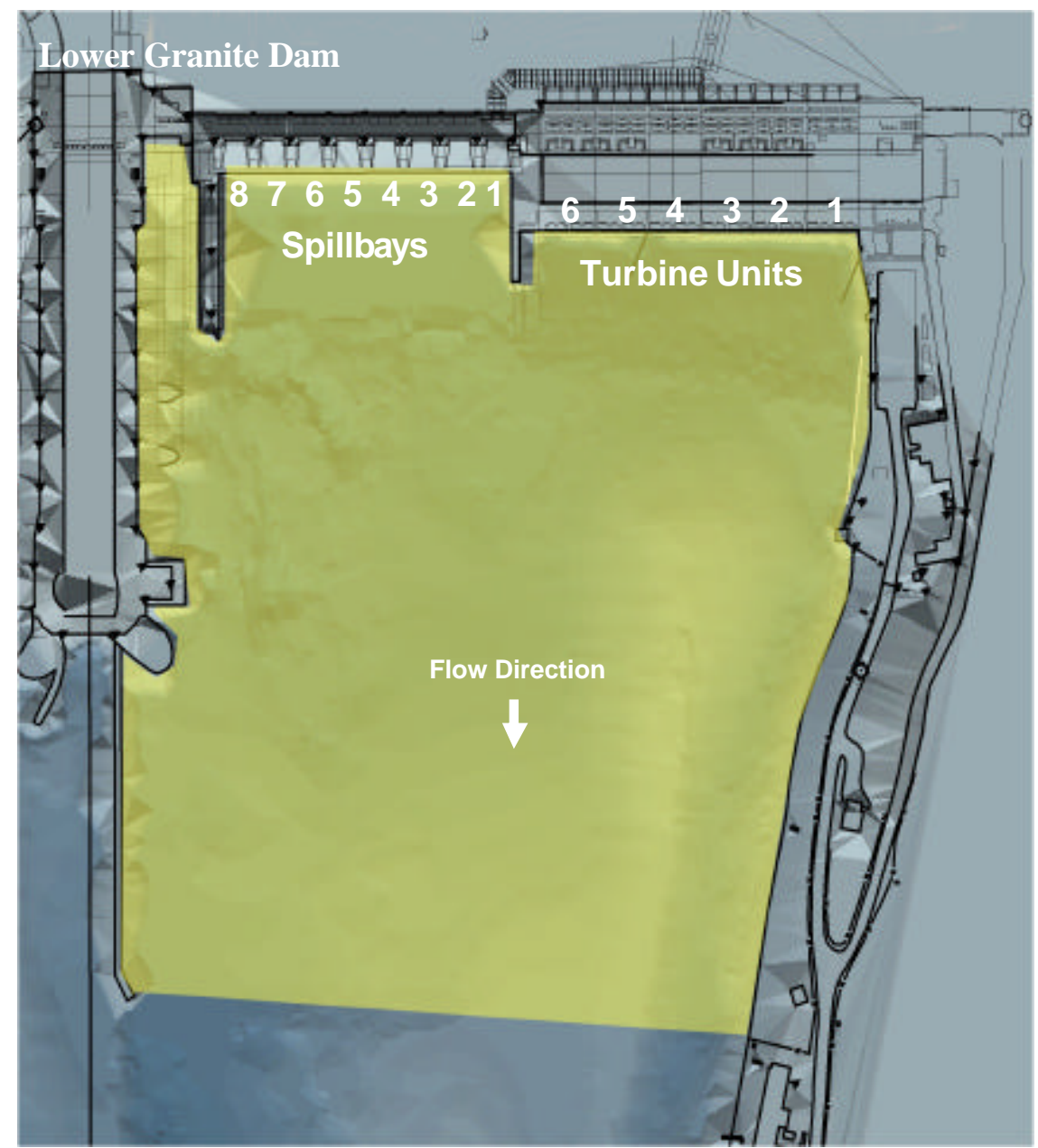

Figure 2.2. Study Site Location (shaded) at Lower Granite Dam

\subsection{Pre-Deployment}

Prior to deployment we examined the physical model of Lower Granite Dam at the Waterways Experiment Station in Vicksburg, MS, to determine the best placement of hydrophones. Hydrophone placement was selected based on areas that would be less exposed to high-velocity flow or debris. The proper placement of the hydrophones is essential for providing useful position data on fish passing through the tailrace. Additional plans for hydrophone placement were based on available structure that would provide a secure anchor point as well as provide the best geometry of hydrophones for the positioning of tags. The relative position of the hydrophones (geometry) was chosen so that the precision and accuracy of the 3D acoustic telemetry positioning algorithms would be optimal. The relative precision for multiple hydrophone deployments was modeled prior to our deployment. This was conducted through the use of a dilution of precision model developed specifically for the use of ultrasonic fish tracking (Faber et al. 2002) 
A thorough testing of the accuracy of the hydrophone array (error testing) was conducted prior to deployment in order to quantify the potential for 3D tracking and test how accurate 2D tracking would be when using the ultrasonic fish tracking system. We performed error testing by using an error model, FishTrack3D ${ }^{\mathrm{TM}}$, developed by PNNL, USGS, and the University of Washington for the COE-Portland District. A deployment strategy followed thorough modeling of the acoustic telemetry array.

The FishTrack3D ${ }^{\mathrm{TM}}$ model was based on testing of an UFTS in a forebay and had not been designed or used for a tailrace array. It is primarily based on relative geometries of four hydrophones that receive a tag signal. The model uses the relative geometry of hydrophone four-tuples ${ }^{1}$ to calculate a matrix of dilution of precision estimates for a specified volume. However, the model does not take into account range detectability of fish tags or survivability of UFTS hydrophones. These values were thought to be different in a hydroelectric dam tailrace than in a hydroelectric dam forebay, although the magnitude of difference was unknown. The determination of this magnitude was a key objective of this study so testing of the precision and accuracy of 2D and 3D tracking was conducted under the assumption that the detection range of fish tags was similar to that in the forebay environment. Using these assumptions, the array that was installed in the Lower Granite Dam tailrace showed sufficient $\left(<2 \mathrm{~m}^{2}\right)$ tracking capability before deployment (Figure 2.3).

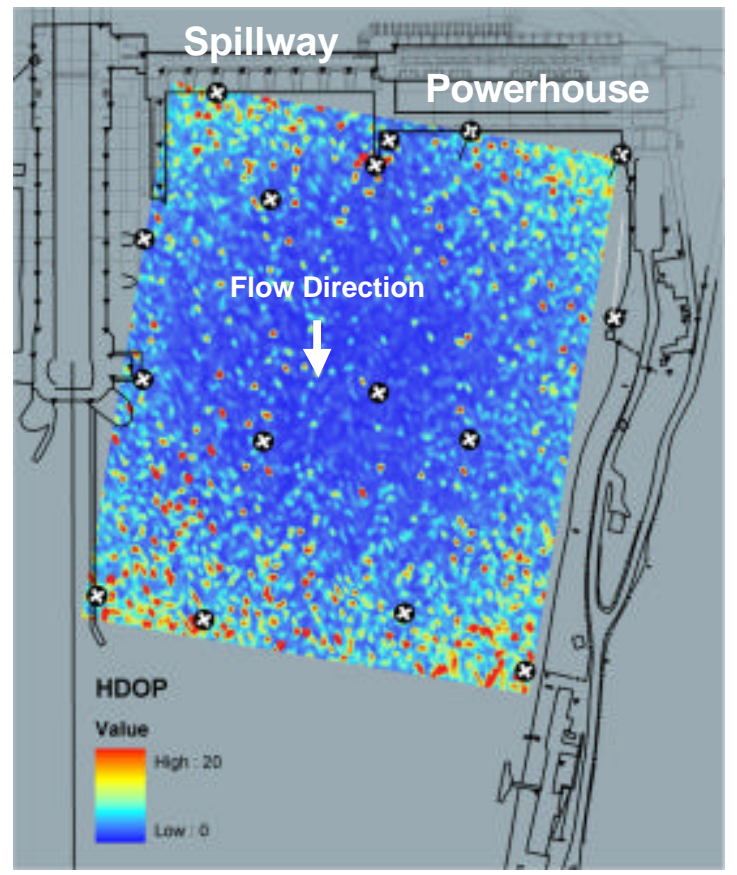

Figure 2.3. Modeled Horizontal Dilution of Precision (HDOP) for the Hydrophone Array Placed in Lower Granite Dam Tailrace with Assumed Tag Detection Range of $150 \mathrm{~m}$. Hydrophone positions are symbolized by yellow cross in black border, legend units are in $\mathrm{ft}$ or 0.3 $\mathrm{m}$ for each unit.

\footnotetext{
${ }^{1}$ A "four-tuple" is a set of four hydrophones that is used to solve for the position of a tagged fish using the differences in signal time of arrival between hydrophones via trilateration.
} 


\subsection{Project Operations}

Dam operations were scheduled so that the RSW and spillway operated under three separate and distinct treatments: 1) Low training spill, 2) High training spill, and 3) Spill provided under the NOAA biological opinion. "Training" spill was developed by the U.S. Army Corps and NOAA using physical model measurements made at the physical model of Lower Granite Dam tailrace located at the Waterways Experiment Station in Visckburg, MS, and was designed to move RSW flow out of the tailrace with minimal eddy formation. Testing of the spill treatments in the spring of 2002 used various research methods by the BRD and PNNL including fixed hydroacoustics, radio-telemetry and acoustic telemetry to monitor juvenile salmon movement and to determine if differences in juvenile salmon behavior existed between spill treatments.

However, due to a late-spring run-off and higher-than-average spring and summer flow conditions, the treatment schedule was compromised in the third week of the study. Contributing factors to the deviation in study treatments were uncontrolled spill and lower-than-expected power demand. Since the planned treatment schedule was impossible to implement, we partitioned our data collection into four categories based on discharge levels through both the powerhouse and the spillway. We divided the discharge levels into "high" and "low" using the median hourly discharge for each structure as the dividing line. For the powerhouse, the median hourly discharge was $54 \mathrm{kcfs}$ and for the spillway it was 24 kcfs. Hours with discharge above and below these median values were designated as "high" and "low" hours, respectively. The four categories were 1) "Low Powerhouse-Low Spill," 2) "Low Powerhouse-High Spill,"3) "High Powerhouse-Low Spill," and 4) "High Powerhouse-High Spill." The majority of juvenile salmon behavioral statistics for our tailrace study were generated based on these four project treatments.

\subsection{Smolt Passage during Study Period}

Figure 2.5 shows smolt passage at the juvenile bypass facility at Lower Granite Dam in 2002. The spring migration of juvenile salmon fell within our study period which is shown in the figure as the shaded area. The peaks of the juvenile wild and hatchery steelhead, wild and hatchery yearling chinook, and coho all fell within our study period. 


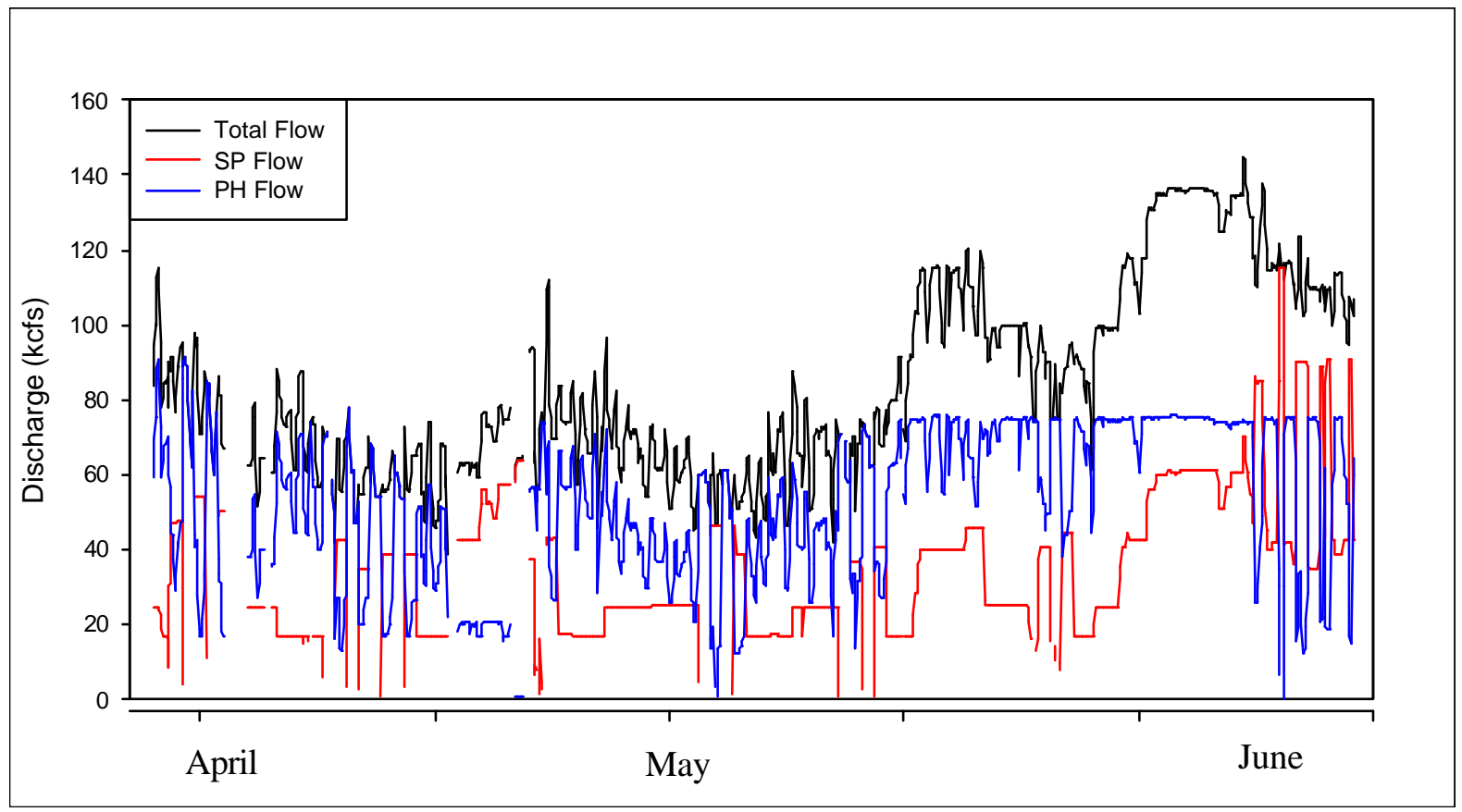

Figure 2.4. Discharge from Lower Granite Dam from April 17, 2002 (Julian Day 108) through June 8, 2002 (Julian Day 159). The shaded area represents the period of study in the tailrace at LGR. The red line indicates powerhouse $(\mathrm{PH})$ discharge and the blue line indicates spillway (SP) discharge. The black line represents the total project discharge.

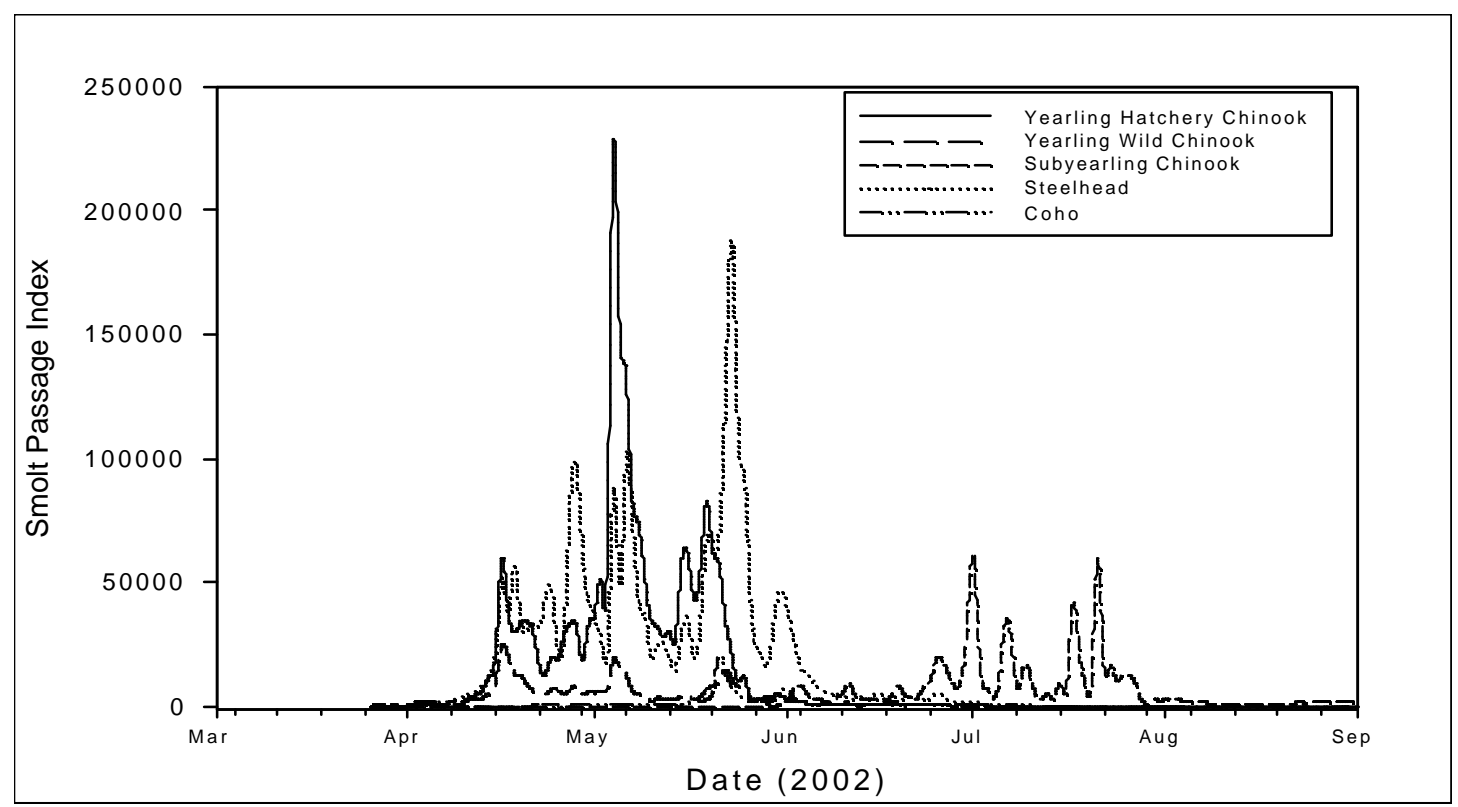

Figure 2.5. Smolt Passage at the Juvenile Bypass Facility at Lower Granite Dam. Shaded area is the period of our study. 
The Feasibility of Using an Ultrasonic Fish Tracking System in the Tailrace of Lower Granite Dam 


\subsection{Methods}

Our methods were divided into three portions with each addressing a separate set of objectives to complete the study. Those abbreviated objectives were to 1) Evaluate the level of acoustic noise in the tailrace of Lower Granite Dam, 2) evaluate the performance of an UFTS in the spillway of Lower Granite Dam, and 3) track the path of juvenile salmon and drogues under all spill treatments. Methods that describe the processes of data collection and analysis to complete these objectives are presented in this section.

\subsection{Evaluating the Level of Acoustic Noise in the Lower Granite Dam Tailrace}

\subsubsection{Measuring the Acoustic Noise Using a Spectrum Analyzer}

There are challenges in tracking fish with implanted acoustic tags through the tailrace of hydroelectric dams. One of the challenges is tracking an individual fish for a great enough distance to be able to make inferences about its movement through the tailrace, and it can even be difficult to make a single detection of a tag in a fish. The detectable range of a $307.2-\mathrm{kHz}$ acoustic tag, the standard acoustic tag used in the Columbia and Snake River Basins, depends on the tag's source level (SL), the water environment, and noise from other sources. Transmission loss of the acoustic tags in water is due to spherical spreading loss and attenuation (Urich, 1983). Loss due to spherical spreading can be calculated as a logarithmic loss of signal strength with increase in range from the source. Attenuation in the tailrace of dams is caused by absorption and scattering and cannot be calculated but must be measured in order to estimate loss. Another factor affecting the detectability of the acoustic tag by a receiver is the ratio of the signal produced by the tag to the noise in the water produced by the dam and other sources. The signalto-noise ratio must be greater than a determined threshold in order for the signal to be detected reliably.

The main goals for this portion of our study were to evaluate the noise levels and detectability of acoustic tags in the tailrace of Lower Granite Dam. We measured the sound pressure level (SPL) over the frequency range of interest of ultrasonic acoustic tags at the exit to the draft tubes and in the tailrace. Our ability to detect the acoustic tag in the tailrace above the background SPL could be determined from these measurements.

A Reson TC4014 omnidirectional hydrophone similar to the one used with the Hydroacoustic Technology, Inc. (HTI) acoustic tracking system was used to collect SPL measurements at the outlet of the draft tubes and along the shore downstream of LGR in both spring and late summer of 2002. The hydrophone used was broadband with a range from $15 \mathrm{~Hz}$ to $480 \mathrm{kHz}$. Data were output to a computer through a National Instruments DAQPad-6070E data acquisition card, and then processed using a LabVIEW ${ }^{\mathrm{TM}}$ program developed specifically for use with this hydrophone.

To evaluate the detectability of the acoustic tags used to track fish in the tailrace of LGR, tags of the same type were suspended in a $3.7 \times 7.3 \times 1.8$-m water-filled tank. Measurements of the tag's output were recorded in the tank at a distance of $1 \mathrm{~m}$ from the hydrophone. These measurements were used to 
estimate source level (SL) of the acoustic tag. Using the SL measurements collected in the tank, the detectable range of the acoustic tag was estimated for loss attributed only to spherical spreading. Detectable range, affected only by spherical spreading loss, was calculated by subtracting the spherical spreading loss of the acoustic signal with increase in distance from the hydrophone in water, from the SL measurement of the tag where:

$$
\begin{gathered}
P_{d B}=S L_{d B}-20 \log \left(R_{m}\right) \\
P_{d B}=\text { sound pressure in } \mathrm{dB} \text { at range } \\
S L_{d B}=\text { source level in } \mathrm{dB} \text { at range } 1 \mathrm{~m} \text { from the hydrophone } \\
\mathrm{R}_{\mathrm{m}}=\text { distance in meters of the tag from the hydrophone. }
\end{gathered}
$$

This equation was used to estimate the distance that an acoustic tag could be detected in a tailrace by measuring the attenuation of the signal due to spherical spreading loss alone. The average of the SLP in the tailrace at $307.2 \mathrm{kHz}$ was calculated and $10 \mathrm{~dB}$ was added to allow for a minimum signal to noise ratio (SNR) threshold at which the receiver could detect the signal.

Actual detectable range of the acoustic tag in the tailrace was measured by placing a tag in the tailrace at different locations and collecting SPL measurements at different distances from the hydrophone. To determine the maximum detectable range of the tag, the hydrophone was placed at a depth of $3 \mathrm{~m}$ at one end of the powerhouse about $7.6 \mathrm{~m}$ downstream of the dam. An acoustic tag was lowered off the face of the dam to a depth of $3 \mathrm{~m}$ and moved along the downstream face of the dam away from the hydrophone at 15.25- $\mathrm{m}$ increments to measure the tag's signal strength and tag signal strength relative to SPL.

Measurements were collected with no gain and also using a Reson VP2000 voltage preamplifier, with 20 $\mathrm{dB}$ and $40 \mathrm{~dB}$ gain to increase the detectable tag range. The SNR of the acoustic tag relative to noise levels at draft tube exits was calculated by summing the spectral power calculated using a Fast Fourier Transform (FFT) over the bandwidth of the acoustic tag pulse and comparing this to the power of the spectral range of the same bandwidth on either side of the tag pulse.

$$
\begin{gathered}
\text { SNR }=10^{\star} \log _{10}(\mathrm{P} 1 / \mathrm{P} 2) \\
\mathrm{P} 1=\text { the power of the transmitted signal } \\
\mathrm{P} 2=\text { background noise level }
\end{gathered}
$$

\subsubsection{Measuring the Acoustic Noise Using the UFTS}

Sound pressure (noise) due to spill, generation, and other sources reduces the detectability of the acoustic tags by hydrophone arrays and so reduces the resolution and accuracy of the estimates of the trajectories of tagged fish. Knowing the factors affecting noise received by the hydrophones and the intensity of the noise is useful in the design of future acoustic tracking arrays for deployment in tailraces of hydropower facilities and other noisy environments. This section describes our methods for collecting and examining data on ambient sound (noise) in the tailrace of Lower Granite Dam. We only considered noise in the frequency range of the acoustic tags. We examined sound pressure levels and quantity of 
noise relative to the deployed hydrophone array in the tailrace. We examined the amplitude of the noise level associated with each hydrophone relative to their proximity to spillways or turbines.

Data were collected with the HTI Model 290 receiver and hydrophones to analyze the amplitude and "amount" of noise detected by the hydrophone and to estimate the effect of dam operation on noise levels at the frequency of the acoustic tags. Sound pressure measurements at $307.2 \mathrm{kHz}$ detected by each hydrophone in the acoustic tracking array from April 10 through June 8, 2002, were used in the analysis. The sound pressure amplitude from the raw acoustic tag (RAT) file was converted to a 10-volt scale (volts=amplitude/32767*10) and the amplitude was averaged for each hour by individual hydrophone. Due to the nonparametric distribution of the data, the hourly median amplitude value was used for each hydrophone.

An unbalanced four-factor ANOVA was used to analyze the data and determine the effect of hydrophone location relative to the powerhouse and spillway and by project operations. The factor variables used in the model were converted to class variables. The variables used were spill level (kcfs), generation level (kcfs), location of the hydrophone (either in front of the powerhouse or spillway), and distance of the hydrophone downstream of the dam. PROC GLM (SAS Institute) was used to determine the significance of factor variables and interactions in the model. In the means statement, a Duncan multiple range test was performed on all main effects to determine which class levels were significantly different. Dependent variables in the analysis were the median sound pressure amplitude (median amplitude) and number of sound pressure detections per hour (n). Hours where fish containing acoustics tags were present in the array were removed to remove bias due to tag signal on the analysis.

Hydrophones 7, 10, and 12 were removed from analysis due to damage to the hydrophones or the cables, as were hydrophones 15 and 16 after day 145. Hydrophone 6 was removed because it was out of the water when the spill gates were open.

\subsection{Hydrophone Setup}

Hydrophone positions were predetermined based on model testing (FishTrack3D ${ }^{\mathrm{TM}}$ ), physical model observations at the Waterways Experiment Station (WES) in Vicksburg, Mississippi, and by the availability of suitable structures to mount hydrophones. Figure 3.1 shows the positioning of the 16 hydrophones in the tailrace. 


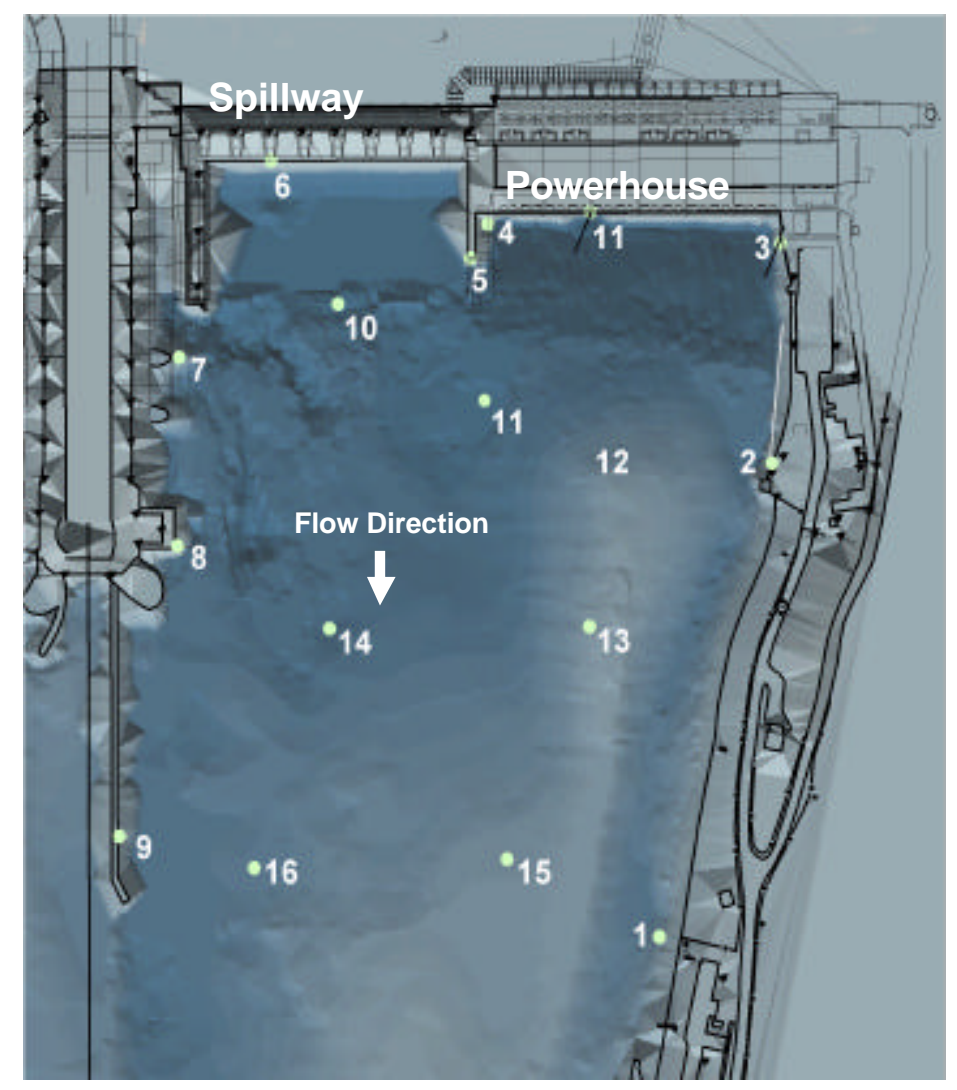

Figure 3.1. Layout of Hydrophones as Deployed in the Lower Granite Dam Tailrace. Hydrophone \#12 was deployed as a buoy-mounted hydrophone and was quickly removed due to debris build-up. Hydrophone \#11 was deployed in the open water of the tailrace on a clump mount for the first two weeks of the study; a hydrophone cable break forced us to relocate it to a fixed mount downstream of turbine unit 4.

There were two ways that we deployed hydrophones into the tailrace: 1) by "clump" mounts, and 2) by "fixed mounts." Clump mounts consisted of a pyramid-shaped steel structure with the hydrophone mounted in the top (Figure 3.2). Clump anchors weighed approximately 900 kilograms, with greater than $80 \%$ of the weight in the bottom $15 \mathrm{~cm}$ of the pyramid (the dimensions of the clump anchor were $1.8 \mathrm{~m} \mathrm{x}$ $1.8 \mathrm{~m} \times 0.6 \mathrm{~m}$ ). Clump anchors were placed in six open-water locations in the LGR tailrace and secured at the corners of the pyramid to the bedrock surface by divers. An armored hydrophone cable was strung from each clump-mounted hydrophone to the nearest fixed dam structure or shore rip-rap (bank stabilizing rocks), and secured at that point. Five-pound weights were deployed along the armored cable every $6 \mathrm{~m}$. 


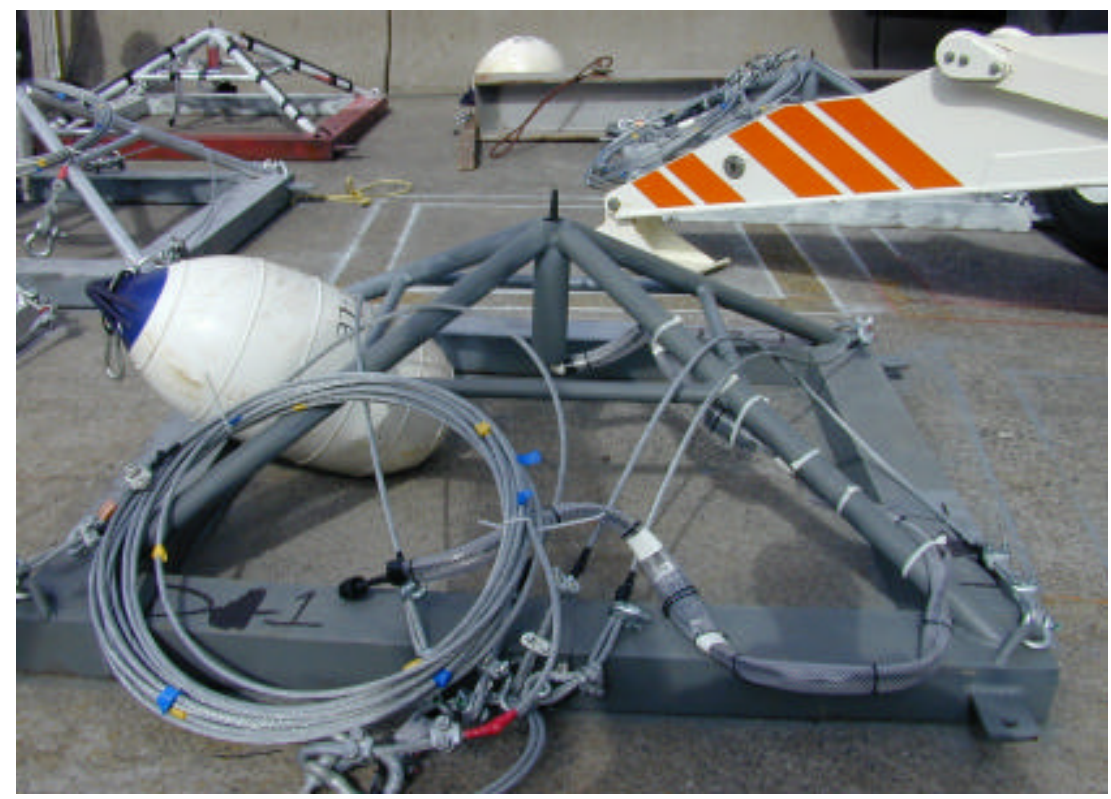

Figure 3.2. A "Clump" Hydrophone Anchor Mount. The anchor was $1.8 \mathrm{~m} \mathrm{x}$ $1.8 \mathrm{~m}$ at the base and $0.6 \mathrm{~m}$ tall and was constructed with approximately $900 \mathrm{~kg}$ of steel. The hydrophone tip is seen protruding from the apex of the pyramid.

Fixed mounts housed the remaining 10 hydrophones. The fixed mounts were constructed of aluminum and were bolted to existing concrete structures throughout the LGR tailrace. The mounts were an "L" shape $6.1 \mathrm{~m}$ long and extending $1 \mathrm{~m}$ from the mounting surface. A single hydrophone was mounted at the end of the one-meter section. Each hydrophone cable was protected by a 3-cm $x$ 7.6-cm inner diameter aluminum tube. Divers bolted the fixed mounts to the concrete underwater using fourteen 1.5-cm rock-bolts for each mount. The fixed mounts were installed so that the tip of the hydrophone was $3.2 \mathrm{~m}$ below the water surface at the time of installation.

\subsection{Evaluating the Ultrasonic Fish Tracking System (UFTS) Performance}

The performance of the UFTS was directly evaluated by measuring the range of tag detectability with and without spill. However, indirect evaluation was also useful to assess the UFTS performance. Indirect evaluation was conducted throughout the spring research season by determining the percent of tagged fish and drogues that were detected and if spill or powerhouse operations affected that detectability. The survivability of the UFTS and the ability of hydrophones and cables to withstand the dynamic environment of a hydroelectric dam tailrace were also monitored.

The detectable range of hydrophones was tested using two different methods. The first method involved "ping-around" testing under one tailrace condition without spill. In the initial stages of setup, we conducted a "ping-around" test to measure the detectable range of all hydrophones. A "ping-around" is a procedure used during setup of acoustic tracking systems to verify hydrophone pos itions and range detectability. During "ping-around," the hydrophones are changed from a receiving only state to an 
active "pinging" state whereby they are transmitting the same codes as fish tags. In an effort to select the best tag code for this tailrace egress study, the vendor programmed five separate transmit signals into the 16 hydrophones. The vendor provided both "coded" and "non-coded" signals that could be programmed into the tags, where coded tags are frequency modulated at transmit and non-coded tags are not. Hydrophones were programmed to transmit two separate "coded" signals (5 ms, and $3 \mathrm{~ms}$ ) and three separate non-coded signals ( $4 \mathrm{~ms}, 3 \mathrm{~ms}$, and $2 \mathrm{~ms}$ ). Thru the preliminary "ping-around" testing without spill, we determined that the 3-ms coded pulse had the greatest range and detectability. This was the code selected for the fish tags. The initial "ping-around" test also showed that all hydrophones were functional at setup and that hydrophones had sufficient range detectability to locate tagged fish during a no-spill condition in the tailrace.

The second method to determine tag detectability under varying spill conditions involved measuring the distance from a hydrophone at which a tag signal was no longer received. This was accomplished by suspending a tag $3.2 \mathrm{~m}$ deep at 1-m intervals from the hydrophone. The final interval in which the hydrophone detected the tag was recorded as the maximum range. During this portion of range testing, the open water of the tailrace was inaccessible during spill treatments and the only option was to suspend a tag along accessible routes adjacent to the tailrace. This test was done for three fixed-mount hydrophones that had structures in line of sight of the hydrophone so that we could traverse the distance between the hydrophones by moving the tag fixed distances away from the hydrophone.

Indirect measures of tag detectability were conducted throughout the research period. The number of fish that exited the forebay into the tailrace using various passage routes at the dam was known from the forebay BRD study. The total number of fish known to enter the tailrace was compared to the total number detected. The detection rate was also evaluated by the route by which each fish exited the forebay.

The survivability of hydrophones and cables was also monitored throughout the research period. Hydrophones and cables were constantly subjected to high flow, which often carried with it debris in the form of logs or rocks. These objects traveling at high speed had the potential to disable a hydrophone with one strike. The armament of electronic hydrophone cable could have been compromised by abrasion due to the cable's exposure to rock and flow. Hydrophone mounts were designed to withstand these elements, however the tip of a hydrophone as well as the electronic cable connecting the hydrophone to the receiver had to be exposed for tracking fish. By monitoring the receiving capability of each hydrophone for the research period, we were able to determine the time and likely cause of any malfunction.

\subsection{Tracking the Path of Juvenile Salmon and Passive Drogues}

Tracking juvenile salmon and drogues through the tailrace of Lower Granite Dam involved two separate release strategies to address research objectives. The first strategy was to release juvenile spring chinook and passive particle drogues into the tailrace as paired releases. This strategy was to address objective $3 \mathrm{a}$, to compare the passage routes taken by drogues (passive particles) and those routes taken by juvenile salmon when released from the same location. The other strategy was to take advantage of a separate study conducted by the BRD, and attempt to track the paths and tailrace residence times of juvenile wild steelhead, juvenile hatchery steelhead, and ju venile hatchery chinook that had equal opportunity to exit any passage route available at Lower Granite Dam (turbines, spillways and fish passage routes); this strategy addressed objective 3b. (Evaluate the passage routes of juvenile salmon by 
species, time of day, and entry into the tailrace.) Therefore, our study sought to track the movement of three different classes of objects:

1) acoustic tagged fish that were released upstream of the dam (forebay fish)

2) acoustic tagged fish that were released into the tailrace (tailrace fish)

3) acoustic tagged drogues that were released into the tailrace (drogues).

\subsubsection{Fish Handling and Tagging}

We used procedures for surgically implanting ultrasonic tags by following those outlined by Adams et al. 1998, for surgically implanting juvenile salmonids with micro-radio tags. Juvenile steelhead and yearling chinook over $125 \mathrm{~mm}$ in length were collected at Lower Granite Dam juvenile bypass facility. Fish over $125 \mathrm{~mm}$ were selected due to ultrasonic tag size (1.5 g) and the possible inability of smaller fish to compensate for tag weight. It has been shown that the swimming performance and buoyancy compensation of fish can be influenced if fish are surgically implanted with a tag greater than 5\% of their body weight (Perry et al. 2001).

Ultrasonically tagged juvenile salmon were divided into two groups to address separate research objectives. One group was released solely as a part of our feasibility study and the other group was released by the BRD for use in the RSW evaluation study (forebay fish). Those fish were also available to track during our feasibility study. There were six days of PNNL releases into the Lower Granite Dam tailrace (two at the spillway and four at the turbines). A total of eight juvenile spring chinook was desired for each of PNNL's six releases and 15 fish (five juvenile spring chinook, five juvenile wild steelhead, and five juvenile hatchery steelhead) were wanted for the BRD RSW evaluation; however, due to limited availability of fish at the bypass facility on June 5, only seven fish were released on June 6. Fish were transported from Lower Granite Dam to the tagging area located at Blyton Landing, approximately $8 \mathrm{~km}$ upstream of Lower Granite Dam. Fish destined for tailrace release were then transported back to Lower Granite Dam for release into the tailrace, and fish that were released for the BRD RSW evaluation were randomly distributed across the Snake River at Blyton Landing.

\subsubsection{Surgical Implantation}

Tags were coded a minimum of one hour (maximum 3 hours) prior to any surgical implantation and then placed in a sterile saline solution. A unique tag code was assigned to each fish or drogue; codes varied from $300 \mathrm{~ms}$ to $600 \mathrm{~ms}$ between pings for tailrace-released fish and between $800 \mathrm{~ms}$ and $1500 \mathrm{~ms}$ for forebay-released fish. The surgical procedures were as follows. Prior to surgery, fish were placed in buckets containing an anesthetic solution of Tricaine Methanesulfonate (MS-222) in quantities of 5.5 to $7.0 \mathrm{ml} / 10$ liters depending on fish size. Fish were kept in the anesthetic tank for no longer than 150 seconds.

As soon as a fish lost equilibrium, it was immediately removed from the bucket, weighed, and measured. The fish was then placed on the surgery table and given anesthesia through rubber tubing from a gravity-fed bucket in the form of MS-222 in quantities of $0.2 \mathrm{ml} / 1$ until one minute before the surgical procedure was completed, whereupon the anesthetic mixture was changed to fresh river water. With the fish facing ventral side up, a 10-mm incision was made $3 \mathrm{~mm}$ from and parallel to the mid-ventral line 
between the pelvic girdle and anal fin (Figure 3.3). The ultrasonic tag was then implanted, while species, weight, fork length, and tag code were recorded. Oxytetracycline was injected into the incision at a concentration of $100 \mathrm{mg} / \mathrm{ml}$ in an amount of $50 \mathrm{mg} / \mathrm{kg}$ body weight. The incision was sutured immediately following the oxytetracycline injection with three stitches. Antibacterial cream was applied to the stitches using a Q-tip. Post surgery, fish were placed into a recovery bucket with fresh, oxygenated river water and monitored to insure that they recovered equilibrium, after which they were placed into a holding tank for 24 hours before transport.

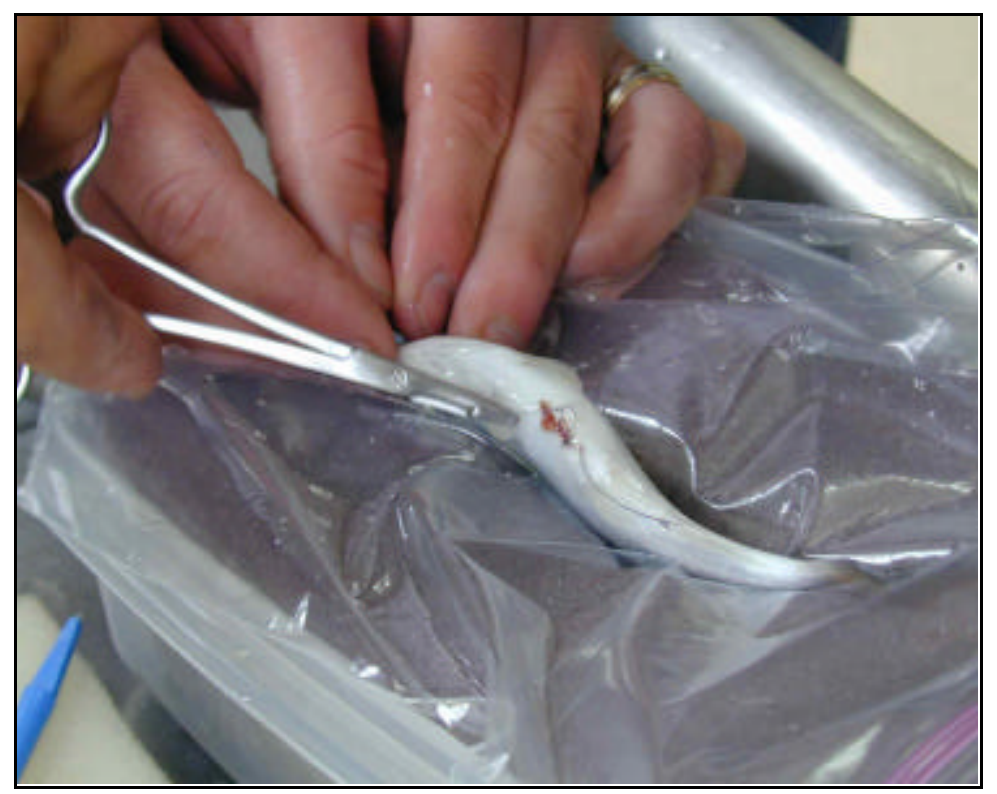

Figure 3.3. Surgical Implantation of Ultrasonic Tag

\subsubsection{Holding and Release Protocol}

\subsubsection{Juvenile Salmon and Drogue Releases in the Tailrace}

After the 24-hour holding period, fish were transported from Blyton Landing to the tailrace release site. Fish and drogue releases were conducted from May 21 to June 7, 2002. Releases were conducted at the downstream side of spillbays 3 and 6, as well as downstream of turbine units 2 and 4. Each ultrasonically tagged fish was paired with an ultrasonically tagged neutrally buoyant drogue and then lowered in a 5-gallon bucket downstream of an operating spillbay or turbine unit. The bucket was then tipped over at a distance of $<1 \mathrm{~m}$ from the water surface, and the fish and drogue were released. The UFTS was operating during the releases to monitor the tailrace egress of juvenile salmon and the drogues.

There were a total of six releases of eight juvenile hatchery chinook each day and five of those releases had paired drogue releases. Sixteen fish and eight drogues were released on the downstream side of the spillway and 31 juvenile spring chinook and 31 drogues were released on the downstream side of the powerhouse. 
The operating conditions of the tailrace were not consistent with the schedule of "high training," "low training," or "BiOp" spill scenarios due to the timing of the spring run-off peak and lower-than-expected power demand. Lower Granite Dam was being operated under an uncontrolled spill condition during the releases, and was under the "high powerhouse-high spill" treatment for all releases where the powerhouse operations were above $54 \mathrm{kcfs}$ and all spill discharges were above $24 \mathrm{kcfs}$. The average discharge during the fish releases was $46 \mathrm{kcfs}$ for spill and $75 \mathrm{kcfs}$ for powerhouse operations. We released a greater number of fish and drogues on the powerhouse side of the tailrace due to the poor initial detection results from spillway releases.

\subsubsection{Juvenile Salmon Releases at Blyton Landing}

After the 24-hour holding period, fish were transported to mid-channel of the Snake River at Blyton Landing for the BRD RSW evaluation. During transport, fish were given a constant supply of oxygen and their holding tanks were covered to reduce stress. Fish were then tested to verify activity of ultrasonic tags and released one at a time. This procedure involved placing individual fish into 5-gallon (19-liter) buckets filled with river water to verify tag operation before lowering the bucket into the river and releasing the fish. The juvenile salmon then migrated downstream to the study site at Lower Granite Dam. The BRD detected the fish in the forebay using a similar UFTS and relayed the tag code, fish species, exit location, and exit times for all tagged fish for our benefit to use as entry data of fish into the tailrace.

\subsection{Computational Flow Modeling}

We modeled the flow in the Lower Granite Dam tailrace to provide insight into the movements of juvenile salmon and passive drogues. The flow conditions established by hydroelectric dam operations directly influence the tailrace environment and a better understanding of this environment can be gained through computational fluid dynamic (CFD) modeling. In recent years emphasis has been placed on the validation of computational models so they could pass the scrutiny of peer-reviewed publications, and it was hoped that the drogue releases could provide baseline data for the model created for Lower Granite Dam. Due to circumstances to be described below, the drogue tracks were not sufficient to validate the model. Therefore the model was created using standard fluid-dynamic protocols using a depth-averaged steady-state model developed by Peter Steffler of the University of Alberta and not validated with the drogue tracks (Steffler and Blackburn 2002). Steffler's model is called "River2D" and was designed as a "Two-Dimensional Depth Averaged Model of River Hydrodynamics and Fish Habitat." The model requires inputs of inflow for any source of water entering the tailrace, inflow elevation, outflow elevation, a bathymetric surface, a grid that describes points within the model's bounds, and a boundary to encompass the model. The output of the model provides a depth-averaged water velocity magnitude and direction as well as a suite of other flow characteristics for each grid point given these variables.

We modeled four flow conditions that were selected to mimic actual flow conditions experie nced during the research period: 1) a low powerhouse-low spill, 2) high powerhouse-high spill, 3) low powerhouse-high spill, and 4) high powerhouse-high spill conditions. 
The Feasibility of Using an Ultrasonic Fish Tracking System in the Tailrace of Lower Granite Dam 


\subsection{Results}

\subsection{Evaluating the Acoustic Noise in Lower Granite Tailrace}

\subsubsection{Noise Levels Measured Using a Spectrum Analyzer}

\subsubsection{Source Level Measurements}

Sound pressure level (SPL) measurements of the acoustic tags measured in a test tank showed the $307.2 \mathrm{kHz}$ acoustic tag to have an average source level (SL) of 147 decibels referenced to 1 micro-Pascal $(\mathrm{dB} \mathrm{re} / / 1 \mu \mathrm{Pa})$ at $1-\mathrm{m}$ range at $307.2 \mathrm{kHz}$, this is within the range provided by the vendor. For the rest of this report all SPL measurements in $\mathrm{dB}$ will be referenced to $1 \mu \mathrm{Pa}$ at $1 \mathrm{~m}$ and a SL of $147 \mathrm{~dB}$ for the acoustic tags we used. Analysis of the frequency distribution of the acoustic tag showed a signal range of about $3 \mathrm{kHz}$, from $306 \mathrm{kHz}$ to $308 \mathrm{kHz}$. This distribution will be used in calculation of the signaltonoise ratio (SNR) of the tag to noise in the tailrace of the dam.

\subsubsection{Tailrace Sound Measurements}

SPL measurements in the tailrace downstream of the draft tube outlets at LGR showed SPL of frequencies above $10 \mathrm{kHz}$ averaged about $109 \mathrm{~dB}$ in spring during high spill and when 5 of the 6 turbine units were operating (high powerhouse-high spill condition). In late summer, when only one turbine was operating and there was no spill, SPL averaged about $94 \mathrm{~dB}$ (Figure 4.1, low powerhouse-low spill).

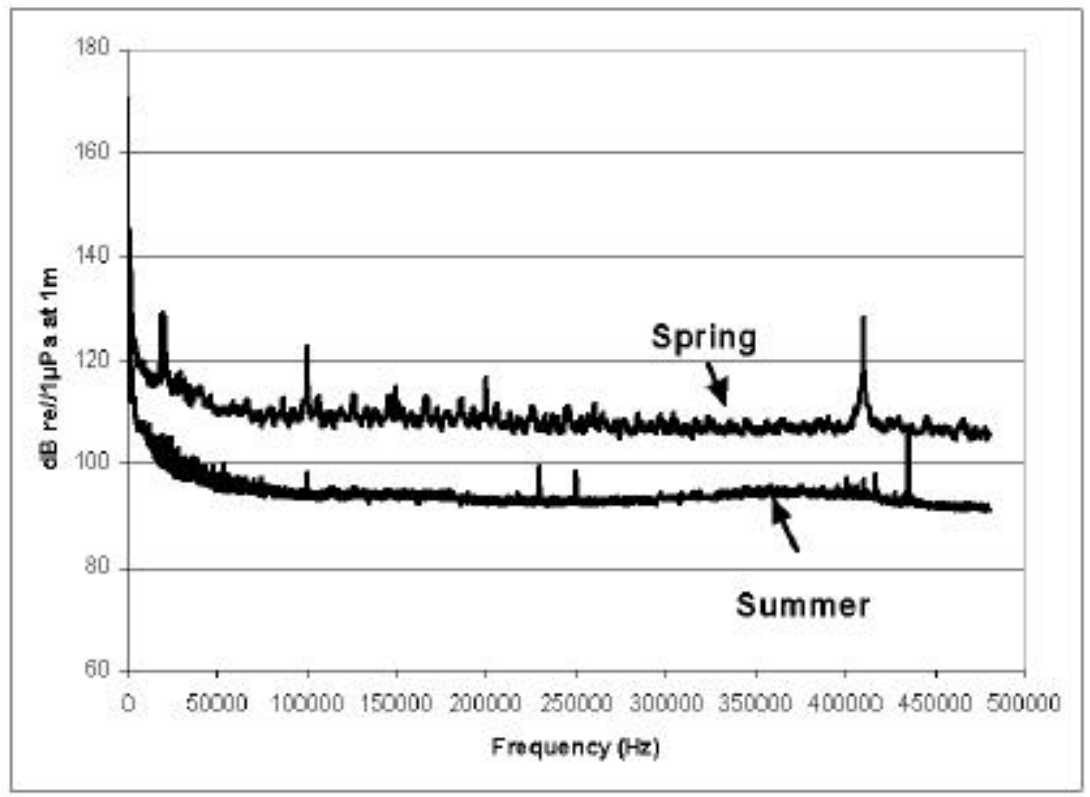

Figure 4.1. Average Sound Pressure Levels in the Tailrace of Lower Granite Dam in the Spring with High Spill and 5 of 6 Turbine Units Operating, and in Summer with No Spill and One Turbine Unit Operating (high powerhouse-high spill condition). 
To determine if SPL varied among discharge plumes in the tailrace, the hydrophone recorded SPL measurements behind four turbine units $(1,4,5 \& 6)$ during high generation and spill in the spring. SPL measurements were lowest at units 1 and 6, at opposite ends of the powerhouse, and were highest at units 4 and 5. From these data it appears that SPL are highest near the center of the powerhouse and are not dependent on the generation of a single unit, since Unit 5 was off line during our testing (Figure 4.2).

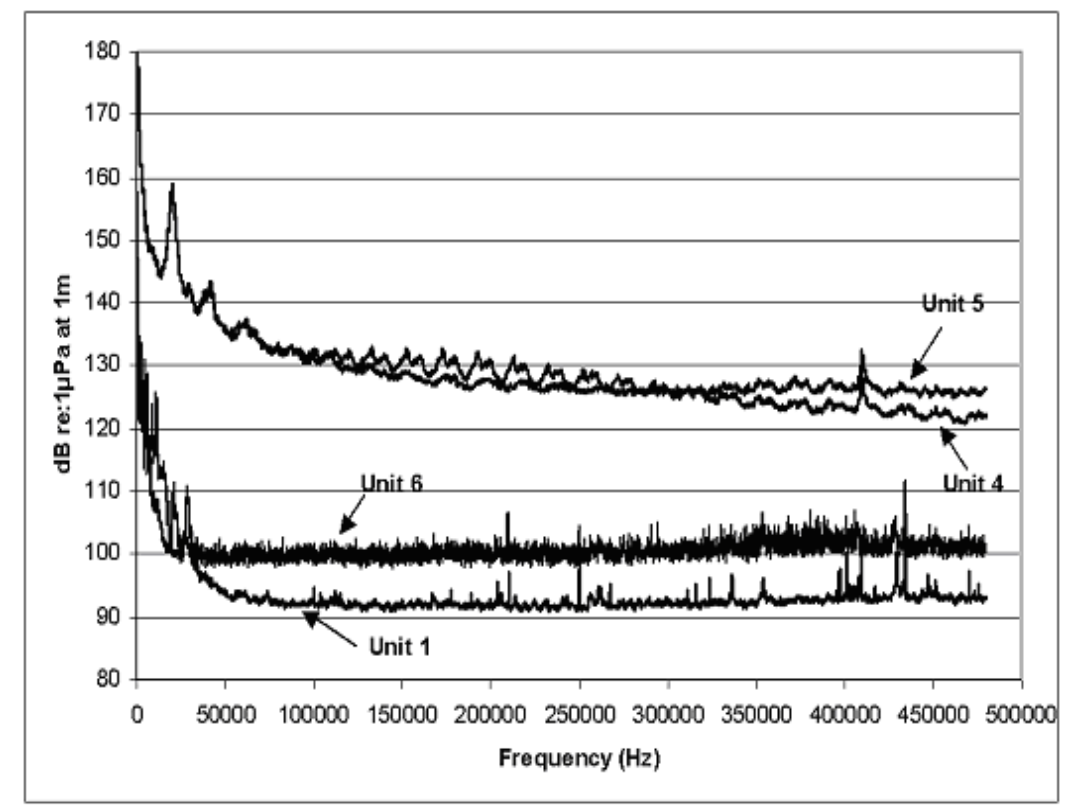

Figure 4.2. Sound Pressure Levels $(\mathrm{dB})$ at the Draft Tube Exits of Turbine Units at Lower Granite Dam in Spring during High Spill with Five of Six Turbine Units Operating. Unit 5 was not operating during these tests.

SPL measurements were also collected along the southwest shore of the tailrace and the southwest side of the downstream channel navigation lock wall in the spring (Figure 4.3). SPL were highest at $307.2 \mathrm{kHz}$ along the navigation wall closest to the spillway and decreased in intensity with increased distance from the spillway along the navigation lock wall. The SPL measured closest to the spillway were similar to levels measured outside the draft tubes of units 4 and 5 of about $125 \mathrm{~dB}$. 


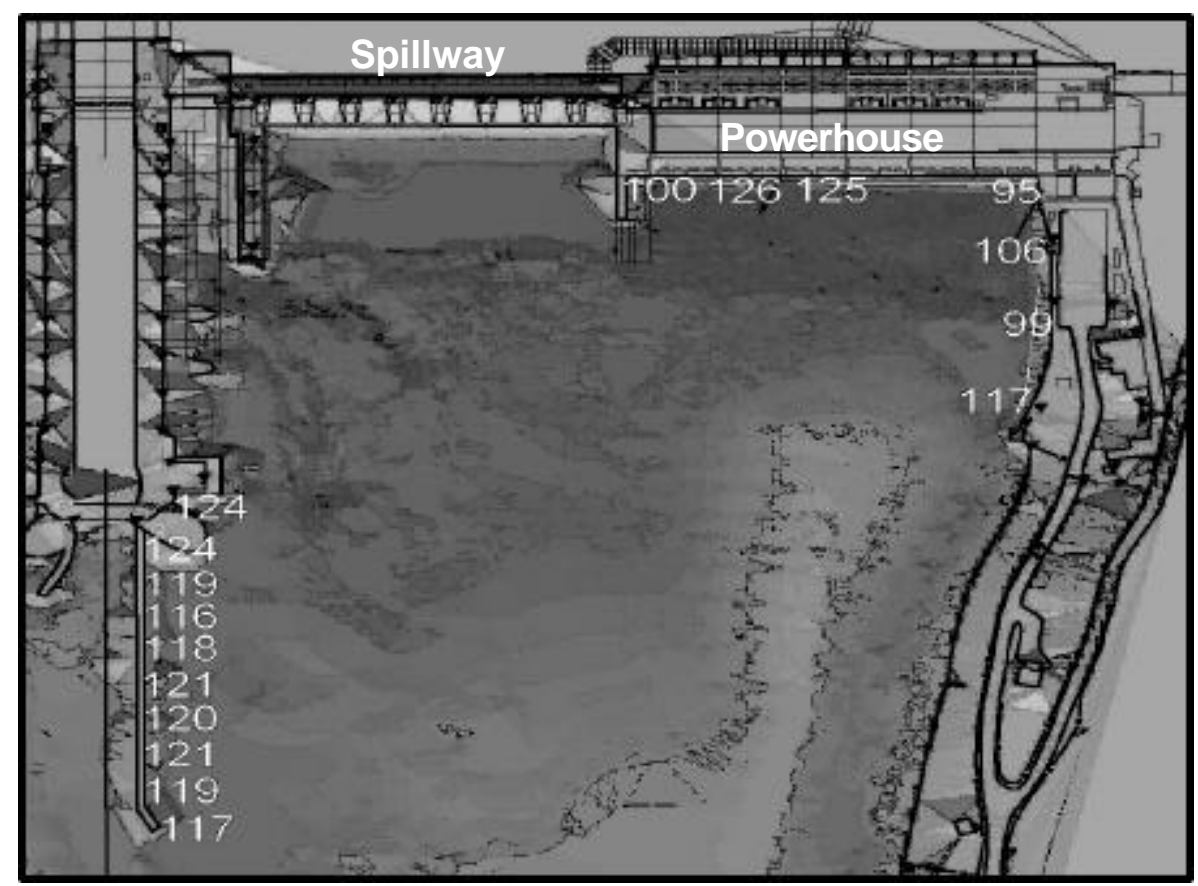

Figure 4.3. Sound Pressure Levels (dB) at $307.2 \mathrm{kHz}$ in the Tailrace of Lower Granite Dam in Spring during High Spill and When Five of Six Turbine Units Were Operating. Units in $\mathrm{dB}$ ref/ $/ \mu \mathrm{Pa}$

\subsubsection{Signal Detection Range}

The detection range of an acoustic tag depends on the source level (SL) of the tag, signal attenuation in the water, and other noise at the frequency of interest affecting the SNR. If the SNR is not above a certain threshold level, the signal will not be detected. Using the $147 \mathrm{~dB}$ SL determined in the tank for the $307.2 \mathrm{kHz}$ acoustic tags, we estimated the theoretical distance we should be able to detect the tag assuming only spherical spreading loss, using the average background SPL found downstream of the draft tubes at $307.2 \mathrm{kHz}$ and assuming a 3-dB signalto-noise ratio as our detection threshold. At Lower Granite Dam, estimated detection range with loss due only to spherical spreading varied from $70 \mathrm{~m}$ in spring to $375 \mathrm{~m}$ in summer (Figure 4.4). 


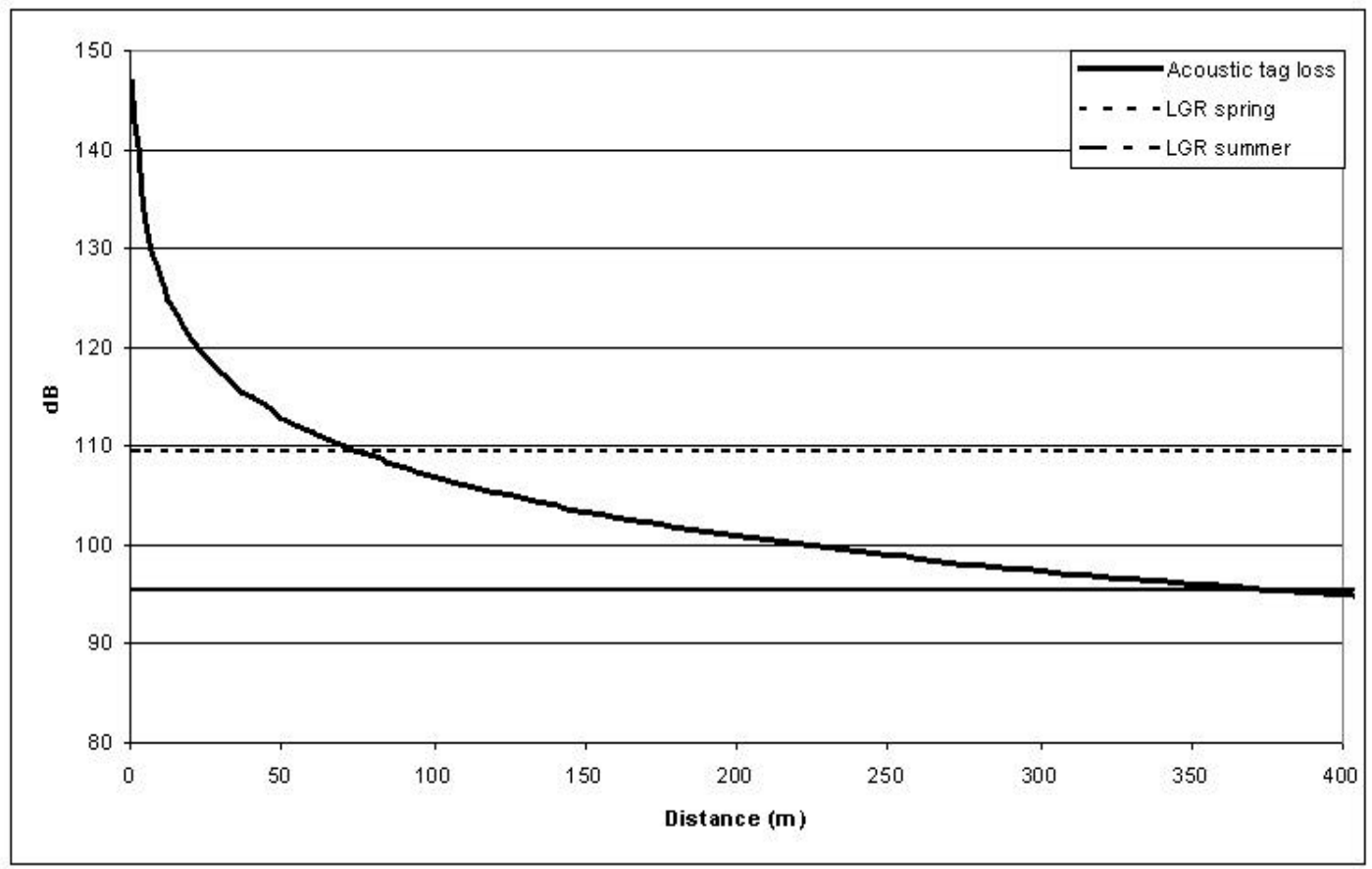

Figure 4.4. Calculated Loss in Tag Signal Strength with Increase in Distance due only to Spherical Spreading Relative to Threshold Detection Levels Measured in the Tailrace of LGR in Both Spring and Summer

To determine the actual detection range of the tag, the contribution of signal loss due to scattering and absorption of the acoustic energy also must be considered. Energy is scattered and absorbed by particles in the water, fish, water boundaries, and air bubbles. In the tailrace of hydroelectric dams, air bubbles are a major cause of signal loss. Since the variables that cause the scattering and absorption of energy vary by location, and in this case by dam operations, it is not possible to determine the actual affect scattering and absorption have on the detection range of the signal without measurements. We used field data to estimate the range of tag detection relative to SNR. The power of the signal was estimated by summing the power over the range of the acoustic signal and estimating the noise level by summing the $3-\mathrm{kHz}$ frequency bin centered at the frequency of the acoustic tag signal. Results of calculated signal-to-noise ratios by distance from the hydrophone and relative to gain added to the incoming signal show that the tag should be detected to at least $120 \mathrm{~m}$ with 20 and $40 \mathrm{~dB}$ of gain, and $60 \mathrm{~m}$ with no gain added in summer when only one unit was operating (Figure 4.5). We did not have an amplifier available for measurements in the spring and were not able to identify the signal above the noise without an amplifier even at the closest tag distance from the receiver of $15 \mathrm{~m}$. 


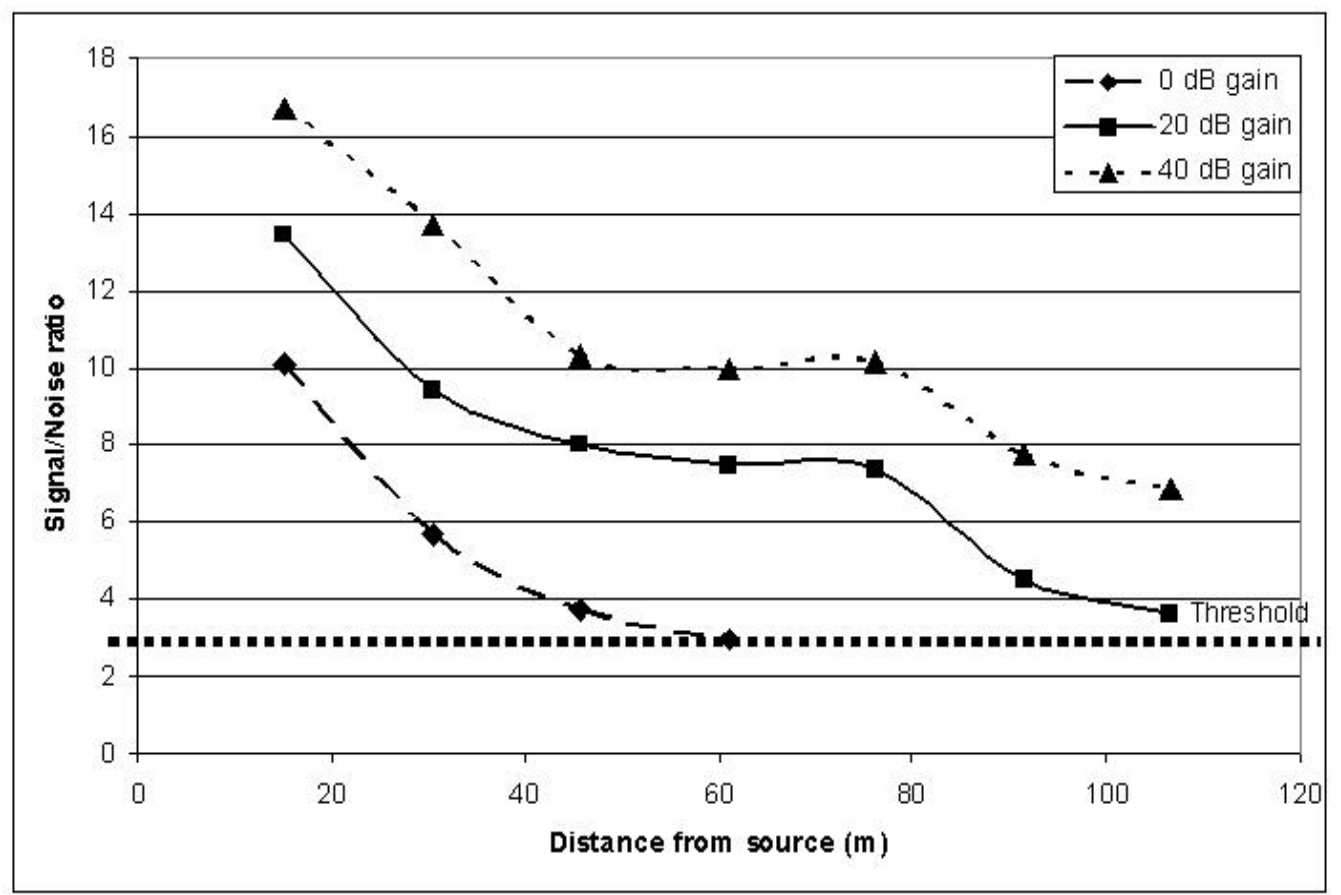

Figure 4.5. Signalto-Noise Ratio of the Acoustic Tag Relative Noise Levels at 307.2 $\mathrm{kHz}$ in the Tailrace Downstream of the Draft Tubes at Lower Granite Dam. The dotted line at $3 \mathrm{~dB}$ is detection threshold, where below this line the receiver will most likely not detect the acoustic signal.

\subsubsection{Noise Levels Measured Using the UFTS}

Median sound pressure levels for individual hydrophones varied throughout the testing period and were significantly correlated $(\mathrm{P}<0.05)$ to spill and generation levels, though the correlation was weak. Peak sound pressure levels varie d between hydrophones and was highest at hydrophone 5, which was mounted to the wall between the powerhouse and the spillway (Figures 4.6 to 4.7). The number of tag detections per hour at $307.2 \mathrm{kHz}$ was also highest at hydrophone 5 (Figures 4.8 to 4.9).

Results of the ANOVA for median sound pressure showed a significant relationship between median sound pressure and spill level, generation level, location of the hydrophone relative to the powerhouse and spillway, and distance of the hydrophone from the dam. Interaction between each pair of factors was also significant. Median sound pressure increased with increase in spill volume. Conversely, we found that median sound pressure decreased with increase in generation level (Figure 4.10). We compared spill level with generation level to determine if spill and generation were correlated resulting in this negative trend but found no correlation between spill and generation level. However, these significant findings may be influenced by the large sample size, whereby the significant difference that was found is only significant due to the great volumes of data that were collected. Interpretation of these analysis findings should take this into consideration. 


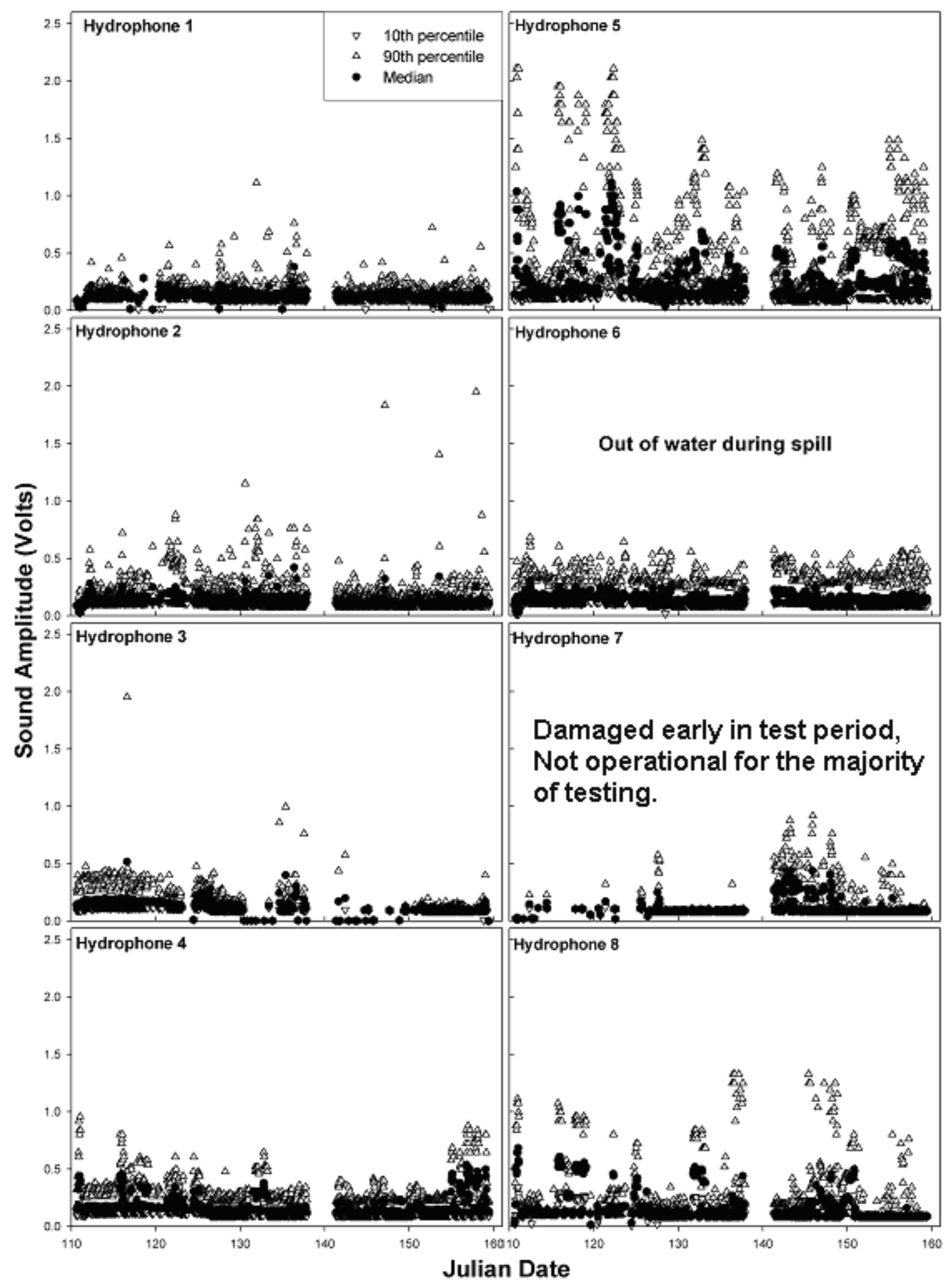

Figure 4.6. Median Sound Pressure Levels, and 10th and 90th Percentile Bounds, Detected at Hydrophones 1 through 8 of the Acoustic Tracking Array in the Tailrace of Lower Granite Dam between April 20 and June 20, 2002. Note: Hydrophone 6 was out of the water during spill and hydrophone 7 was damaged early in collection and most of the ir values are erroneous. 


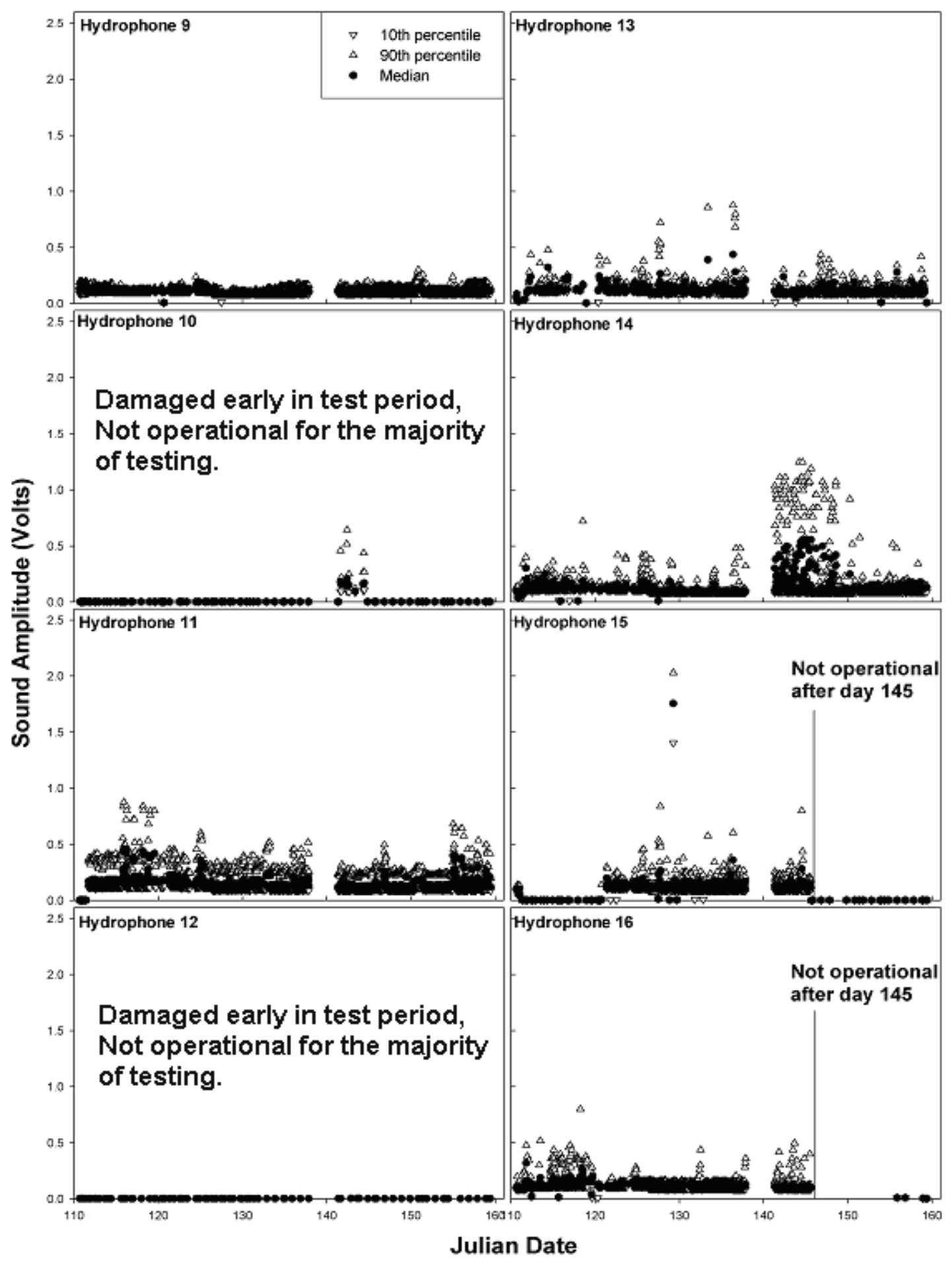

Figure 4.7. Median Sound Pressure Levels, and 10th and 90th Percentile Bounds Detected at Hydrophones 9 through 16 in the Acoustic Tracking Array in the Tailrace of Lower Granite Dam between April 20 and June 20, 2002. Note: Hydrophones 10 and 12 were damaged early in collection and hydrophones 15 and 16 stopped working on day 145 . 


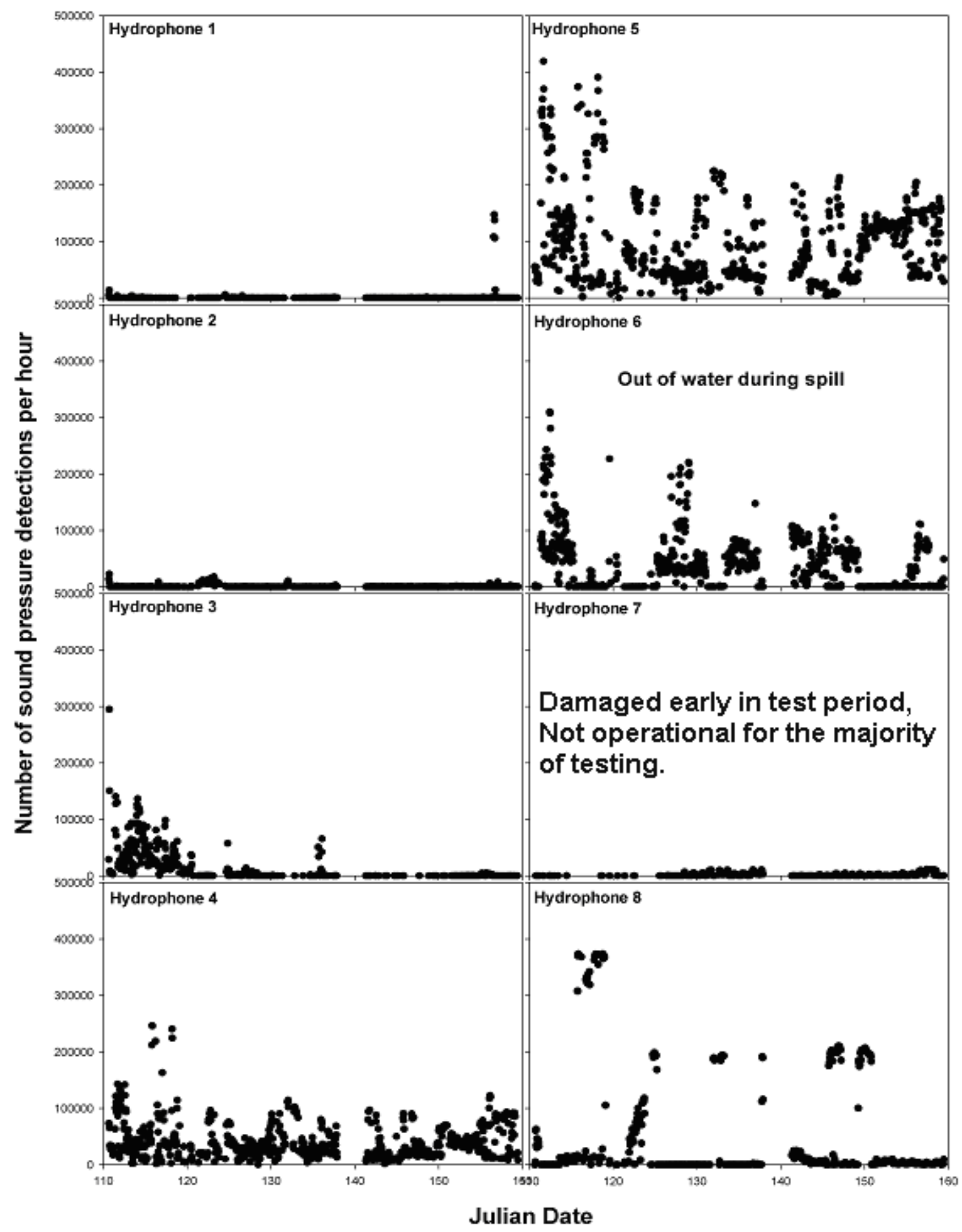

Figure 4.8. Number of Sound Pressure Detections at $307 \mathrm{kHz}$ Collected above the Threshold Level Detected at Hydrophones 1 through 8 in the Acoustic Tracking Array in the Tailrace of Lower Granite Dam between April 20 and June 20, 2002. Note: Hydrophone 6 was out of the water during spill and hydrophone 7 was damaged early in collection so most of their values are erroneous. 


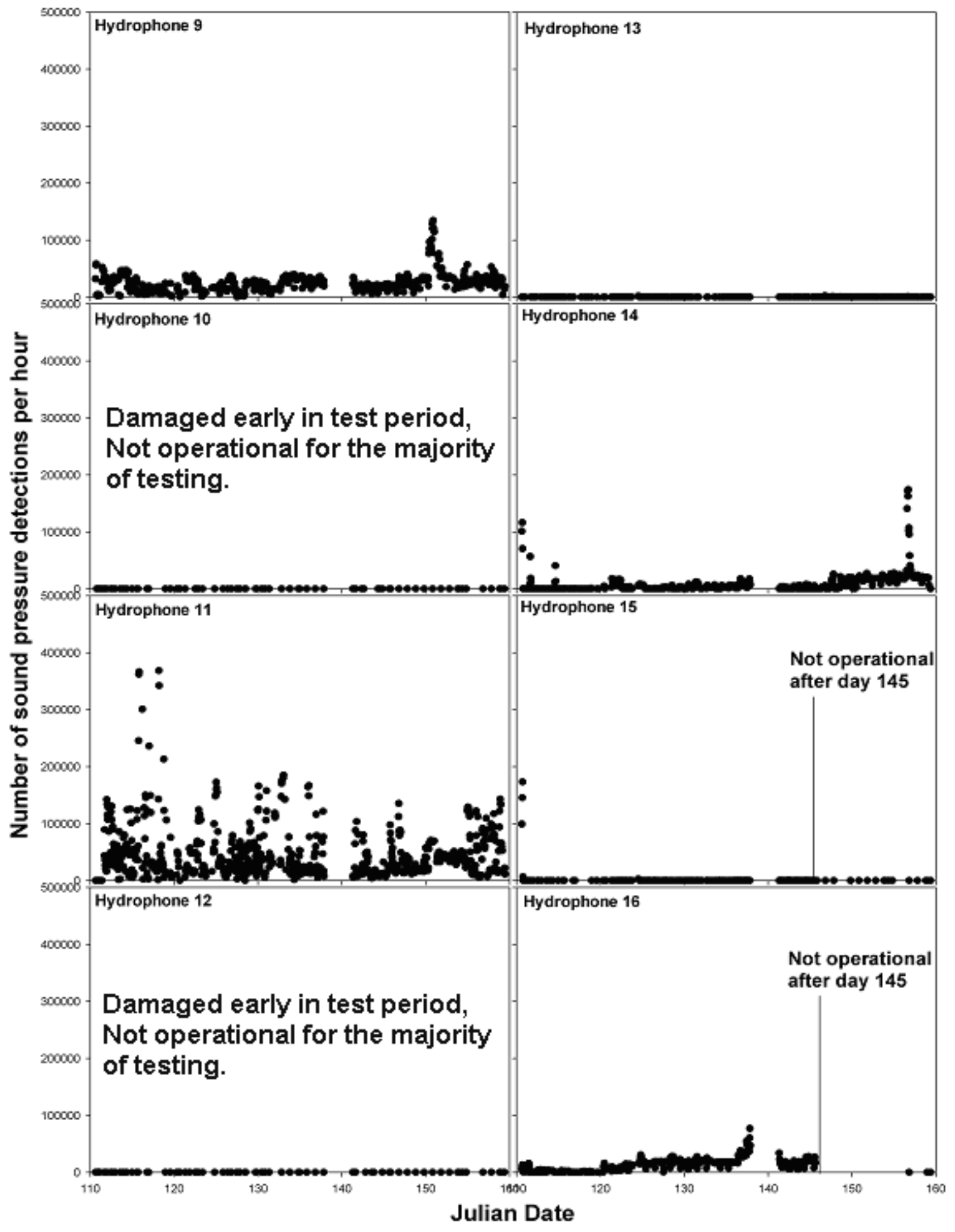

Figure 4.9. Number of Sound Pressure Detections at $307 \mathrm{kHz}$ Collected above the Threshold Level Detected at Hydrophones 9 through 16 in the Acoustic Tracking Array in the Tailrace of Lower Granite Dam between April 20 and June 20, 2002. Note: Hydrophones 10 and 12 were damaged early in collection and hydrophones 15 and 16 stopped working on day 145 . 
Median sound pressure was significantly higher for hydrophones located downstream of the spillway than for hydrophones located downstream of the powerhouse (Figure 4.11). Median amplitude declined with increase in distance downstream of the dam (Figure 4.12) and decreased significantly for hydrophones downstream of both the powerhouse and the spillway. Results of the ANOVA are provided in Appendix A.

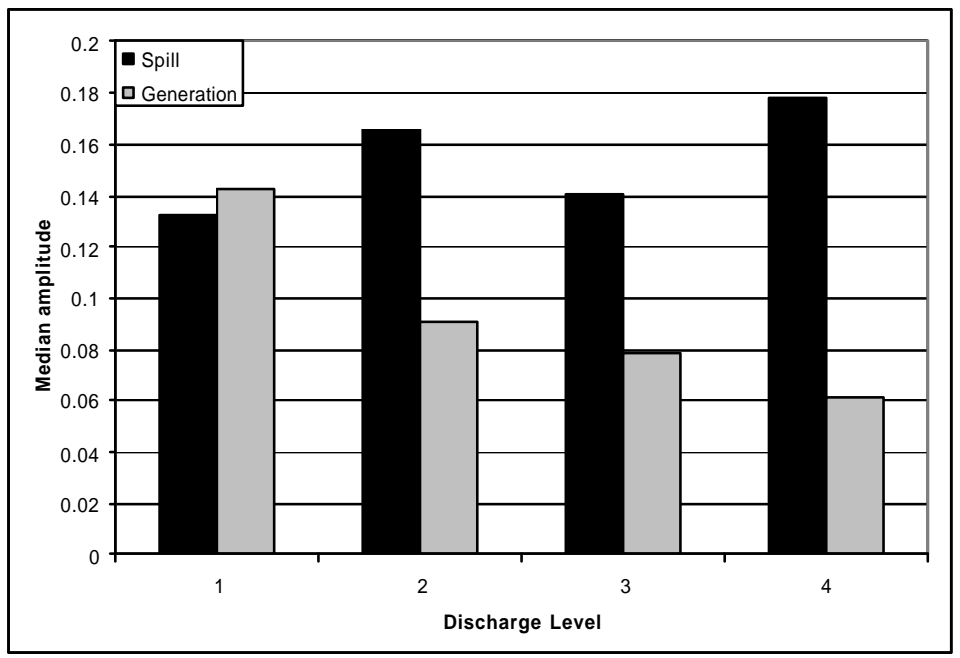

Figure 4.10. Median Sound Pressure Detected by Hydrophones Relative to Spill and Generation Levels

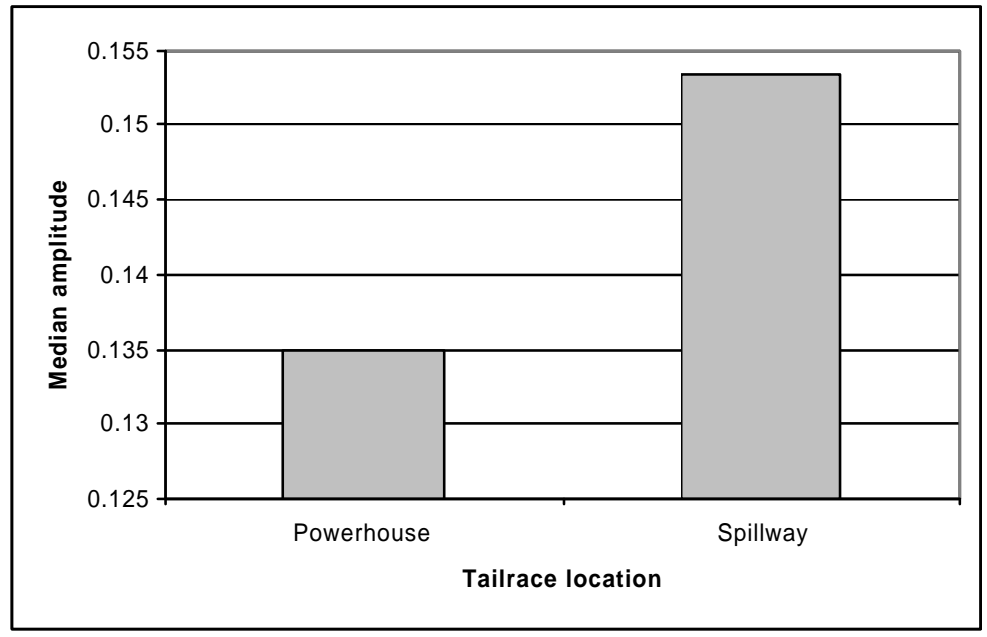

Figure 4.11. Median Sound Pressure Detected by Hydrophones Located Downstream of the Powerhouse and the Spillway

The results of the ANOVA for number of sound pressure detections per hour $(\mathrm{N})$ were similar to those for median sound pressure with a significant relationship between $\mathrm{N}$ and spill level, generation level, location of the hydrophone relative to the powerhouse and spillway, and distance of the hydrophone from the dam (Figure 4.13). Interaction between each pair of factors was also significant. 


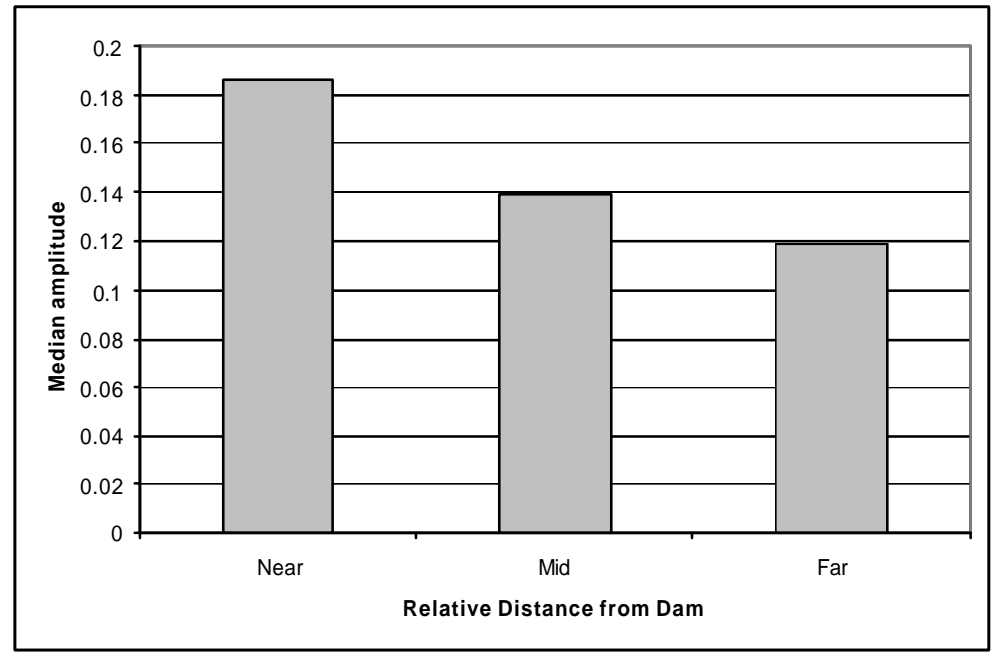

Figure 4.12. Median Sound Pressure Detected by Hydrophones Relative to Distance of the Hydrophone from the Dam

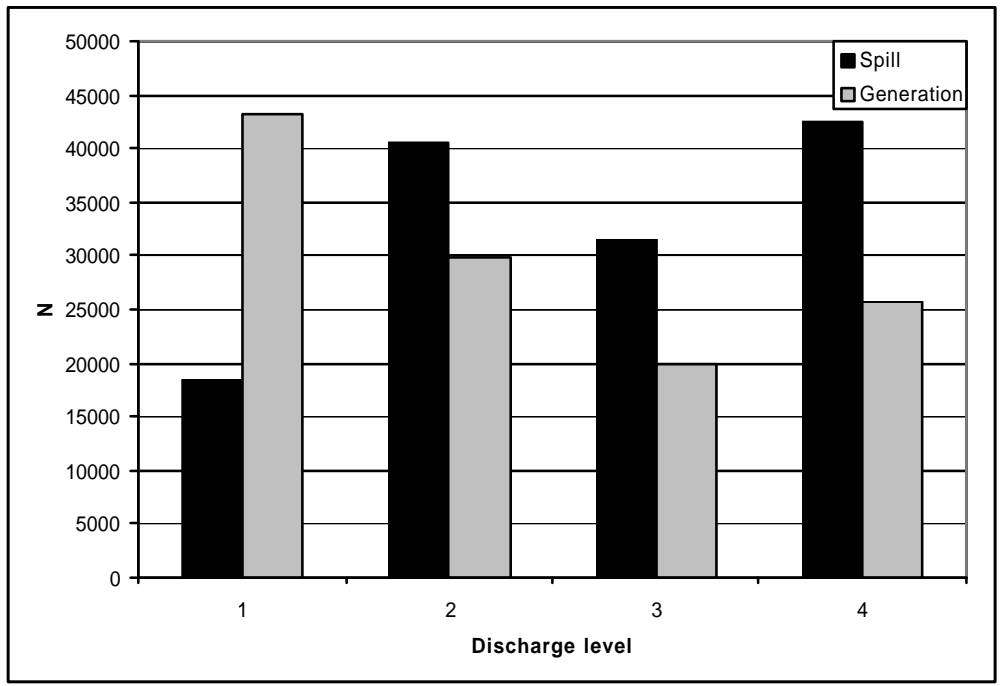

Figure 4.13. Number of Sound Pressure Detections by Hydrophones Relative to Spill and Generation Levels. Discharge levels varied for spill and powerhouse operations due to the distribution of discharge throughout the research period. The discharge levels for spill were, 1) $<30 \mathrm{Kcfs}$, 2) 30-60 Kcfs, 3) 60-90 Kcfs, and 4) >90 Kcfs. The discharge levels for powerhouse operations were 1) $<25 \mathrm{Kcfs}$, 2) $25-50 \mathrm{Kcfs}, 3) 50-75$ Kcfs, 4) >75 Kcfs.

$\mathrm{N}$ increased with increase in spill volume and decreased with increase in generation level (Figure 4.13), though the trend was not as strong. $\mathrm{N}$ was also significantly higher for hydrophones located downstream of the spillway than downstream of the powerhouse (Figure 4.14). N also declined with increase in distance downstream of the dam (Figure 4.15) and decreased significantly for hydrophones downstream of both the powerhouse and the spillway. Results of the ANOVA are provided in Appendix B. 


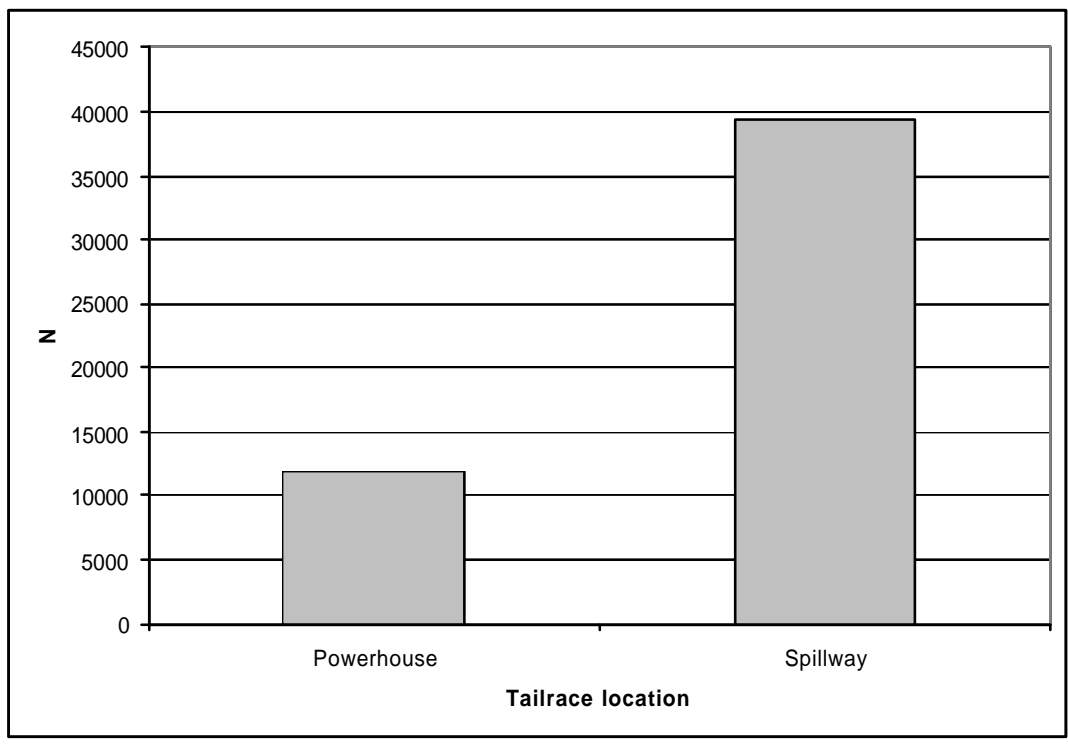

Figure 4.14. Number of Sound Pressure Detections by Hydrophones Located Downstream of the Powerhouse and the Spillway

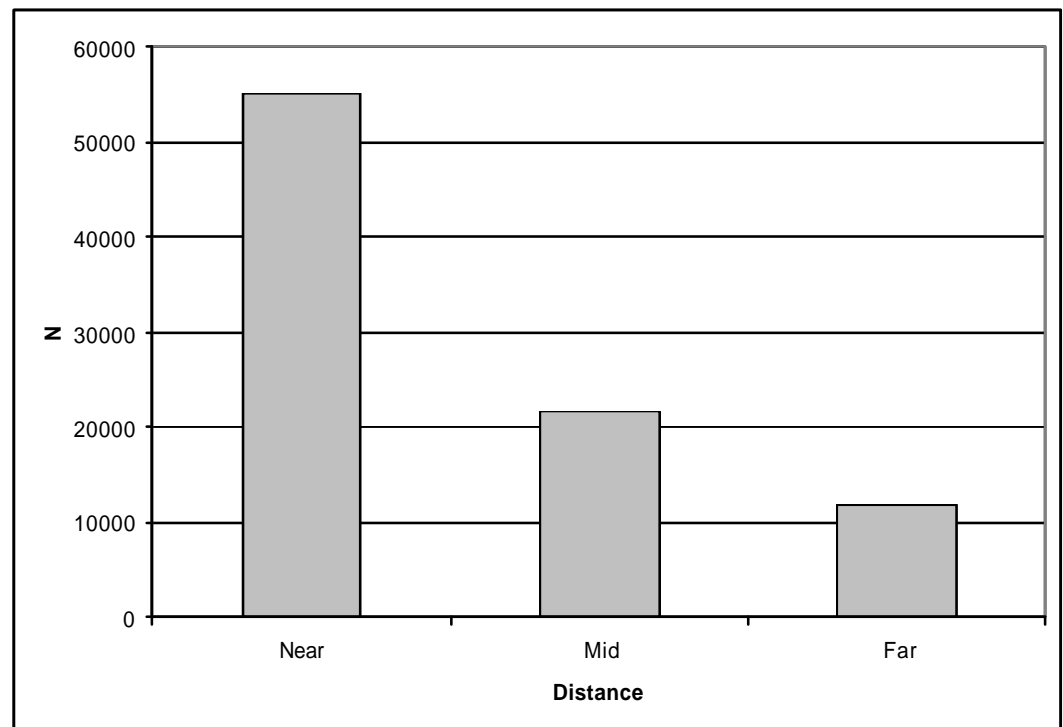

Figure 4.15. Number of Sound Pressure Detections by Hydrophones Located Downstream of the Powerhouse and the Spillway 


\subsection{Performance of Ultrasonic Fish Tracking System}

\subsubsection{UFTS Performance by Direct Measure}

Direct measurement of the tag detection range produced varied results depending on spill and powerhouse operations. "Ping-around" results suggested that during "no-spill" conditions, ultrasonic tags could be tracked anywhere in the tailrace (Figure 4.16). During the "ping around," each hydrophone could detect and receive the signal produced from at least three other hydrophones that were emitting the same signal at the same source level as the acoustic tags. The detection of a tag on four hydrophones was the minimum required to locate the position of an ultrasonic tag using the software provided by the vendor, and this minimum requirement was satisfied by "ping-around" tests.

The maximum detection ranges of hydrophones during spill on May 9 were directly measured for three hydrophones: hydrophones 2, 8, and 9 resulting in measurements of $83 \mathrm{~m}, 6.7 \mathrm{~m}$, and $34 \mathrm{~m}$, respectively (Figure 3.1 and 4.17). The range measurements were taken by suspending a tag below the water surface at $1-\mathrm{ft}(0.3-\mathrm{m})$ intervals away from the hydrophone until the tag signal was lost. The ranges for the remaining hydrophones could not be directly measured due to their locations in the tailrace. Estimates of the ranges of these hydrophones (shown on Figure 4.17) were derived from spring noise measurements and orientation rela tive to structures adjacent to the hydrophones. The measured and estimated ranges of detection for the hydrophones did not overlap sufficiently to provide precise position estimates of tagged fish or juvenile salmon for the range tests conducted on May 9, 2002, with $37 \mathrm{kcfs}$ spill discharge and $37 \mathrm{kcfs}$ powerhouse discharge. Therefore positions were only as precise as the detection range of individual hydrophones and varied depending on spillway and powerhouse operations, i.e., the position of a fish detected by hydrophone 9 was accurate within $34 \mathrm{~m}$ of hydrophone 9 during spill conditions.

Other factors, such as the durability of the hydrophones and cables, which were subjected to continued spill and subsequently high flow conditions and debris, also influenced the accuracy of the hydrophone array. Some hydrophones or hydrophone cables were immediately damaged and were made inoperable for the duration of the research period when the spillways were opened. Others were damaged as the research period progressed (Figure 4.18). Any damage to hydrophones or cable was not repairable until the end of the research period due to the hazardous working conditions that were present in the tailrace during the spring RSW tests. Therefore, the fish that were detected in the tailrace were detected on hydrophones that were operational during their egress from the tailrace, and within the range of detection. The range of detection varied depending on hydrophone location and dam operations. We attempted to model this varia nce during spring and summer flow conditions using spectrum analysis described in section 4.1.1. Additional methods we used to evaluate the performance of the UFTS for use in the Lower Granite Dam tailrace were the overall detection percentage of tagged fish and drogues that were present in the tailrace and available for detection by the UFTS. 


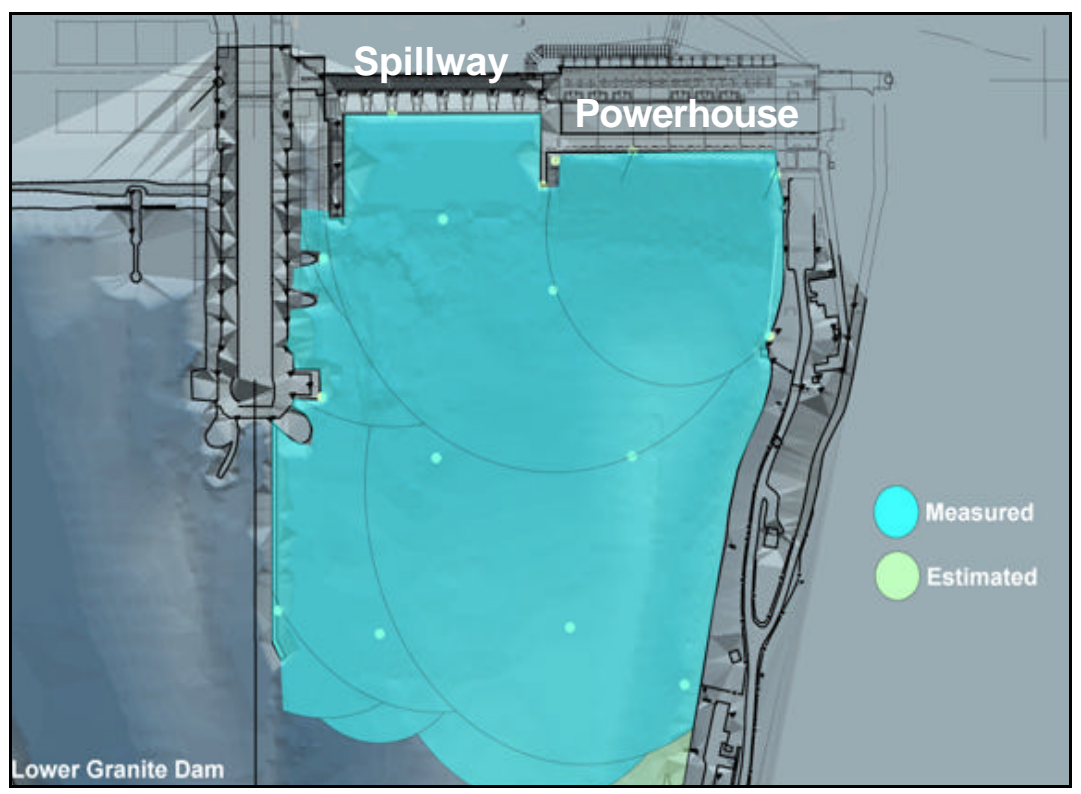

Figure 4.16. Detection Range of Hydrophones as Measured and Estimated with the "Ping-Around" Test during the No-Spill Tailrace Condition. Hydrophones are indicated as the green dots. Estimates were based on sound pressure levels in the tailrace measured during a similar condition.

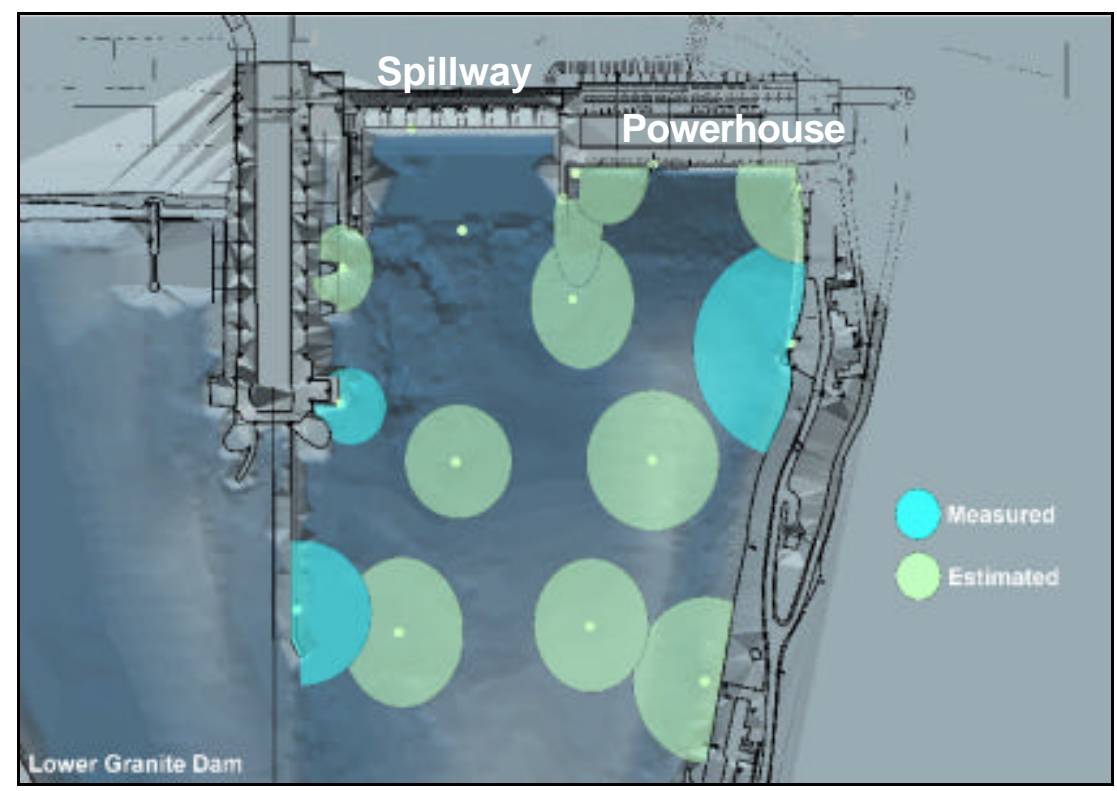

Figure 4.17. Detection Ranges of Hydrophones that Were Directly Measured and Estimated during the NOAA BoOp (high spill) Tailrace Condition. Hydrophones are shown as the green dots. Estimates were based on sound pressure levels in the tailrace measured during a similar condition. 


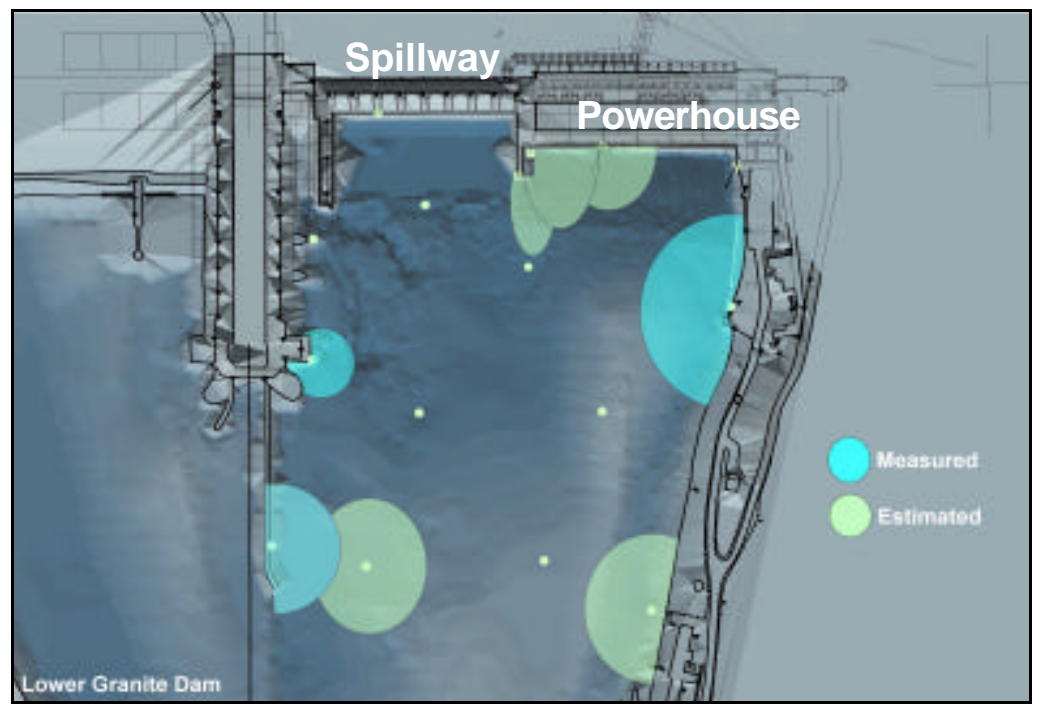

Figure 4.18. Detection Ranges of Hydrophones that Were Directly Measured and Estimated during the NOAA BiOp (high-spill) Tailrace Condition Showing only those Hydrophones still Operational on Day 30 of the Research Period. Hydrophones are shown as the green dots. Estimates were based on sound pressure levels in the tailrace measured during a similar condition.

\subsubsection{UFTS Performance by Release Location}

Fish and drogue detections showed differences in detection by release site. Generally drogues had a lower detection percentage than did fish. Spillway releases of juvenile salmon and drogues also had lower detection percentages than those released at the turbine release sites. The overall detection of both fish and drogues released at spillway and turbine release sites was 38\% (Table 4.1). All releases were conducted during times of uncontrolled spill on May 21, May 22, June 2, June 3, June 6, and June 7, 2002 (Table 4.2). There was not a great enough sample size or range in discharge levels to compare the detectability of fish released at different powerhouse or spill discharges.

\subsubsection{UFTS Performance by Exit Route}

The percentage of fish detected varied by exit route. The average detection of fish in the tailrace that had been released in the forebay and entered the tailrace via any route (spill or powerhouse) was $27 \%$ (Table 4.3, Figure 4.19). This is less than the average detection percentage of those fish released directly into the tailrace $(38 \%)$. This was likely due to variations in exit route discharge and operation throughout the research period. For instance, Turbine Unit 5 was not operational for the duration of the research period, Turbine Unit 1 went offline during the research period, and Turbine Unit 4 was intermittently operational during the research period. Notwithstanding Turbine Unit 5 being inoperable during the research period, the BRD acoustic telemetry study in the forebay indicated that seven fish were last seen entering that unit. This may be possible if the fish entered the fish bypass channels that lead to the collection facility on the south side of the tailrace. We did not have detection capability in this region and could not account for all fish bypassed by screens at any of the powerhouse units. We had the opportunity to detect $100 \%$ of the fish that entered the tailrace via spillway routes; however, only $27 \%$ were detected by hydrophones in the tailrace. We anticipated higher detection rates for fish entering the 
tailrace via the turbines due to lower amounts of entrained air in that region of the tailrace. However, of the fish entering the tailrace from the powerhouse, only $27 \%$ were detected downstream in the tailrace because fish that exited via the juvenile bypass screens were not recorded.

Table 4.1. Number and Percent of Juvenile Spring Chinook (SPCH) and Drogue Detections by Release Site. Mean detection for all releases was $38 \%$.

\begin{tabular}{||l|c|c|c|c||}
\hline Release Location & Type & $\begin{array}{c}\text { Number } \\
\text { Released }\end{array}$ & $\begin{array}{c}\text { Number } \\
\text { Detected }\end{array}$ & $\begin{array}{c}\text { Percent } \\
\text { Detected }\end{array}$ \\
\hline Spillbay 3 & Juv. Spring Chinook & 8 & 2 & $25 \%$ \\
\hline Spillbay 6 & Juv. Spring Chinook & 8 & 4 & $50 \%$ \\
\hline Turbine-Unit 2 & Juv. Spring Chinook & 16 & 8 & $50 \%$ \\
\hline Turbine-Unit 4 & Juv. Spring Chinook & 15 & 13 & $87 \%$ \\
\hline Spillbay 3 & Drogue & 8 & 0 & $0 \%$ \\
\hline Spillbay 6 & Drogue & 8 & 1 & $13 \%$ \\
\hline Turbine-Unit 2 & Drogue & 16 & 2 & $13 \%$ \\
\hline Turbine Unit 4 & Drogue & 15 & 10 & $67 \%$ \\
\hline
\end{tabular}

Table 4.2. Total Lower Granite Dam Discharge (Q) through the Spillway and Powerhouse at the Time of Juvenile Spring Chinook and Drogue Releases

\begin{tabular}{||c|c|c||}
\hline Release Date & Powerhouse Q (kcfs) & Spillway Q (kcfs) \\
\hline May 21, 2002 & 72 & 43 \\
\hline May 22, 2002 & 66 & 25 \\
\hline June 2, 2002 & 74 & 51 \\
\hline June 3, 2002 & 75 & 70 \\
\hline June 6, 2002 & 75 & 35 \\
\hline June 7, 2002 & 75 & 39 \\
\hline
\end{tabular}


South turbine units (1 to 3) were combined and expressed as the South Powerhouse in Table 4.3, due to the lack of 3D coverage that the BRD hydrophone array had in front of those units. Only presence and absence of fish and drogues at those turbine units could be known. The observed differences in detection, as categorized by tailrace entry point, did not show a significant pattern, although a few routes were notable. The majority of BRD-released fish entered via spillbay 1 (RSW), and the detection percentage of those fish is consistent with that for all of the fish. Spillbay 4 had the highest detection percentage. Juvenile salmon passing through spillbay 8 were not detected in the tailrace, and juvenile salmon passing through turbine unit 6 had a very low number of fish detected. It was possible that the juvenile salmon could have passed into the juvenile bypass before entering the tailrace through turbine unit 6 .

Table 4.3. The Percentage of Fish Detected in the Tailrace by Forebay Passage Route. The mean detection for all tagged juvenile salmon was $27 \%$ of the fish released by the BRD. Turbine units 1, 2, and 3 were combined as South Powerhouse (S. Powerhouse), because their exact exit totals were unknown. Turbine Unit 5 was not operational for the entire study.

\begin{tabular}{||l|c|c|c||}
\hline \multirow{2}{*}{$\begin{array}{l}\text { Detection } \\
\text { Location }\end{array}$} & \multicolumn{2}{|c|}{ Number of Detections } & \multirow{2}{*}{ Percent Detected } \\
\cline { 2 - 3 } & Forebay & Tailrace & $29 \%$ \\
\hline S. Powerhouse & 48 & 14 & $35 \%$ \\
\hline Turbine 4 & 68 & 24 & $0 \%$ \\
\hline Turbine 5 & 7 & 0 & $2 \%$ \\
\hline Turbine 6 & 20 & 1 & $27 \%$ \\
\hline RSW & 179 & 48 & $30 \%$ \\
\hline Spillbay 2 & 20 & 6 & $27 \%$ \\
\hline Spillbay 3 & 33 & 9 & $47 \%$ \\
\hline Spillbay 4 & 15 & 7 & $23 \%$ \\
\hline Spillbay 5 & 13 & 3 & $32 \%$ \\
\hline Spillbay 6 & 28 & 9 & $15 \%$ \\
\hline Spillbay 7 & 13 & 2 & $0 \%$ \\
\hline Spillbay 8 & 7 & 0 & $27 \%$ \\
\hline & & Total Detected: & \\
\hline \hline
\end{tabular}




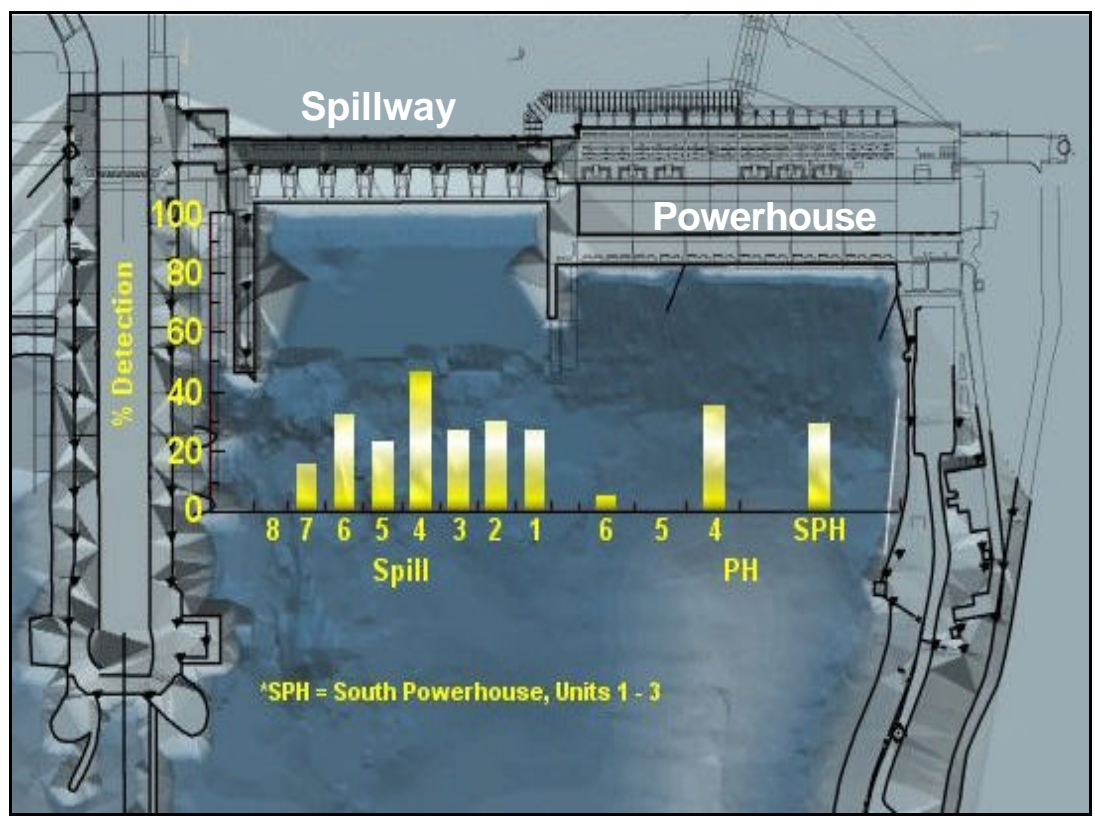

Figure 4.19. The Percentage of Fish that Were Detected in the Tailrace by Forebay Passage Route. The mean detection for all tagged juvenile salmon was $27 \%$ of the fish released by the BRD. Turbine Units 1, 2, and 3 were combined as SPH, because their exact forebay exit totals were unknown. Turbine Unit 5 was not operational for the entire study.

\subsection{Flow Modeling}

Modeling of the tailrace showed flow patterns similar to those general observations made in the field. Flow patterns in the model agreed with several field observations: 1) little eddy formation for the low powerhouse-low spill treatment (Figure 4.20), 2) a large and powerful powerhouse eddy during the low powerhouse-high spill treatment, which was illustrated by the high velocity magnitudes at the edges of the eddy (Figure 4.21), 3) a large but weaker eddy on the spillway side during the high powerhouse-low spill treatment (Figure 4.22), and 4) no significant eddy formation but relatively high velocity magnitudes for the high powerhouse-high spill condition (Figure 4.23). Model observations were also quantifiable in regard to the mean water column velocity over the volume modeled, and were used to identify likely habitat based on water velocity. Our model encompassed the entire downstream habitat that was watered within $823 \mathrm{~m}$ of the spillway and included the back-water area north of the navigation lock, and downstream of the earthen dam.

Mesa and Olson (1993) showed that a major predator of juvenile salmon in the lower Columbia, the northern pikeminnow, may avoid habitat that has water velocities over $100 \mathrm{~cm} / \mathrm{s}$. We determined the available habitat at those mean velocities for the area of the tailrace model (Table 4.4). The habitat was measured as the average water velocity magnitude for each grid point, where grid points were evenly distributed throughout the tailrace and extended downstream $820 \mathrm{~m}$ from the Lower Granite Dam Spillway. The amount of habitat that was less than $100 \mathrm{~cm} / \mathrm{s}(3.28 \mathrm{ft} / \mathrm{s})$ varied by $39.7 \%$ over the range of tailrace conditions shown in Figures 4.20 to 4.23, showing the greatest percentage of habitat $<100 \mathrm{~cm} / \mathrm{s}$ in the low powerhouse-low spill conditions (97.3\%), and the low powerhouse-high spill conditions 
(95.6\%). The percentage of habitat $<100 \mathrm{~cm} / \mathrm{s}$ was $82.2 \%$ for the high powerhouse-low spill condition, and $57.6 \%$ for the high powerhouse-high spill condition. The computational model of the tailrace quantified significant variation in the available habitat that was suitable for northern pikeminnow.

Table 4.4. The Percentage of Water Velocity Habitat Bound by the Extent of the Tailrace Model for Lower Granite Dam. ( $\mathrm{PH}=$ powerhouse)

\begin{tabular}{||c|c||}
\hline \hline Tailrace Condition & \% Habitat $<100 \mathrm{~cm} / \mathrm{s}$ \\
\hline Low PH Low Spill & 97.3 \\
\hline Low PH High Spill & 95.6 \\
\hline High PH Low Spill & 82.2 \\
\hline High PH High Spill & 57.6 \\
\hline
\end{tabular}

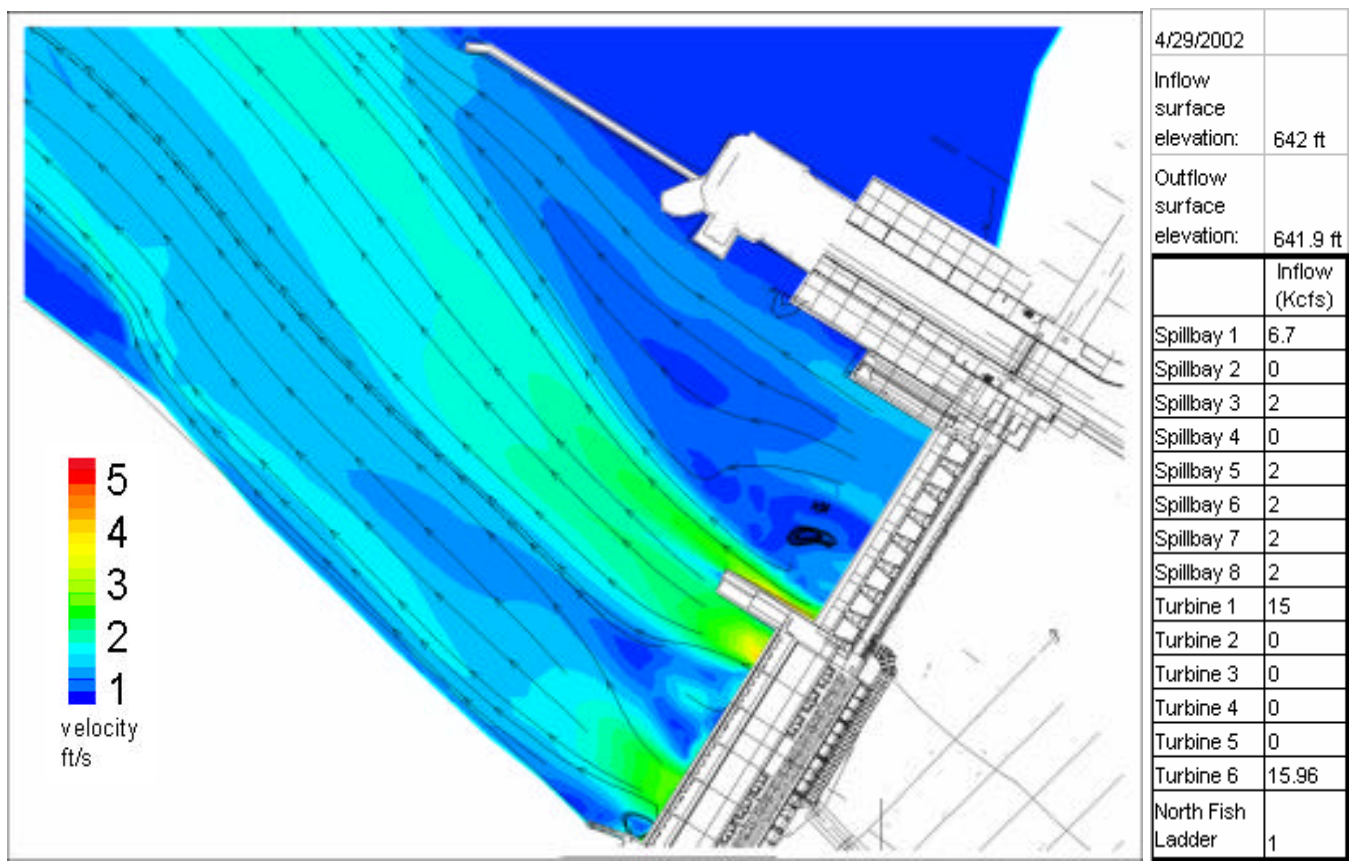

Figure 4.20. Modeled Flow of Lower Granite Dam Tailrace Showing Mean Water Column Speeds and Directions at Low Powerhouse-Low Spill Conditions with RSW on. Initial settings are at the right. 


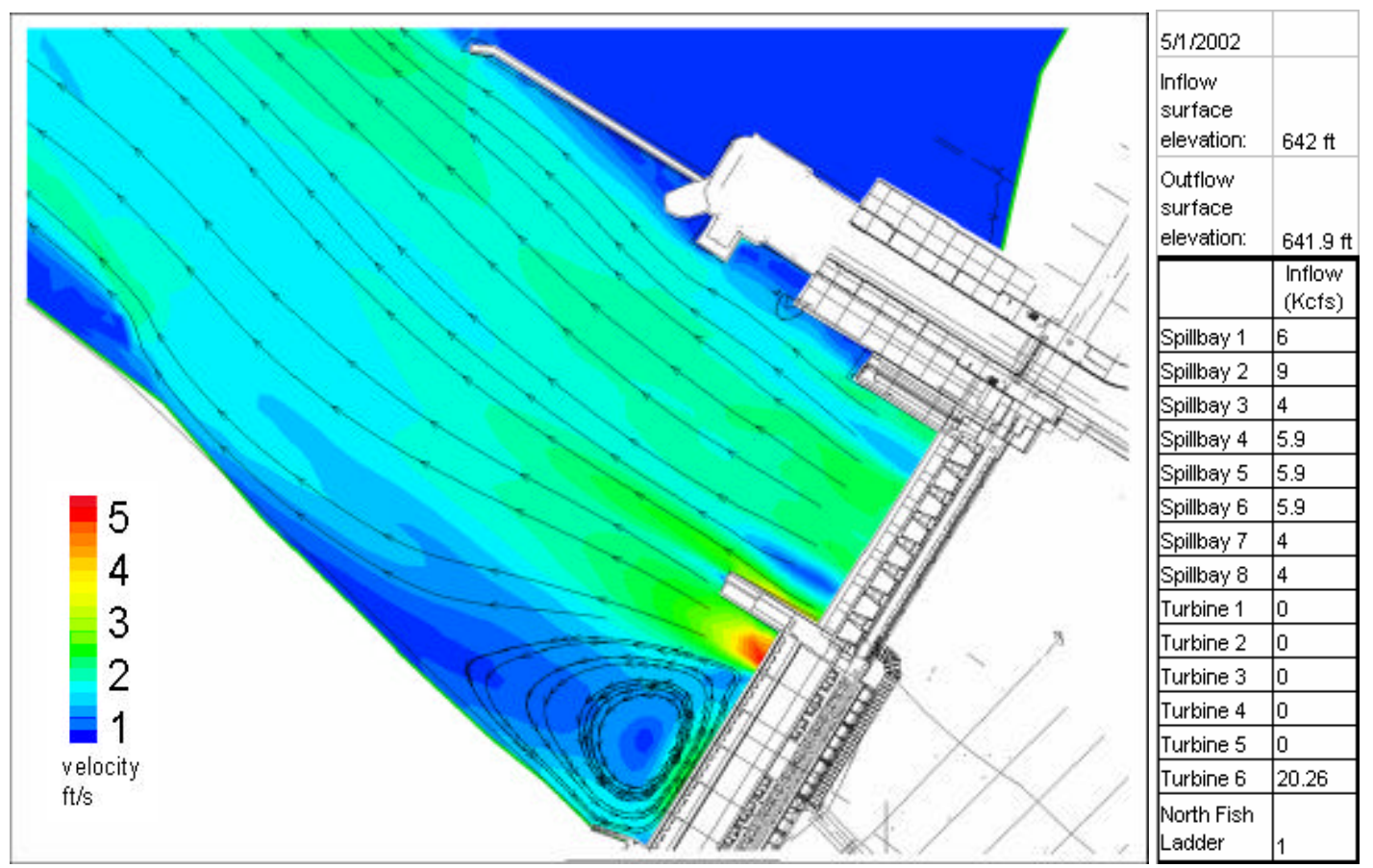

Figure 4.21. Modeled Flow of Lower Granite Dam Tailrace Showing Mean Water Column Speed and Direction at Low Powerhouse-High Spill Condition with RSW on. Initial settings are at the right.
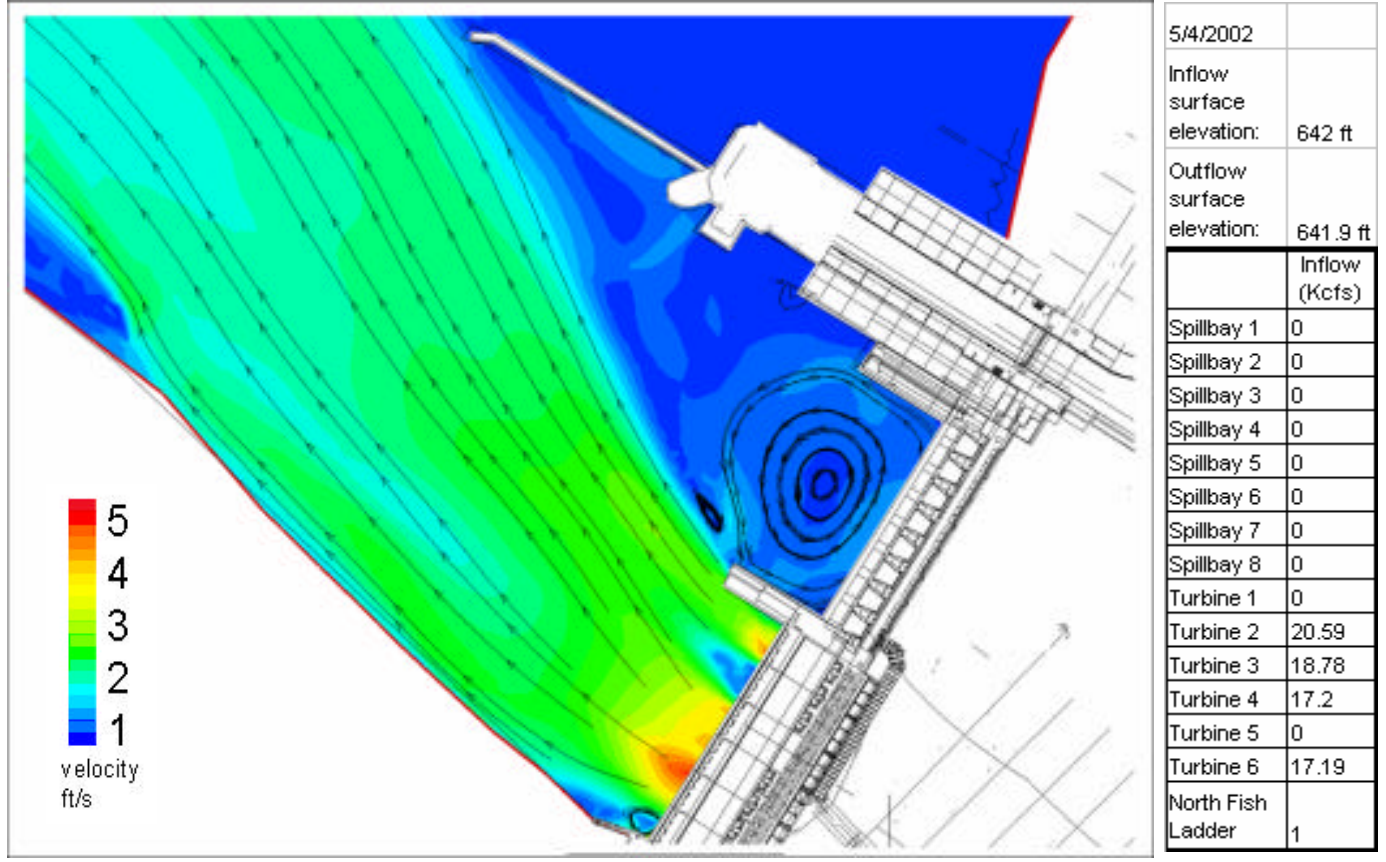

Figure 4.22. Modeled Flow of Lower Granite Dam Tailrace Showing Mean Water Column Speed and Direction at High Powerhouse-Low Spill Condition with RSW off. Initial settings are at the right. 


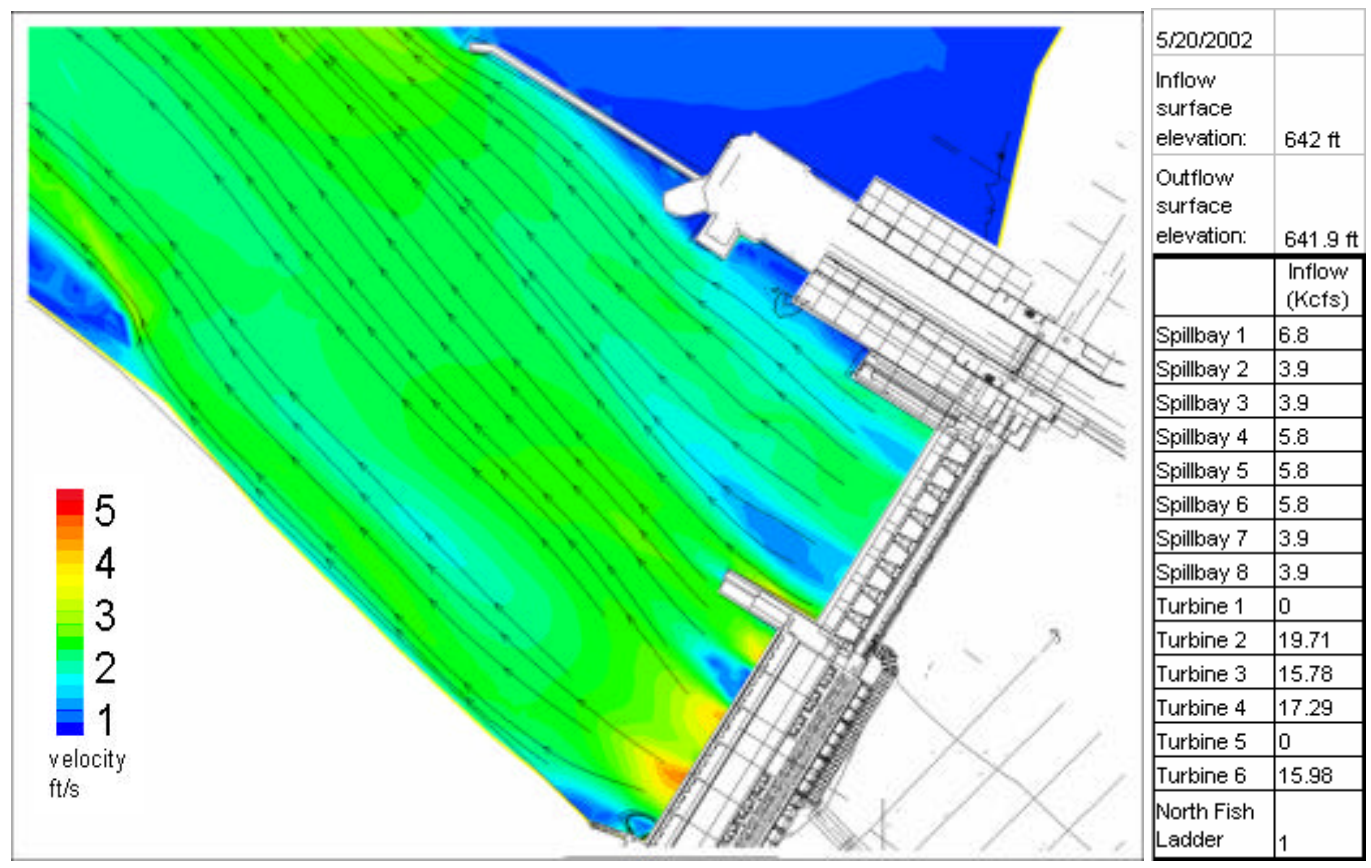

Figure 4.23. Modeled Flow of Lower Granite Dam Tailrace Showing Mean Water Column Speed and Direction at High Powerhouse-High Spill Condition with RSW on. Initial settings are at the right.

\subsection{Juvenile Salmon Behavior}

\subsubsection{Juvenile Salmon and Drogues}

The tailrace residence times of juvenile salmon and the neutrally buoyant drogues released in the tailrace were similar, based on location of release (Figure 4.24). Fish released into the spillway had shorter median residence times than those released at the turbine units, although there were fewer fish and drogues detected from spillway releases than from turbine releases.

Because the hydroplane ranges did not overlap and cover the complete tailrace, we could not fully track each tag through the tailrace. The movement of juvenile salmon and drogues could only be described by the number and estimated locations of tags when they were detected. Spillway-released fish were only detected by the furthest downstream hydrophones so we could only estimate the approximate time and place of tailrace egress rather than tracking their tag trajectories through the tailrace. The movement of juvenile spring chinook could be described as direct and out of the tailrace following the bulk spillway flow. Both spillbays 3 and 6 were operational during the release of juvenile salmon and drogues into those bays.

Juvenile salmon and drogues released at turbine unit release sites displayed different movement patterns. Detection of drogues was minimal for those released at turbine unit 2 (two detected) and so we were unable to describe the overall movement of those drogues. Those drogues that were detected followed the same general movement pattern as the tagged juvenile spring chinook (Figures 4.25 and 4.26). The low number of detections may also suggest that the majority of drogues were following other 
routes to areas that were not covered by the hydrophone array. Juvenile spring chinook and drogues that were released at turbine unit 4 had a high detection percentage (50\% and $63 \%$, respectively) by the nearest hydrophones (hydrophones 4 and 11), but the detection of both fish and drogues dropped after those detections. During this period, hydrophone 15 and 16 were not operational due to cable and hydrophone damage, so there was a large gap in the detection field. It is likely that the drogues and juvenile spring chinook passed through this gap and out of the detection range of the remaining two exit hydrophones.

All juvenile spring chinook and drogue releases took place within one tailrace condition (high powerhouse-high spill), therefore the difference between movement of juvenile salmon and drogues and their relationship to tailrace conditions could not be evaluated, but this relationship became important when we evaluated the movement of BRD-released juvenile salmon that moved into the tailrace from the forebay.

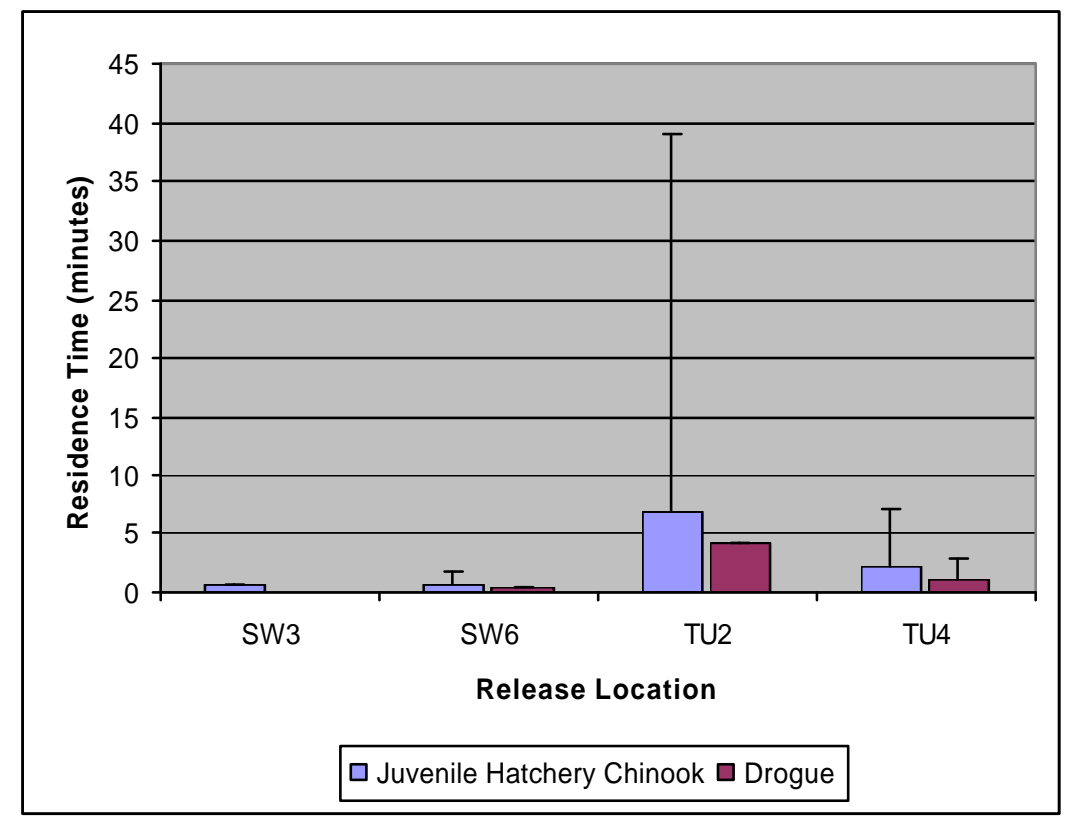

Figure 4.24. Median Tailrace Residence Times of Juvenile Hatchery Chinook Drogues Released into the Tailrace at Spillbays 3 and 6 (SW3 and SW6) or Turbine Units 2 and 4 (TU2 and TU4). Mean detection for all releases was $38 \%$. 


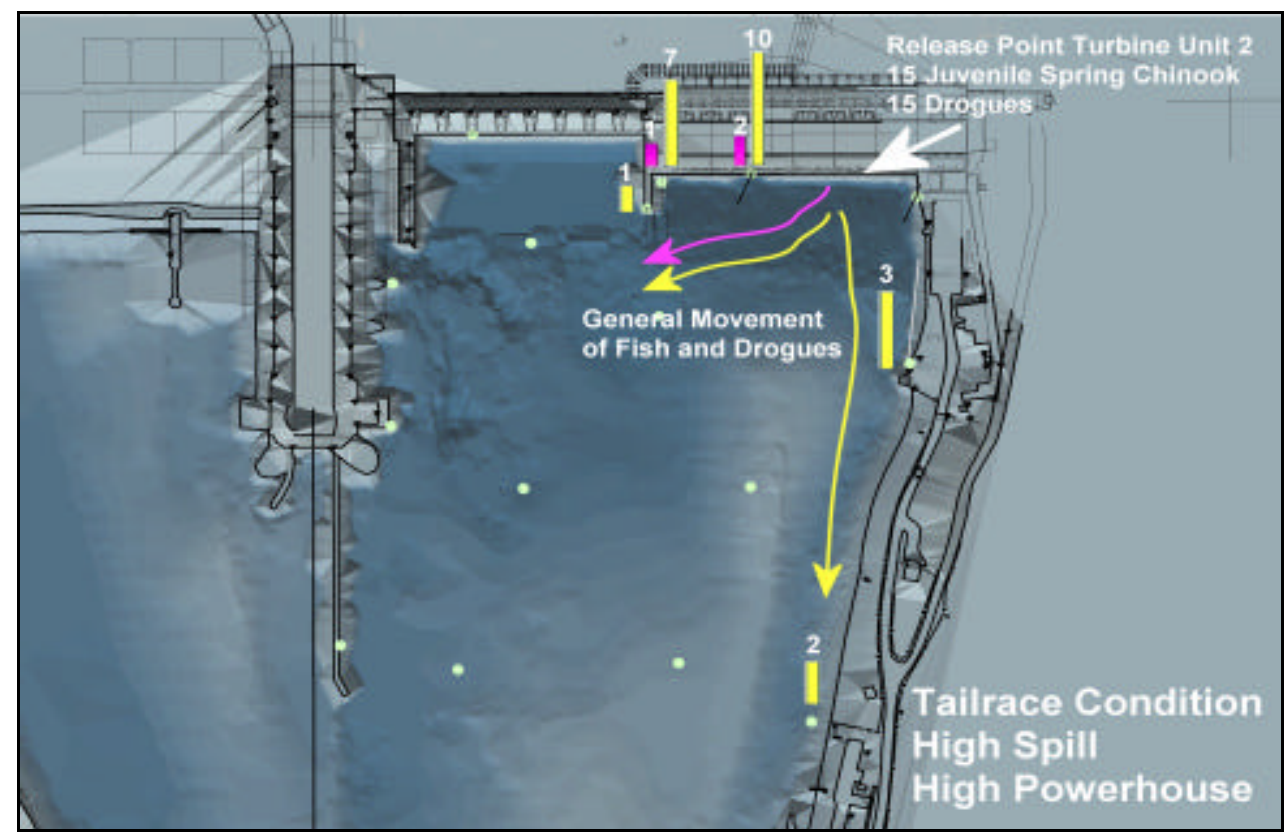

Figure 4.25. General Movement of Fish and Drogues Released at Turbine Unit 2. Bar graphs show the number of individual fish or drogues contacted at each hydrophone.

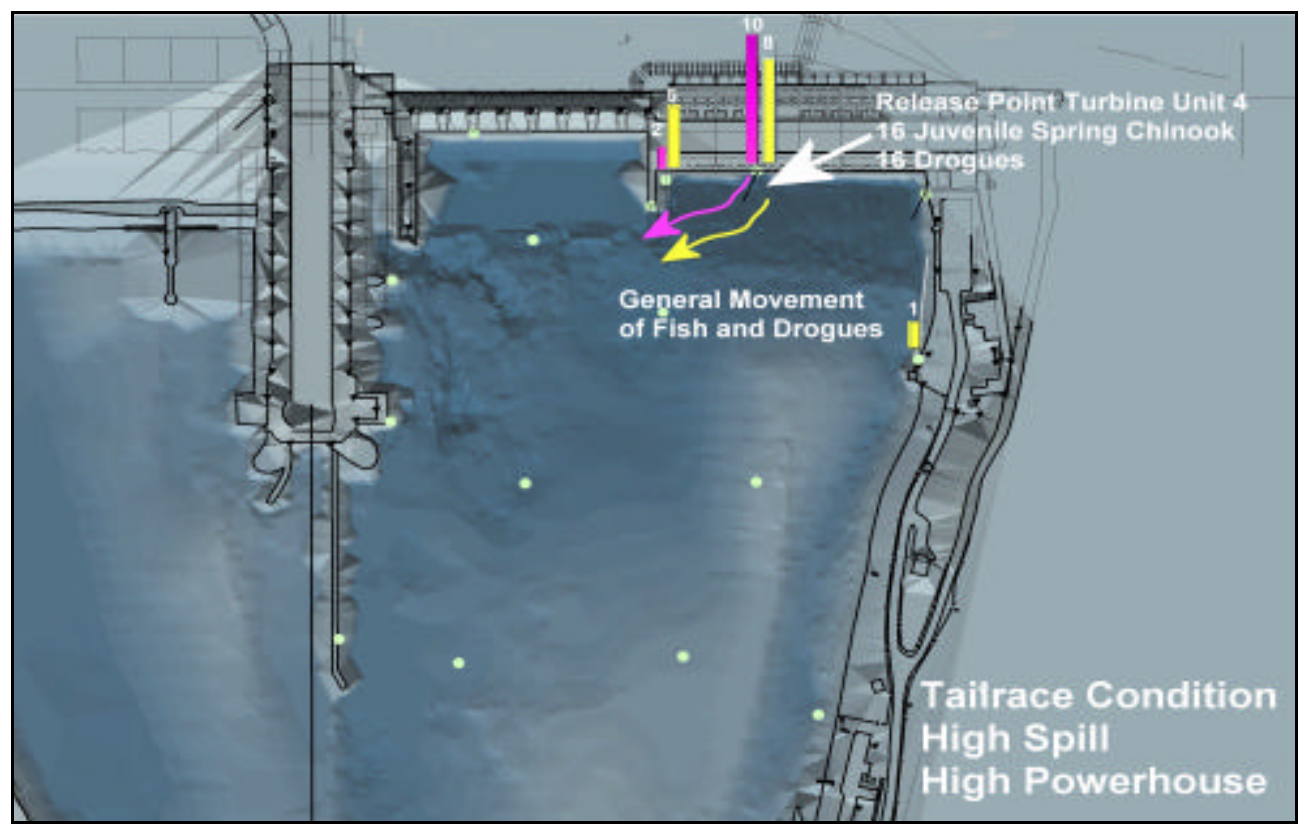

Figure 4.26. General Movement of Fish and Drogues Released at Turbine Unit 4. Bar graphs show the number of individual fish or drogues contacted at each hydrophone. 


\subsubsection{Juvenile Salmon Released by BRD Upstream of Lower Granite Dam}

The entry of BRD-released fish into the tailrace was volitional. All forebay-released juvenile salmon had the opportunity to enter the tailrace via any spillbay or turbine unit from the forebay. Fish that entered the turbine units had the option of entering the juvenile bypass system and avoiding the tailrace completely. The primary means that we used to evaluate the movement of the BRD-released fish was to create statistics based on their residence time in the tailrace, since detailed movement of juvenile salmon was only obtained for one fish during the tailrace study (Figure 4.27). Residence time was defined as the difference in the time between when a fish was last detected in the forebay and when it was last detected in the tailrace. Estimates of the residence times of the juvenile salmon were compared according to tailrace conditions based on powerhouse and spillway operations.

The median spillway discharge and median powerhouse discharge were used to establish four separate treatments, as discussed in the Methods section, and estimated juvenile salmon residence times were segregated into four groups accordingly. These four conditions are illustrated in Figure 4.28, where the median discharge for the research period was $24 \mathrm{kcfs}$ for spill and $54 \mathrm{kcfs}$ for powerhouse discharge. The residence times of juvenile salmon were tested using the four tailrace conditions as treatments for statistical evaluation. The results indicated that the high spill-low powerhouse condition significantly delayed juvenile salmon egress of the tailrace for both species combined (Figure 4.29). When separated by species, similar significant results were seen for the juvenile wild steelhead and juvenile hatchery steelhead (Figure 4.30). However, juvenile spring chinook did not show a significant difference for any tailrace condition because the residence times of juvenile spring chinook were highly variable by treatment.

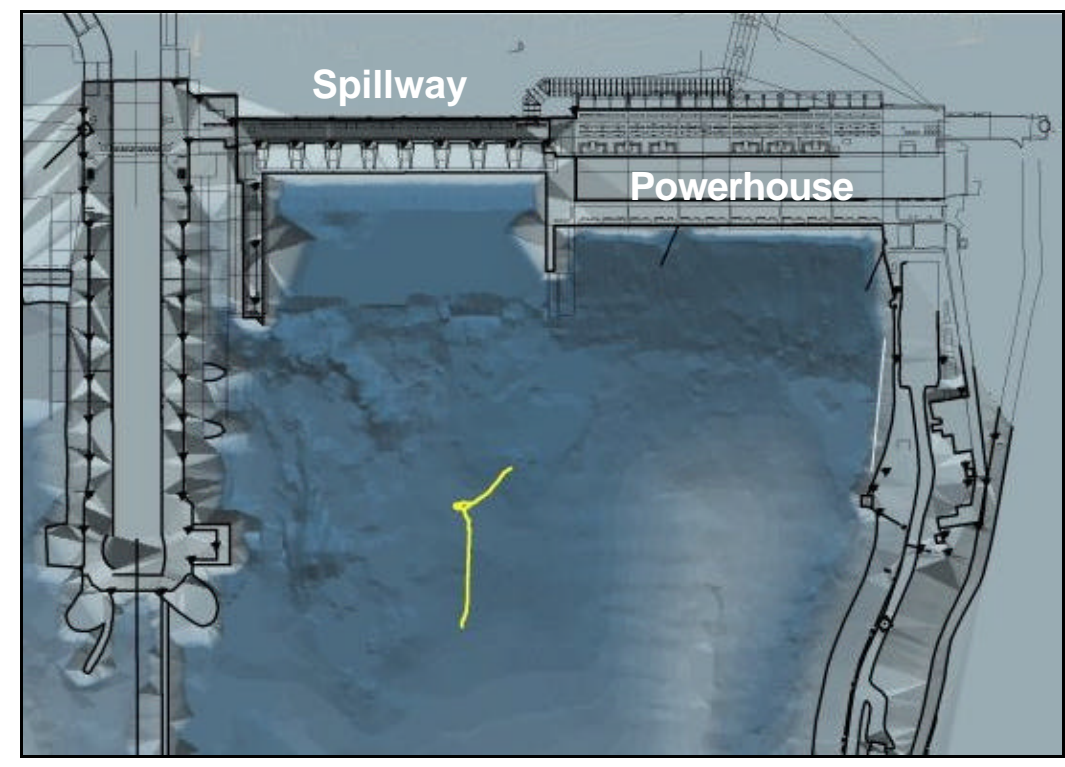

Figure 4.27. Movement of a Juvenile Spring Chinook in the Tailrace of Lower Granite Dam during a No-Spill Tailrace Condition. The fish was headed downstream. The fish was located by the ultrasonic fish tracking system. 
Juvenile salmon that were detected passing through spillbays 3 to 8 were only detected during the high spill-low powerhouse tailrace condition. Their movement had to be south and orthogonal to the flow to reach the detection zones of the powerhouse hydrophones. We can speculate on reasons for detecting fish only during the low powerhouse-high spill condition for those spillbays. Spill discharge through spillbays 3 to 8 was low or non-existent for the low spill conditions, and when spill was high the detection capability of spillway-placed hydrophones was reduced.

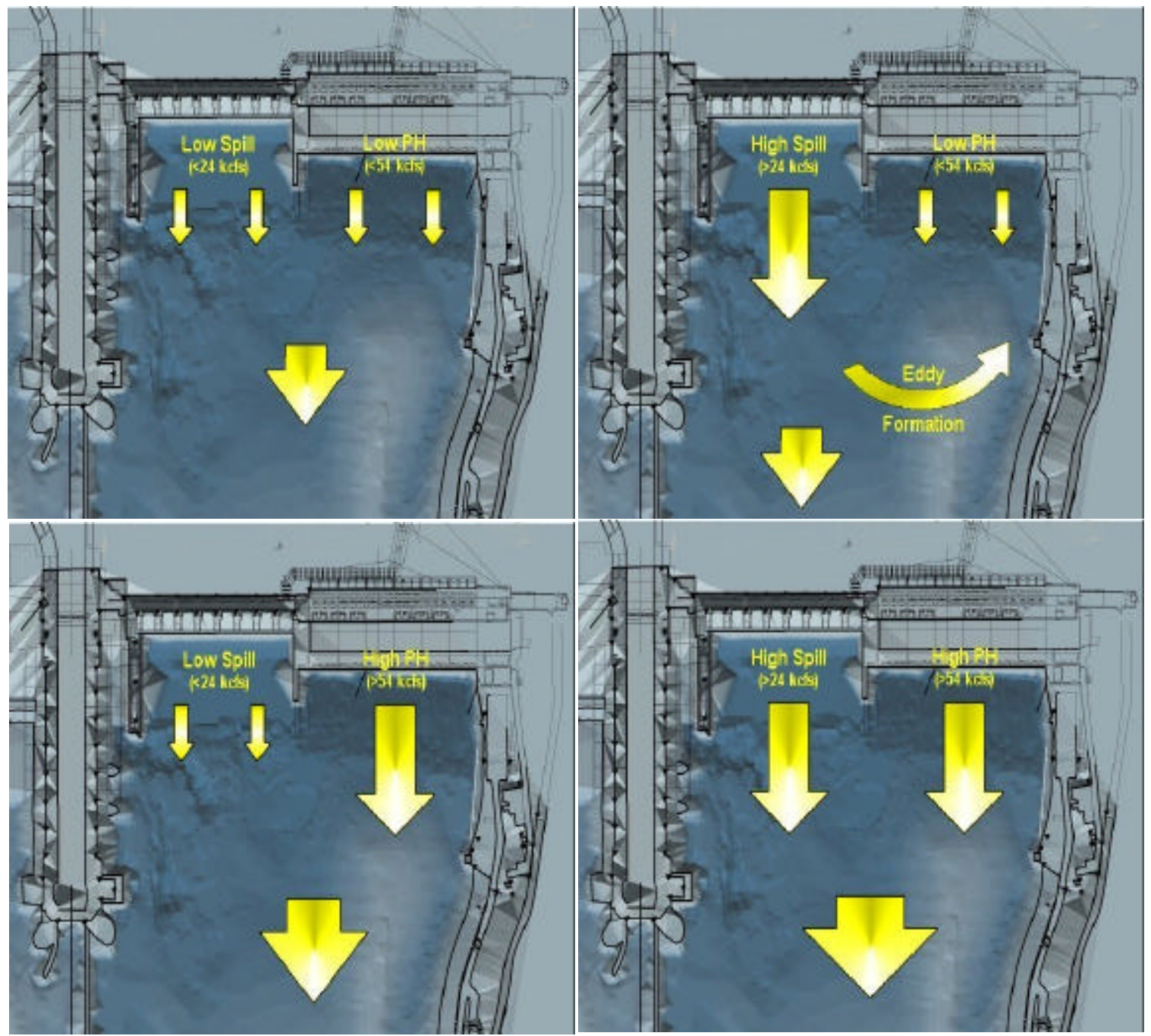

Figure 4.28. Tailrace Conditions that Were Used as Treatments to Compare the Behavior of Juvenile Salmon as They Exited the Tailrace. The conditions were defined by the median spill and powerhouse discharge for the season, $24 \mathrm{kcfs}$ and $54 \mathrm{kcfs}$ respectively. 


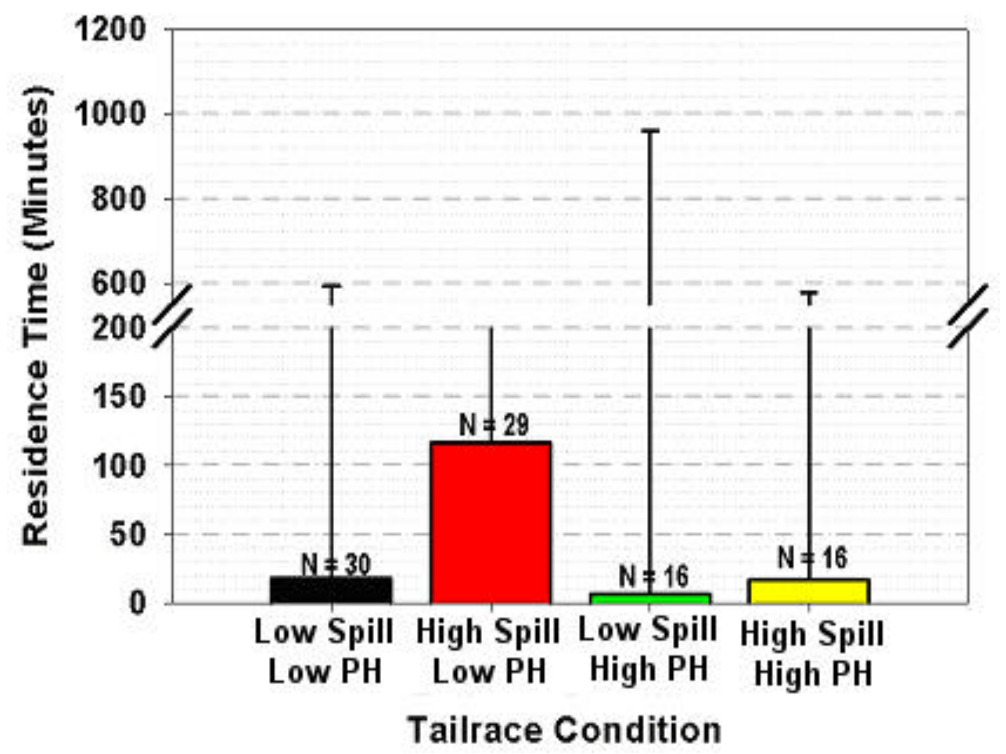

Figure 4.29. Median Residence Times for all Species Categorized by Tailrace Condition. Conditions were defined by the median discharge throughout the spring sampling period: $54 \mathrm{kcfs}$ for powerhouse operations and $24 \mathrm{kcfs}$ for spill operations. The residence times were significantly different using a nonparametric ANOVA at the $95 \%$ CL with a p-value of 0.003 .

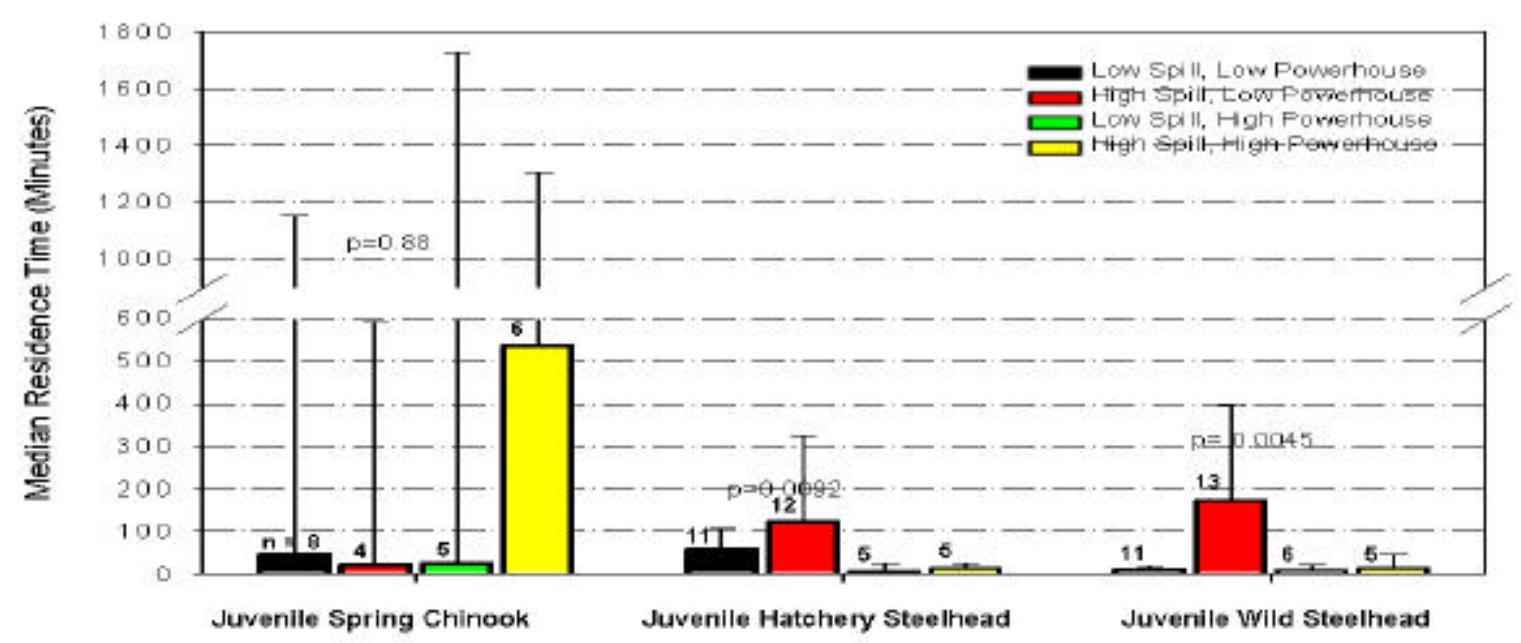

Figure 4.30. Median Residence Times of Juvenile Salmon Categorized by Tailrace Condition and Species. Conditions were defined by the median discharge throughout the spring samplin g period: $54 \mathrm{kcfs}$ for powerhouse operations and $24 \mathrm{kcfs}$ for spill operations. Juvenile hatchery steelhead and juvenile wild steelhead showed significant differences at the 95\% CL using Brown and Forsythe's test for homogeneity of absolute deviations from group medians, with $\mathrm{p}=0.0092$ and $\mathrm{p}=0.0045$ respectively. The median of juvenile spring chinook residence times by condition were not significantly different. 
Juvenile wild steelhead and juvenile hatchery steelhead also showed significant trends in tailrace residence time that were related to powerhouse discharge $(\mathrm{Q})$, spill discharge $(\mathrm{Q})$, and the ratio of powerhouse to spill discharge (Figures 4.31 and 4.32). Powerhouse and spill $Q$ values were those values provided by the dam operators for the hour of entry of a fish into the tailrace. The strongest trend was with the ratio of spill Q to powerhouse Q, where the likelihood of forming an eddy downstream of the powerhouse increased with an increasing ratio, and the likelihood of forming an eddy downstream of the spillway increased with a decreasing ratio. The ratio of spill $\mathrm{Q}$ to powerhouse $\mathrm{Q}$ provided $\mathrm{r}^{2}$ values of 0.65 and 0.38 for juvenile wild steelhead and juvenile hatchery steelhead respectively. The $\mathrm{p}$-values for the regression were also significant for the ratio of spill $Q$ to powerhouse $Q$ for juvenile hatchery steelhead and juvenile wild steelhead. The trend in powerhouse $\mathrm{Q}$ related to residence time was also significant for wild and hatchery steelhead with weaker $r^{2}$ values of 0.29 and 0.31 respectively. The trend in spill Q related to residence time was significant for wild and hatchery steelhead as well as providing $\mathrm{r}^{2}$ values of 0.38 and 0.03 respectively. Juvenile spring chinook did not show significant trends relating tailrace residence time to powerhouse Q, spill Q, or the ratio of spill to powerhouse discharge (Figure 4.33).

There were no apparent differences in the diel movement of juvenile salmon when categorized by Lower Granite Dam discharge levels (Figure 4.34). The residence times of fish entering the tailrace during the daytime or nighttime were similar for juvenile hatchery steelhead and juvenile wild steelhead and followed the same general pattern as the combined daytime and nighttime graphs (Figure 4.29). Residence time for the high spill-low powerhouse condition was significantly longer for both daytime and nighttime samples. Juvenile hatchery chinook again did not show a significant difference in tailrace residence times between treatments.

The distribution of flow conditions (treatments) was evenly distributed throughout the research period (Figure 4.35, Table 4.5). However, the distribution of flow conditions in the tailrace varied based on the operation of the RSW. With the RSW operating, the majority of flow conditions were skewed toward the high spill-high powerhouse (46\%) and low spill-low powerhouse (31\%) conditions. In contrast, with the RSW not operating the flow conditions were skewed toward the high spill-low powerhouse (45\%) and high spill-high powerhouse (45\%) conditions. This indicates that very different tailrace conditions occurred when the RSW was operational compared to when it was not operating. When comparing the median tailrace residence times of forebay-released juvenile salmon that entered the tailrace with the RSW operating to when it was not operating, there was a significant difference in the tailrace residence times for all species (Figure 4.36). The residence times of juvenile wild steelhead, juvenile hatchery steelhead, and juvenile spring chinook were significantly lower when the RSW was operating compared to when it was not operating. 


\section{Wild Steelhead}
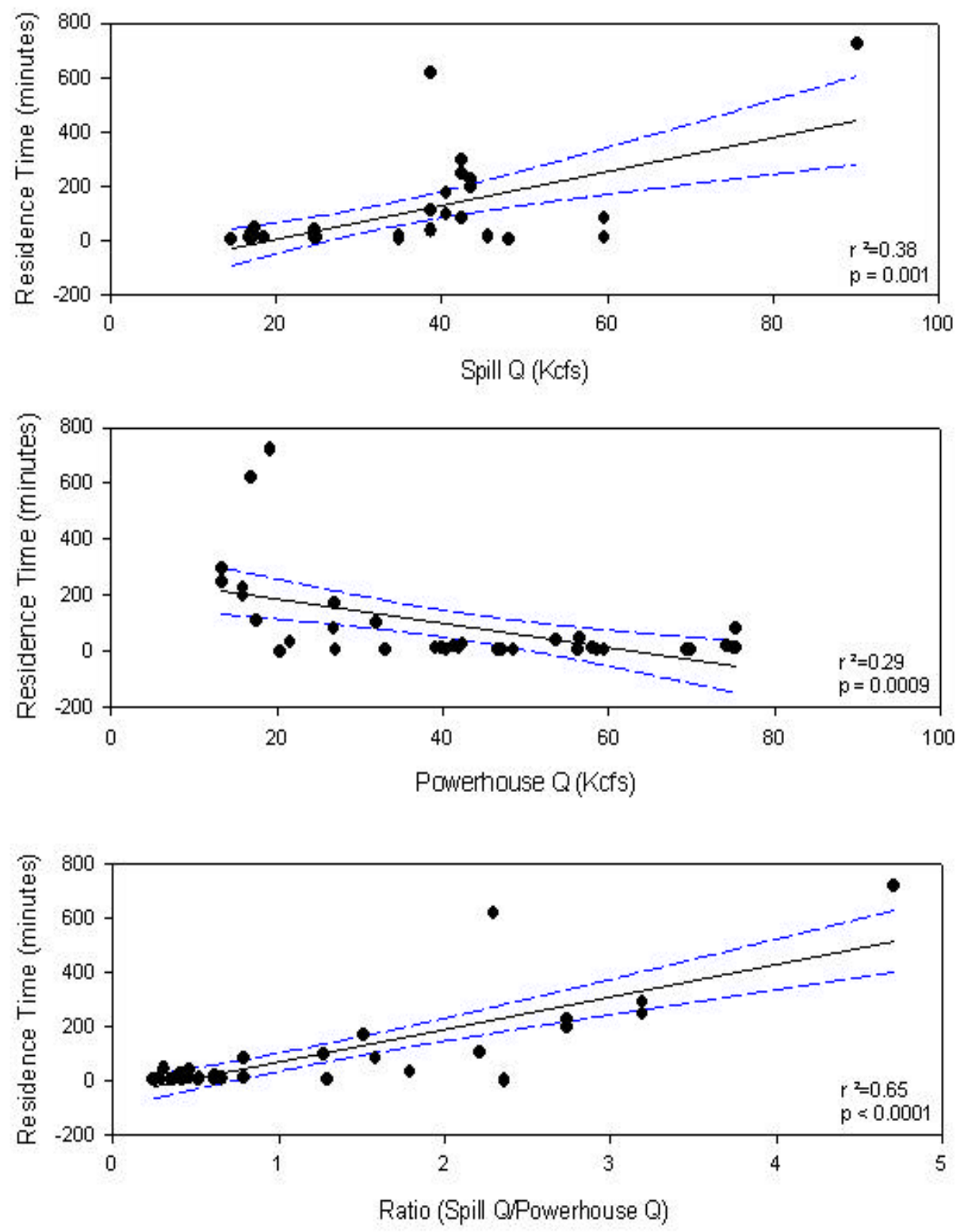

Figure 4.31. Correlation of the Tailrace Residence Times of Juvenile Wild Steelhead to Spill Discharge, Powerhouse Discharge, and the Ratio of Spill to Powerhouse Discharge. Solid line is linear trend; dotted line is the confidence interval at $95 \%$. All were significantly correlated. 


\section{Hatchery Steelhead}
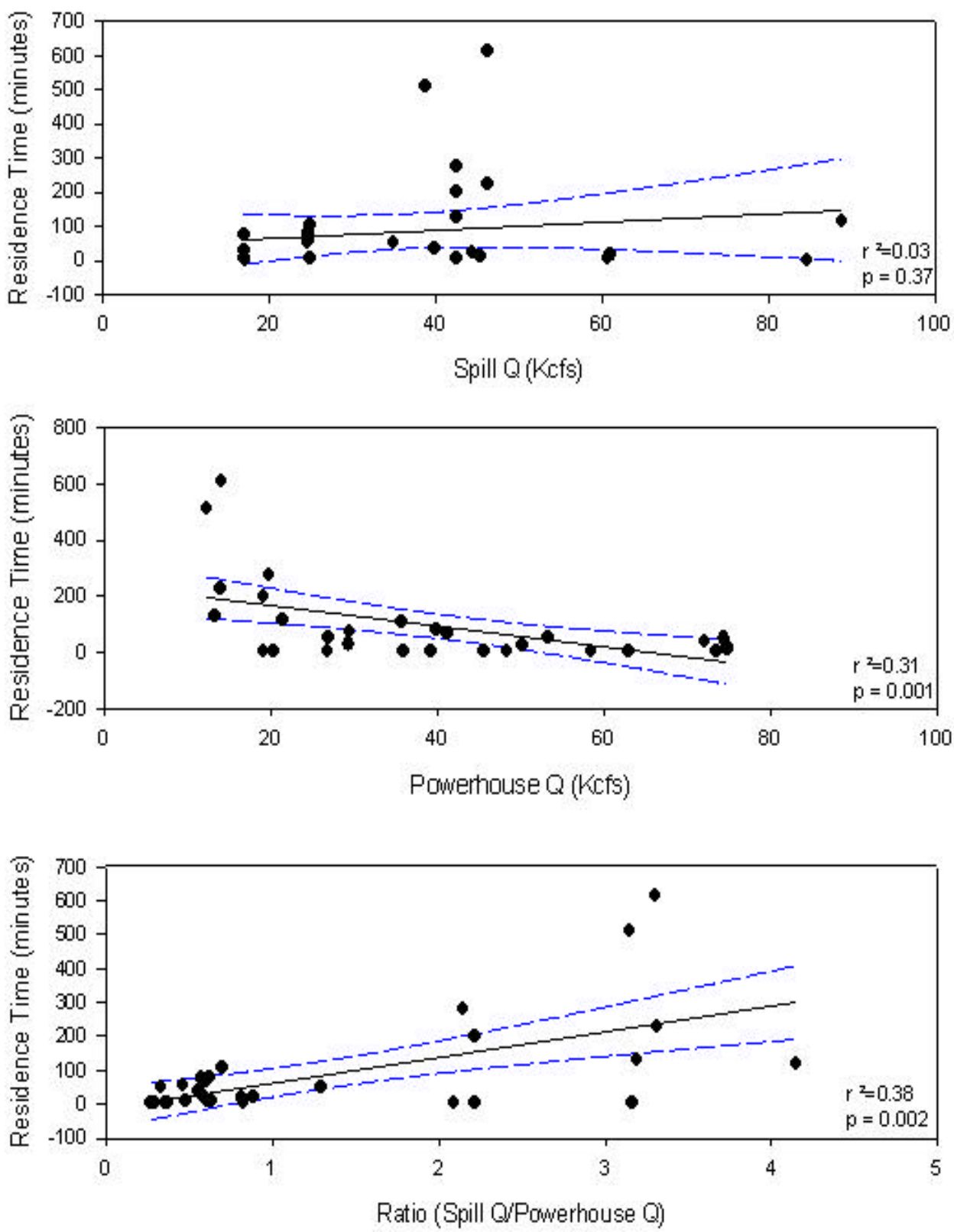

Figure 4.32. Correlation of the Tailrace Residence Times of Juvenile Hatchery Steelhead to Spill Discharge, Powerhouse Discharge, and the Ratio of Spill to Powerhouse Discharge. Solid line is linear trend; dotted line is the confidence interval at $95 \%$. Powerhouse discharge and the ratio of powerhouse to spill were significantly correlated. 


\section{Juvenile Spring Chinook}
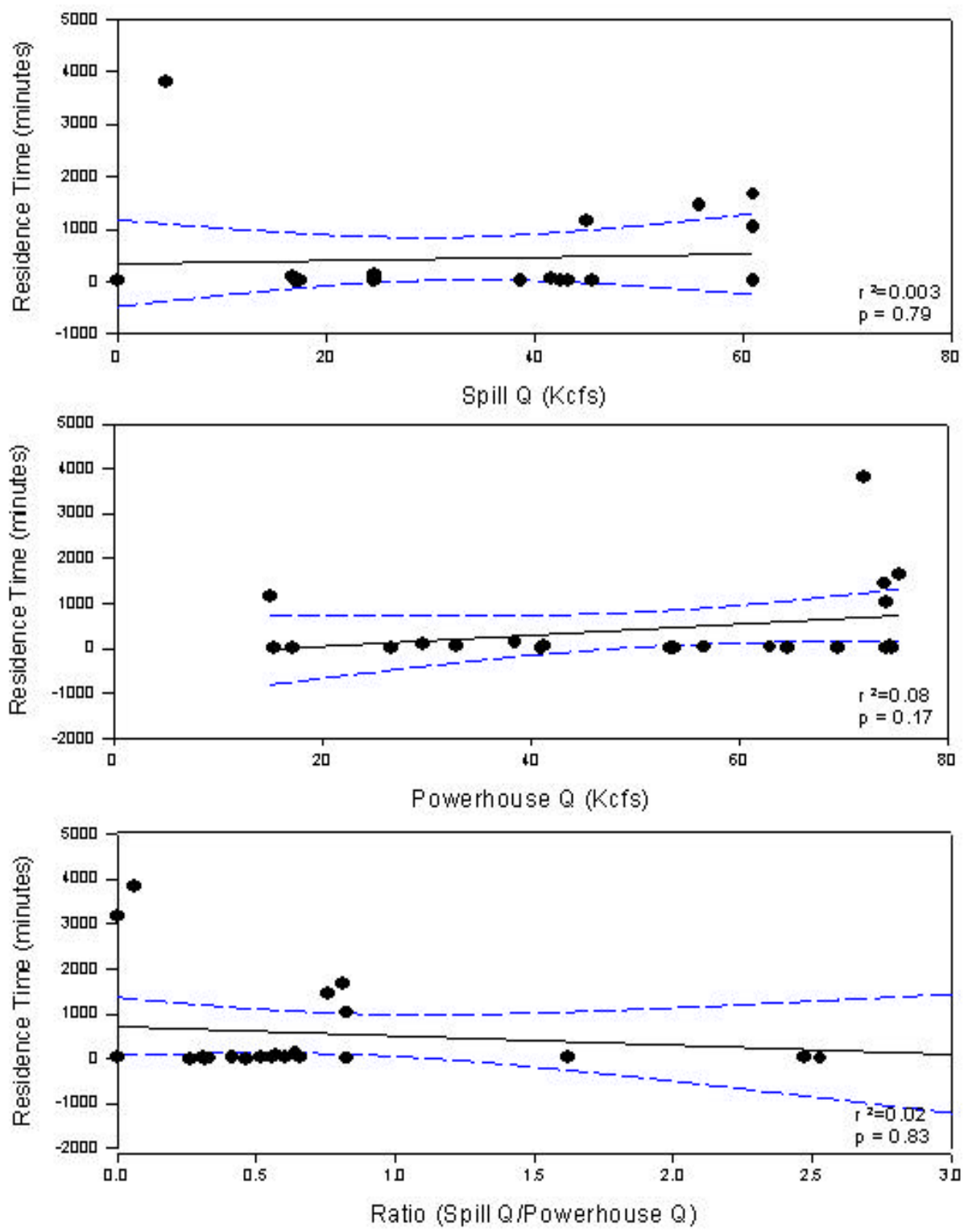

Figure 4.33. Correlation of the Tailrace Residence Times of Juvenile Spring Chinook to Spill Discharge, Powerhouse Discharge, and the Ratio of Spill to Powerhouse Discharge. Solid line is linear trend; dotted line is the confidence interval at 95\%. All were not significantly correlated. 

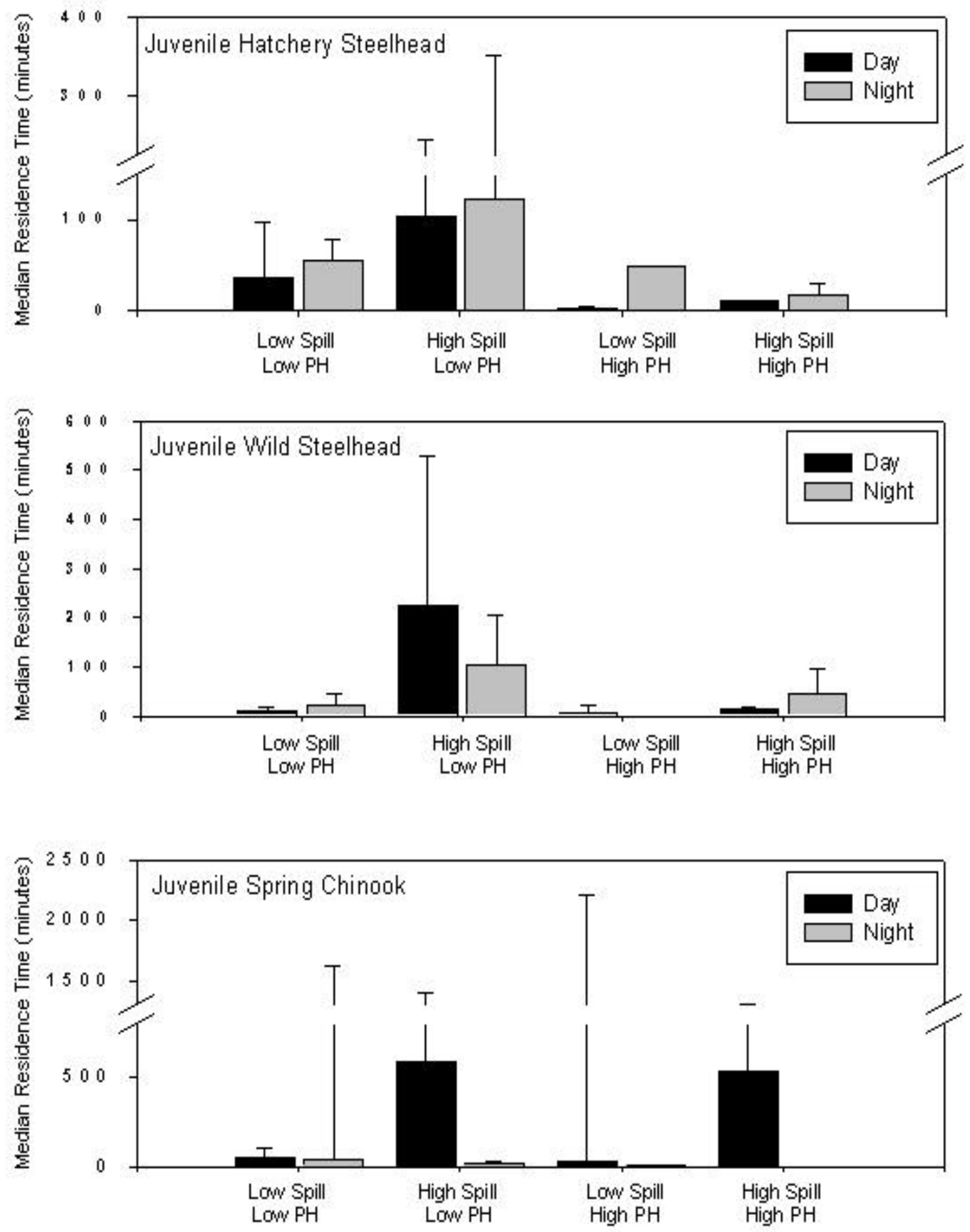

Figure 4.34. Median Residence Times of Juvenile Salmon Categorized by the Time Period in which They Entered the Tailrace at Lower Granite Dam. Error bars are showing the upper standard deviation. Day and night were separated by the sunrise and sunset time. 


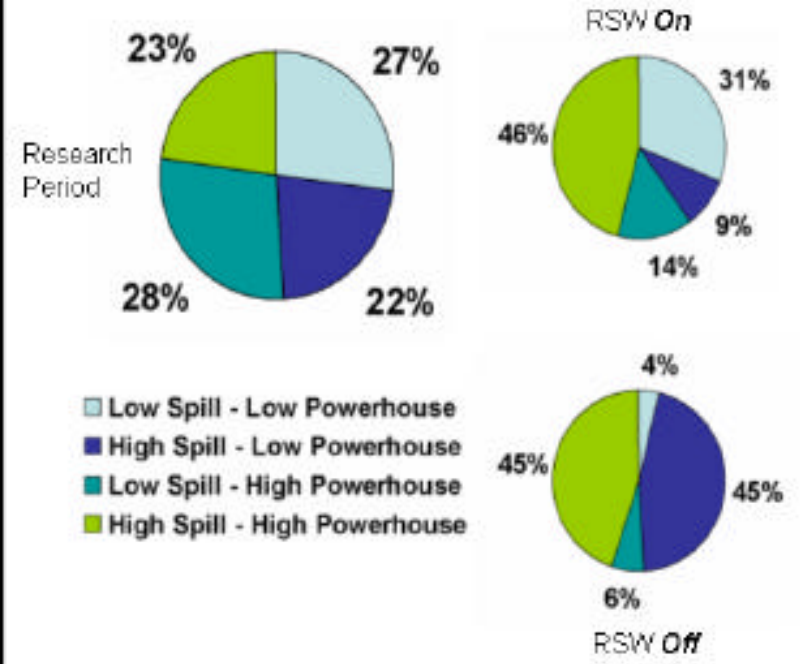

Figure 4.35. Distribution of Tailrace Conditions by the Research Period (April 14 to June 7) and by RSW Operation during the Research Period (on or off).

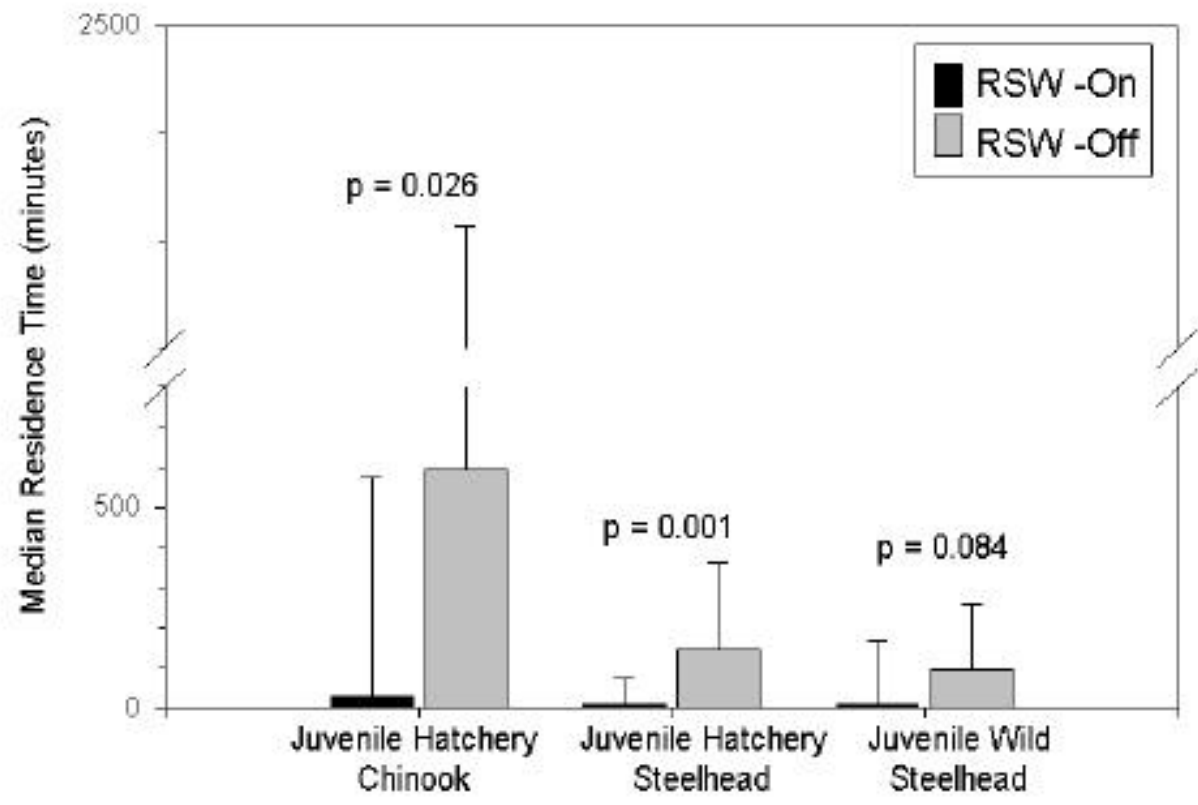

Figure 4.36. Median Residence Times for Juvenile Salmon Exiting the Tailrace with the RSW On vs. RSW Off. P-values are for two sample t-tests for the means with equal variances; all were significantly different at the $95 \% \mathrm{CL}$. Residence time is defined as the difference between the entry into the tailrace from the measured BRD forebay exit time, and last contact time by hydrophones in the tailrace. 
Table 4.5. Descriptive Statistics for the Residence Time (minutes) of Juvenile Salmon with the RSW On and RSW Off

\begin{tabular}{|c|c|c|c|c|c|c|c|}
\hline & Species & $\mathbf{N}$ & Min & Max & Mean & $\begin{array}{l}\text { Standard } \\
\text { Deviation }\end{array}$ & Median \\
\hline \multirow{3}{*}{ 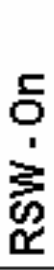 } & $\begin{array}{r}\text { Juvenile Spring } \\
\text { Chinook }\end{array}$ & 17 & 0.1 & 1662 & 270.1 & 542.3 & 31.5 \\
\hline & $\begin{array}{r}\text { Juvenile Hatchery } \\
\text { Steelhead }\end{array}$ & 25 & 2.6 & 277.8 & 43 & 67.1 & 10.6 \\
\hline & $\begin{array}{r}\text { Juvenile Wild } \\
\text { Steelhead }\end{array}$ & 20 & 0.7 & 720.7 & 48.1 & 158.7 & 9 \\
\hline \multirow{3}{*}{$\begin{array}{c}\frac{4}{0} \\
\vdots \\
0 \\
0 \\
0\end{array}$} & $\begin{array}{r}\text { Juvenile Spring } \\
\text { Chinook }\end{array}$ & 6 & 11 & 3823 & 1371 & 1720.6 & 592.4 \\
\hline & $\begin{array}{r}\text { Juvenile Hatchery } \\
\text { Steelhead }\end{array}$ & 8 & 23 & 611.7 & 229 & 215.8 & 147.2 \\
\hline & $\begin{array}{l}\text { Juvenile Wild } \\
\text { Steelhead }\end{array}$ & 15 & 2.9 & 617.8 & 145.6 & 161.5 & 98.8 \\
\hline
\end{tabular}


The Feasibility of Using an Ultrasonic Fish Tracking System in the Tailrace of Lower Granite Dam 


\subsection{Discussion}

\subsection{Evaluation of the Acoustic Noise in the Lower Granite Dam Tailrace}

\subsubsection{Evaluation of Acoustic Noise Using a Spectrum Analyzer}

Our results suggest that it is possible to detect acoustic tags in the tailrace of LGR although tag detection range will depend on dam operations during tag monitoring. Hydrophone position relative to the operating turbine units and spillbays will also influence tag detection range. Attenuation and noise in the tailrace significantly reduced the range of signal detection for the tag, from an estimated $160 \mathrm{~m}$, when calculated signal loss was due only to spherical spreading, down to an actual detection range of $15 \mathrm{~m}$ in summer. Even when gain was increased to $40 \mathrm{~dB}$, the range of detection was increased to only $75 \mathrm{~m}$. In the spring when powerhouse generation and spill were high, we were not able to detect the acoustic tag above the noise floor without amplification.

Knowing the spectral signature of the tailrace is important for determining the optimum tag frequency. We found peaks at $410 \mathrm{kHz}$ and $430 \mathrm{kHz}$ in the tailrace at LGR in spring and summer, respectively. We are unsure of the source of this sound energy. Hydroacoustic equipment was being used in the forebay at a frequency of $420 \mathrm{kHz}$ to monitor fish passage during the spring sampling but not during SPL measurements that were collected in the summer. A similar peak was found at Bonneville Dam Powerhouse 2 (Bonn 2) at $425 \mathrm{kHz}$ during sampling in the summer. Acoustic tags with a frequency of $420 \mathrm{kHz}$ have been used to track the trajectories of fish through turbine intakes at McNary Dam (Carlson et al, 2002) and would not be suitable for use in the tailrace with spectral peaks near the frequency of the tag.

Similar measurements were collected at Bonn 2 in summer when 6 of the 8 units were operating. The detection threshold at $307.2 \mathrm{kHz}$ was $108 \mathrm{~dB}$ and maximum calculated detection range was $90 \mathrm{~m}$, when signal loss was due only to spherical spreading. The actual detection range above the threshold was 10 , 35, and $40 \mathrm{~m}$ with no gain, $20 \mathrm{~dB}$ and $40 \mathrm{~dB}$ gain, respectively (Weiland and Carlson, in prep). Range of detection and the detection thresholds for summer measurements at LGR and Bonn 2 are provided in Table 5.1. Available data for LGR in spring are provided also, though no detection range measurements are available.

It was necessary to amplify the input signal during data collection. The signal received by the HTI acoustic telemetry receiver is usually amplified by between 45 and $55 \mathrm{~dB}$. However, increasing amplification too much can saturate the system with noise and make it nearly impossible to track the acoustic tag signal. By amplifying the input signal during spring sampling we probably could have detected the acoustic tag signal above the threshold level when the signal was amplified $40 \mathrm{~dB}$ and also with $20 \mathrm{~dB}$ gain, though detection range would be much shorter than was determined for summer. 
Table 5.1. Estimated Detection Range and Measured Detection Range of Acoustic Tags in the Tailrace of Lower Granite and Bonneville Dam Powerhouse 2

\begin{tabular}{|cc|cc|c|c|c|}
\hline & & & \multicolumn{3}{|c|}{ Measured detection range } \\
\hline Dam & $\begin{array}{c}\text { Time of } \\
\text { year }\end{array}$ & $\begin{array}{c}\text { Estimated } \\
\text { detection } \\
\text { range }(\mathrm{m})\end{array}$ & $\begin{array}{c}\text { Detection } \\
\text { threshold } \\
(\mathrm{dB})\end{array}$ & $\begin{array}{c}0 \mathrm{~dB} \\
\text { gain } \\
(\mathrm{m})\end{array}$ & $\begin{array}{c}20 \mathrm{~dB} \\
\text { gain } \\
(\mathrm{m})\end{array}$ & $\begin{array}{c}40 \mathrm{~dB} \\
\text { gain }(\mathrm{m})\end{array}$ \\
\hline LGR & Spring & 70 & 109.5 & $?$ & $?$ & $?$ \\
\hline LGR & Summer & 375 & 99.5 & 60 & $115+$ & $115+$ \\
\hline Bonn 2 & Summer & 200 & 101 & $60+$ & $60+$ & $60+$ \\
\hline
\end{tabular}

Detection ranges will differ between dams and operating conditions and will need to be assessed during study planning. Differences in SPL and frequency between LGR and Bonn 2 are consistent with differences at low frequencies found by Anderson et al. 1989 in the forebays of Lower Granite, McNary, and Bonneville Dam powerhouses 1 and 2.

The 307.2-kHz tags that we tested are standard tags used to track fish from upstream of a dam through the forebay. These tags have a life of between 7 and 12 days, depending on the ping rate used and river temperature. This life ensures that the tag is still active when the fish reaches the dam and the acoustic array. The duration of 7 to 12 days is not necessary for tags being released directly through the turbines and spillways and directly into the tailrace of the dam where fish have a very short residence time. Without the constraint of long tag life, the signal strength of the tag can be increased to improve detectable range of the signal.

The detectable range of the acoustic tags can be improved by redesigning the tag. The redesign may include increasing tag size by adding an additional battery or by using more of the battery's energy at each ping, which would decrease the life of the acoustic tag. Another way to increase tag detectability is to use a directional hydrophone. The distance the tag can be detected will be increased but the angle of coverage will be reduced, increasing chances of missing a tag signal. It might be possible to increase tag detectability by improving the efficiency of the ceramic element in the hydrophone. The current hydrophones used in the Columbia and Snake River Basins are broadband hydrophones. An element specifically designed for use in the $307.2-\mathrm{kHz}$ range would be more efficient and improve signal detectability.

\subsubsection{Evaluation of Acoustic Noise Using the UFTS}

Knowing the amplitude and "quantity" of noise (number of received acoustic signals above a certain threshold) present in an environment where an acoustic tracking system is deployed is important for several reasons. Positioning hydrophones and estimating the quality of the data relative to position resolution will influence the ability of the UFTS to track a tag. Tracking ability will also be influenced by the bias in tracking due to noise and will increase the difficulty of tracking the tag through the noise. At dams, noise can come from sources such as spill, electrical noise, and other acoustic devices. Thermal noise from water molecules increases in intensity with increase in frequency above $100 \mathrm{kHz}$ (Urick 1983, MacLennan and Simmonds 1992 [not on ref list]). 
Another challenge in acoustic tracking originates from noise produced from other research acoustic devices and has been a problem with tracking tagged fish through a hydrophone array. Noise due to other acoustic devices increased the difficulty in tracking tagged fish through the forebay of Bonneville Dam Powerhouse 1 in 2000. Acoustic signals from $420 \mathrm{kHz}$ hydroacoustic transducers, a $600 \mathrm{kHz}$ acoustic Doppler current profiler, and a $200 \mathrm{kHz}$ multibeam system all added to noise received by the hydrophones (Faber et al. 2001). Electric noise from a stepper motor at Lower Granite Dam in 2002 resulted in enough noise to make tracking of tagged fish through an acoustic array in the forebay impossible when the motor was operating.

Electrical noise due to motors was detected by hydrophones in the tailrace during our study. A gate that automatically adjusted at the downstream end of the fish ladder near the location of hydrophone 2 added recorded noise whenever it was operating. Though noticeable, the noise event was short. This is evident by comparison of the median sound amplitude for hydrophone 2 (Figure 4.8) with the number of sound pressure detections per hour (Figure 4.6). Though amplitude measurement plots for this hydrophone make the environment look noisy, the number of actual noise detections is low. The amplitude of the noise is important because the number of noise events above threshold level that are recorded will affect detection and tracking of an acoustic tag.

\subsection{Performance of Ultrasonic Fish Tracking System}

The performance of the UFTS was primarily evaluated by determining the tracking capability of the UFTS during different project operations. Tracking juvenile salmon and drogues that were released either directly into the tailrace or that were detected entering the tailrace from the forebay was achieved, although the resolution of their paths was generally low. Results of acoustic tracking were similar to what is achieved with fixed radio-telemetry, although we did attain a much better underwater range of detection using the ultrasonic tracking array than can be obtained with radio telemetry. Although radio telemetry can produce aerial detection coverage that can extend for great distances (kilometers in some instances), radio detection capability varies in fresh water when a fish's depth is greater than about $5 \mathrm{~m}$, whereby denser arrays of radio-antennae are required to sufficiently locate juvenile salmon. Radio-telemetry detection also varies with range to a receiv ing antenna and the depth of a tagged fish. With our underwater ultrasonic tracking array, we were able to receive signals from tags up to $75 \mathrm{~m}$ away during spill operations at all depths. Unfortunately the overlap of the detection ranges for four hydrophones was not sufficient to trilaterate the position of a tag, either due to the loss (inoperation) of a hydrophone from environmental causes or because the detection range of a hydrophone was reduced due to spill or powerhouse operations.

The ultrasonic fish tracking system did provide us with useful measures of tailrace egress such as the tailrace residence time of juvenile salmon, and general route of tailrace egress. With these measures we were able to compare the egress times of juvenile salmon to the dam operation and other environmental cues such as diel distribution and tailrace flow composition. The performance of the UFTS was sufficient to relate key behavioral attributes of juvenile salmon to operation of the Lower Granite Dam.

Initial results from the "ping-around" testing that was conducted at the beginning of the feasibility study suggested that detailed tracking of juvenile salmon with implanted ultrasonic tags was possible without spill. However, once spill was initiated, the detection ranges of hydrophones and subsequent tracking ability of the UFTS was reduced. Air entrainment by spill was the most likely cause affecting 
the detection of ultrasonic fish tags and acted to reduce the range by absorbing the acoustic signal (Urick 1983). The maximum range of detection of an ultrasonic fish tag increased the farther a hydrophone was from the spillway or the more isolated a hydrophone was from the spillway. For instance, hydrophones 8 and 9 were $207 \mathrm{~m}$ and $373 \mathrm{~m}$, respectively, away from the spillway. Hydrophone 2 was isolated from direct spillway flow and located downstream of the powerhouse. The maximum detectable ranges for hydrophones 8 and 9 were $6.7 \mathrm{~m}$ and $34 \mathrm{~m}$ respectively. Hydrophone 2 had the greatest detection range, 83 m, on May 9, 2002.

The number of tags that a hydrophone detected also followed a similar pattern, with the greatest number of detections on hydrophones that were farther away from the spillway, or on hydrophones that were isolated from the direct flow from the spillway (Figure 5.1). Greater detectable range would increase the probability of detection. The detection results also show that generally when the RSW was operating more tags (or fish) were detected at all hydrophones. This is likely due to the number of tagged fish that were available for detection during RSW operation because more passed over the RSW than any other route (Table 4.3). The idea that detection would be improved if hydrophones were isolated from direct spill is further bolstered by results from direct releases of fish into the tailrace. In general, juvenile spring chinook and drogues that were released directly into the spillway had a lower detection percentage than those fish and drogues that were released on the powerhouse side downstream of Lower Granite Dam. One cause of this lower detection was that the spillway side of tailrace had more entrained air than the powerhouse side of tailrace; this entrained air dissipated the acoustic energy of the tag more readily, causing a reduction in hydrophone range, and thus detection coverage on the spillway side of the tailrace.

Our findings support the rejection of the first two null hypotheses:

$\mathbf{H}_{\mathrm{o}}$ : Spill discharge does not influence the precision, accuracy, or tracking ability of the ultrasonic fis h tracking system.

$\mathbf{H}_{\mathbf{0}}$ : Spill discharge does not influence the detection of ultrasonic fish tags.

The differences in the range of hydrophone detection during spill and without spill show that spill does influence the precision, accuracy, and tracking ability of the UFTS. The range of detection for individual hydrophones varied, but was reduced during spill to the point where a fish could not be located in a plane or in 3D space due to a lack of the simultaneous hydrophone detections required to locate a fish. There was not sufficient coverage of the tailrace to detect all fish passing through the tailrace.

A future study that takes advantage of these findings and places hydrophones in aquatic habitat that is isolated from direct spill will dramatically increase the detectability of tagged fish. If the behavior of juvenile salmon in the immediate tailrace needs to be tracked, then placing hydrophones in greater densities with built-in redundancies may be the only alternative. 


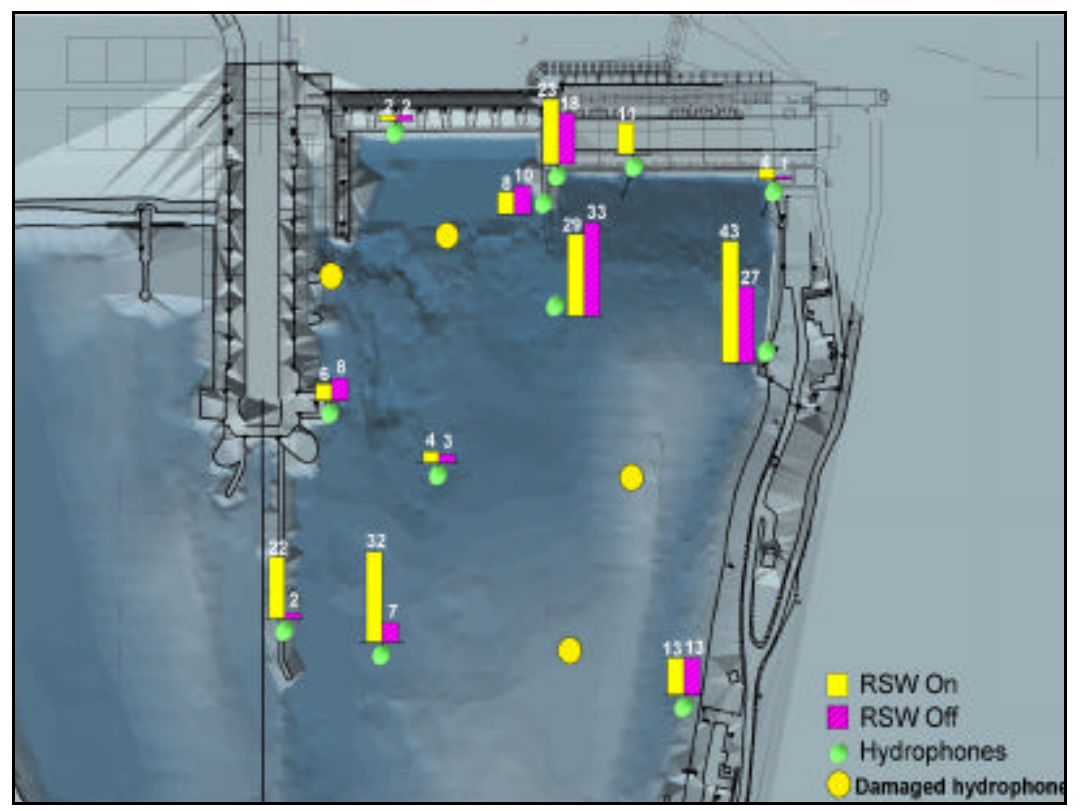

Figure 5.1. Number of BRD-Released Juvenile Salmon that Were Detected by each Hydrophone Based on the Operational State of the RSW. Further detection statistics are shown in Appendix C.

The success of future deployments of ultrasonic fish tracking systems in the tailrace of hydroelectric dams can be much improved. Future research and deployment of UFTS for determining key behavioral attributes of juvenile salmon will be greatly enhanced if the lessons learned from this feasibility study are implemented.

\subsection{Flow Modeling and Habitat}

Ancillary to the primary objectives of this study, which were to determine the feasibility of using an UFTS in the tailrace of Lower Granite Dam, was to describe the movement and distribution of juvenile salmon with respect to their surroundings. Our results did indicate that tracking juvenile salmon was feasible for our deployment, albeit in low resolution, so we were able to provide data on juvenile salmon and drogue movement with respect to the changing project operations. The tailrace habitat was profoundly influenced by dam operations and we had to categorize the environment so that the juvenile salmon behavior in this environment could be described. This categorization included parsing dam operations that were observed during the research period into four separate treatments that were divided at the median discharge that was observed throughout the season (54 kcfs for powerhouse operations, and 24 kcfs for spillway operations).

A representative tailrace condition was modeled for each treatment, which illustrated the dynamic nature of the environment downstream of Lower Granite Dam. The computational model of the tailrace was able to replicate conditions that were observed at the dam for the same project operations. For instance a large eddy downstream of the powerhouse was re-created in the computational model and was similar to what was observed at the dam when it was operating at the high spill (>24 kcfs) - Low 
Powerhouse (<54 kcfs) treatment (Figure 4.20). This changeable tailrace environment directly affected the habitat downstream of Lower Granite Dam. The different discharge levels influenced the egress of juvenile salmon, which will be discussed in the next section, and likely influenced the distribution and composition of aquatic predators such as small mouth bass and northern pikeminnow.

The distribution of predators has been linked to flow characteristics below hydroelectric dams (Petersen 1994, Petersen and Ward, 1999). There was a marked decrease in habitat that was suitable for northern pikeminnow with increased flow from the powerhouse (Mesa and Olson 1993; Table 4.4). The greatest extent of habitat that was suitable for northern pikeminnow $(<100 \mathrm{~cm} / \mathrm{s})$ was during the low powerhouse-low spill, and high spill-low powerhouse treatments. Northern pikeminnow are not necessarily the primary predator of concern at Lower Granite Dam, though their distribution downstream of the lower Columbia River hydroelectric projects is well documented and influences smolt survival.

Another aquatic predator of juvenile salmon, the smallmouth bass, is more populous than is the northern pikeminnow below Lower Granite Dam (Ward et al., 1995) and may have habitat preferences similar to those of the northern pikeminnow (Petersen et al. 2001). Specific dam operations that have a compounded effect of delaying juvenile salmon and creating more habitats that are suitable for predators should be avoided to increase tailrace survival of juvenile salmon. Juvenile salmon that are disoriented are more susceptible to predation (Mesa, 1994), and the tailrace environment contains physical attributes that may cause disorientation of juvenile salmon. If the environment is made so that predators must expend more energy pursuing juvenile salmon than they will gain in capture, predation will be less likely. Also, juvenile salmon may recover as they move downstream from the dam, and increasing the time they are entrained in flow that is not suitable to their predators should aid in their recovery time and survival. The influence that project operations have on the habitat downstream of Lower Granite Dam should be of concern to fisheries managers.

The flow environment within the tailrace changed dramatically over the ranges of discharge from the powerhouse and spillway and influenced the behavior of juvenile salmon exposed to those conditions.

\subsection{Juvenile Salmon Behavior}

Irrespective of the challenges that were faced in deploying an UFTS in the tailrace of Lower Granite Dam, we were able to obtain valuable behavioral information on juvenile hatchery chinook, juvenile hatchery steelhead and juvenile wild steelhead. Those data were obtained from our own releases of juvenile salmon and of neutrally buoyant drogues that were released directly into the tailrace, and from the movement of BRD forebay-released fish into the tailrace under varied project operations.

\subsubsection{Juvenile Salmon and Drogues}

Our initial experimental design was compromised by high late spring runoff causing uncontrolled spill for most of May and early June. After the fact, we divided powerhouse and spillway operations into four different conditions (high powerhouse-spill, low powerhouse-low spill, high powerhouse-low spill discharge, and low spill-high powerhouse) as described above. Juvenile salmon and drogue releases to the tailrace were made under only one tailrace condition, high powerhouse and high spill discharge.

(Table 4.2). The RSW was operational for the spillway releases and two of the four powerhouse releases. 
Juvenile salmon and drogues were released at the spillway downstream of operating spillbays 3 and 6 and at the powerhouse downstream of operating turbine units 2 and 4 . The juvenile salmon and drogues that we released from the spillway and that were detected moved directly (in less than five minutes) out of the tailrace and were only detected by our most downstream hydrophones (Figure 4.23). The acoustic signal of those fish and drogues that were not detected was probably dissipated due to air entrainment caused by spill, although our results are inconclusive on this point. Also spillway-released fish were not detected on any powerhouse hydrophone, suggesting that they passed directly out of the tailrace and did not move to the powerhouse side of the tailrace.

When juvenile salmon or drogues are released at the downstream side of the spillway during this tailrace condition (high spill-high powerhouse), the movement of juvenile salmon seems to be direct and with the main flow out of the tailrace. However, when juvenile salmon or drogues are rele ased from the downstream side of turbine units, their movement is different. Juvenile salmon rele ased from turbine unit 4 were observed to move north and orthogonal to the main flow until they encountered the spillway flow and it was there that they were lost from our tracking array (Figure 4.25). Drogues released downstream of turbine unit 4 had very poor detection rates. It is possible that the drogues passed into areas that were not covered by our hydrophone array at the time of their release.

The high rate of fish detections contrasts with the lower rate of drogue detection, suggesting the fish were taking different routes from those of the passive drogues. This should be investigated with a future study. Those juvenile salmon and drogues released from turbine unit 2 moved in two general directions, north and orthogonal to the flow and down the south bank and out of the tailrace. Juvenile salmon again had a greater detection percentage suggesting the movement of drogues was different than that of the juvenile salmon detected by our hydrophone array.

Route-specific passage information on juvenile salmon and their survival through those routes is an important concern of fishery managers. The route-specific information that was provided by this feasibility study was limited but shows promise for future applications, especially related to survival estimates. The detailed tracking of fish through tailrace routes is not necessarily the primary objective of survival investigations but the detection capability of each tag that is implanted into a fish is necessary so that survival estimates are unbiased for juvenile salmon. Using an UFTS could provide the necessary downstream coverage that is needed. UFTSs deployed downstream of the bulk air entrainment that is generally observed at spillways, and away from powerhouse-generated acoustic noise, would dramatically increase detectability of acoustic tags. Increasing the density of hydrophones would allow greater probability of detection and higher tracking resolution than was managed in this study. Higher detection rates and tracking resolution would permit a given level of confidence in passage route or survivorship estimates to be achieved with fewer tagged fish. The gathering of detailed movement information would be costly using the current technology due to the hydrophone densities that would be necessary to track individual fish so new methods and updates in ultrasonic technology are essential.

The study of juvenile salmon movement in relation to flow is becoming increasingly important for the management of Columbia and Snake River Dams. The movement of juvenile salmon in the forebays of Columbia and Snake River Dams has recently been the focus of many research investigations, which have included the use of computational models and flow data taken in the field. These data sets are being combined and analyzed so that some aspects of juvenile salmon orientation and navigation will be revealed. If the environmental factors such as hydrodynamic stimuli can be described and then modeled, the understanding gained will be useful for decision support of project and river management. These 
models must eventually take into consideration the downstream environment of hydroelectric dams where the habitat is directly and profoundly under the influence of project operations. It is very likely that the rules for fish movement in forebays will not apply to fish in a tailrace. A holistic approach to modeling juvenile salmon behavior that incorporates both their movement and survival near and through hydroelectric dams should be investigated, as well as fish orientation and navigation in unimpounded reaches and rivers so that all habitat types can be evaluated with respect to the behavior of juvenile salmon. Using the advancing technology and methods that are provided by ultrasonic fish tracking systems for use in tailraces and forebays will aid in providing these data and create comprehensive decision support tools that incorporate all the necessary information.

\subsubsection{Juvenile Salmon Behavior after Dam Passage}

Fish from the BRD forebay study that passed the dam into our study area were monitored and juvenile wild steelhead and juvenile hatchery steelhead exhibited different tailrace passage times as a function of the operation of Lower Granite Dam. The time that they spent in the tailrace was significantly longer during the High Spill ( $>24 \mathrm{kcfs})$ - Low Powerhouse ( $<54 \mathrm{kcfs})$ tailrace condition where a large tailrace eddy was present downstream of the powerhouse. The tailrace residence time of juvenile wild steelhead and juvenile hatchery steelhead was also significantly correlated to the powerhouse and spill operations at the dam. Residence time increased with increasing spill and decreased with increasing powerhouse operations. The greatest positive correlation $(\mathrm{r} 2=0.65$ wild steelhead, $\mathrm{r} 2=0.38$ hatchery steelhead) was with the ratio of spill discharge to powerhouse discharge. Juvenile spring chinook tailrace residence times were not significantly affected by changing dam operations, or the four dam operational treatments. The variability of residence time between flow treatments was greater for juvenile spring chinook and showed no significant relationship between tailrace residence and flow treatment.

The diel movement of juvenile salmon with respect to flow conditions did not show any significant change with treatment. Results from observations made on the day and night residence times of juvenile salmon were comparable to those observed for the combined species of forebay-released fish. Juvenile steelhead showed similar trends for daytime and nighttime egress (Figure 4.4.11), and juvenile spring chinook egress time was more variable across flow conditions.

The BiOp spill scenario was the primary spill scenario that resulted in the greatest delay of juvenile hatchery steelhead and juvenile wild steelhead. The combination of these findings provided us sufficient evidence to reject the null hypothesis: Ho: Juvenile steelhead passage route is not influenced by spill pattern.

Our results support the existence of large tailrace eddies and show that these eddies cause delay in juvenile steelhead egress. Our results also indicate that juvenile salmon movement was influenced by the relative discharges of the powerhouse and spill and not influenced by daytime or nighttime entry into the tailrace. This is not likely to be unique to Lower Granite Dam. Hydroelectric dams with similar layouts to Lower Granite Dam should be expected to have comparable tailrace flow conditions. Powerhouse and spillway layout and relative orientation at a hydroelectric project, as well as tailrace bathymetry, are important physical attributes that influence the way eddies form in the immediate downstream environment of a dam. Hydroelectric projects such as the four lower Snake River Dams, as well as McNary Dam and John Day Dam on the Columbia River, are examples of hydroelectric dams where the spillway is adjacent to the powerhouse and those dams are predisposed to establishing conditions where 
large tailrace eddies will form. Formation of eddies depends on the relative discharge of spill bays and turbines at the dam.

Our flow model and observations showed that during the Low Powerhouse - High Spill flow condition more habitat existed that was suitable for northern pikeminnow (Mesa 1993), than existed during the two of the other three tailrace conditions tested (treatments) because of the creation of large eddies and slack water areas that were produced by those conditions. The High Spill - Low Powerhouse tailrace condition delayed juvenile steelhead in the tailrace and may have created more suitable habitat for northern pikeminnow and possibly for other piscivorous fishes. Although ours was not a survivorship study, we suggest that the combined delay, expansion of habitat suitable for predators, and disorientation of juvenile salmon may increase predation on juvenile steelhead during this tailrace condition as compared to the other three that were tested. Juvenile chinook showed more variable responses to tailrace conditions, and we could not make inferences based on their observed movement.

While the routes of juvenile salmon were less defined than we anticipated, the time that juvenile salmon took to leave the tailrace suggests that powerhouse and spill discharge can influence the behavior of juvenile salmon. Expanding the scope for future studies that investigate juvenile salmon behavior in hydroelectric dam tailraces will provide valuable information on route-specific survival. Ultrasonic fish tracking technology will provide a valuable tool that may be used to investigate juvenile salmon movement.

\subsection{Recommendations for Future UFTS Deployment}

The greatest challenge with using ultrasonic fish tracking technology in spillway tailraces of hydroelectric facilities that employ spill as a means to improve juvenile salmon survival is the maintenance of an array of sensitive hydrophones in the dynamic flow environment. Once this is accomplished, ultrasonic fish tracking can be very effective for describing the movement of juvenile salmon. The deployment of tailrace hydrophones must also be optimized to meet study objectives for either gross tailrace movements such as what would be required in survival studies or to describe detailed tailrace movement of juvenile salmon.

Tailrace arrays of hydrophones for survival type studies would need to cover key exit routes that will be used by juvenile salmon where the concentration of hydrophones will provide tailrace residence time and gross movement patterns. An example of this type of deployment may be a hydrophone array that is deployed in a line that spans the river with hydrophones every $50 \mathrm{~m}$, so that the tailrace exit location and time to exit are known to within $50 \mathrm{~m}$. It is possible that a dense array of hydrophones could provide fine-scale movement information on tagged fish. It is not likely that, due to air entrainment in the immediate vicinity of a spillway, fine-scale movement will be observed there. Areas within a tailrace where the route of juvenile salmon is of concern and air entrainment and noise are low must be identified and sufficiently covered so that fish movement can be estimated with adequate precision. Sufficient coverage of such areas would entail dense arrays of hydrophones and would provide two-dimensional tracking ability within those areas.

Three-dimensional tracking would not likely be possible when using the existing technology. Advances in tag or system development of ultrasonic fish tracking technology must be made to track tagged fish in three dimensions within a tailrace. Limitations of the present UFTS are specific to the 
shallow tailraces of hydroelectric dams, where the separation of bottom- and surface-mounted hydrophones is insufficient to solve for tag position in three dimensions. The dynamic tailrace environment also limits the possibility of surface deployment of hydrophones to a greater extent than do forebays but, with careful planning, future investigation of juvenile salmon behavior in the tailraces of hydroelectric dams will provide valuable information. 


\subsection{Conclusions and Recommendations}

Based on PNNL's and USGS's ultrasonic fish tracking study at Lower Granite Dam in spring 2002, we make the following conclusions and recommendations.

\subsection{Conclusions}

It is feasible to track juvenile salmon in the tailraces of hydroelectric facilities. With our underwater ultrasonic tracking array, we were able to receive signals from tags up to $75 \mathrm{~m}$ away during spill operations at all depths.

Large tailrace eddies delay juvenile steelhead. These eddies occurred with relatively high spill operations ( $>24 \mathrm{kcfs}$ ), and relatively low powerhouse operations ( $<54 \mathrm{kcfs}$ ), the threshold of which can only be determined through extensive physical model runs or computational model runs. The delay of juvenile chinook or drogues was not observed during tailrace conditions where large tailrace eddies were observed.

Adequate hydrophone density depends on the detection range, which is a function of entrained air and noise, and the required tracking resolution. Precise tracking in very noisy and turbulent environments, such as spillways and tailraces, requires very dense arrays. A less dense array may be adequate for less precise tracking such as studying routes through quieter volumes. Simply studying passage at a point, such as in a survivorship study, may be possible with a fairly simple linear array.

Alternate methods of hydrophone deployment, such as a denser array with more closely spaced hydrophones and greater redundancy or moving the hydrophones downstream in the tailrace away from the effects of direct spill, would likely provide very high levels of detection of tagged fish released for studies that measure the survival of juvenile salmon through dam passage routes. The actual number of hydrophones needed would depend on the deployment and tailrace environment relative to a specific deployment, but we speculate that, if the array is deployed at more than $2000 \mathrm{ft}$ downstream of the spillway, with sufficient coverage across the channel (e.g., one hydrophone every $75 \mathrm{~m}$ ), one is likely to see detections of $>95 \%$. This can, and should, be tested in the field through the study period to confirm.

Advances in 3D acoustic fish tracking technology are needed to track fish in three dimensions in a hydroelectric dam tailrace, although two-dimensional tracking is possible using the existing technology as long as specific guidelines for deployment are followed.

\subsection{Recommendations}

Limiting the formation of large tailrace eddies is recommended to reduce delay and improve survival of juvenile salmonids.

Tests using UFTS in tailrace areas should be completed in as little time as possible to minimize hydrophone and cable exposure to potential damage from the dynamic flow and water-borne objects. 
For accurate tracking in highly turbulent environments, hydrophones should be deployed in a dense array that includes redundancies in case of hydrophone damage (e.g., one hydrophone every $49 \mathrm{~m}^{2}$ ). In turbulent tailrace environments, hydrophones should be located at the downstream end of the tailrace away from the effects of direct spill.

The detection capability of a UFTS would be greatly improved if moved downstream at least away from the effects of direct spill, or have a denser deployment of hydrophones that includes redundancies in case of hydrophone damage. We would recommend array placement at least 1,100 feet from a spillway that is spilling at $10 \mathrm{kcfs}$. At this distance and spill, you can expect a hydrophone to be able to detect a tag at least $34 \mathrm{~m}$ away from the hydrophone. (This was the maximum spill seen out of one spillbay and minimum distance measured for hydrophone \#9 during a similar spill condition for our study.)

Use of directional hydrophones would increase the signalto-noise ratio, and therefore increase the detectability of tags for selected tailrace areas. Directional hydrophones have much smaller effective angles and so interrogate much smaller volumes than do omnidirectional hydrophones. 


\subsection{References}

Adams, N.S., D.W. Rondorf, S.D. Evans, J.E. Kelly, and R.W. Perry. 1998. Effects of surgically and gastrically implanted radio transmitters on swimming performance and predator avoidance of juvenile chinook salmon (Oncorhynchus tshawytscha). Can. J. Fish. Aquat. Sci. 55:781-787.

Anderson, J.J., B.E. Feist, R.T. Miyamoto, and S.O. McConnell. 1989. Measurement of Low Frequency Sound at Bonneville, McNary and Lower Granite Dams - 1988. Fisheries Research Institute University of Washington School of Fisheries. Prepared for USACE Portland District.

Beamesderfer, R. C., D. L. Ward, and A. A. Nigro. 1996. Evaluation of the biological basis for a predator control program on northern squawfish (Ptychocheilus oregonensis) in the Columbia and Snake rivers. Canadian Journal of Fisheries and Aquatic Sciences 53:2898-2908.

Brown, M.B. \& Forsythe, A.B. (1974) : Robust test for the equality of variances. Journal of the American Statistical Association. Vol. 69: pp. 364-367.

Carlson, T.J., M.A. Weiland, V.K. Sutton, A.R. Wirtz, M. Macaulay, and J.R. Skalski. 2002. Ultrasonic 3_D Tracking of Fish and Drogues Passing through a Kaplan Turbine Intake at McNary Dam, 1999 \& 2000. Report prepared for the U.S. Army Corps of Engineers, Walla Walla District, Walla Walla, Washington.

Cash, KM, NS Adams, TW Hatton, EC Jones and DW Rondorf. 2000. Three-dimensional fish tracking to evaluate the operation of the Lower Granite surface bypass collector and behavioral guidance structure during 2000. Annual Report of Research.

Faber, D. M., T.J. Carlson, M. A. Weiland, and R. W. Moursund. 2001. Evaluation of ThreeDimensional Fish Behavior Associated with Fish Passage Thru, Around, or Under Prototype Surface Flow Bypass Structures. Preliminary report submitted to Portland District, U.S. Army Corps of Engineers.

Faber, DM, TJ Carlson, KM Cash, SA Zimmerman, JR Skalski, P Westhagen, J Lady. 2002. Design of acoustic 3D tracking arrays for fish behavior studies. US Army Corps of Engineers.

Friesen, T. A., and D. L. Ward. 1999. Management of northern pikeminnow and implications for juvenile salmonid survival in the lower Columbia and Snake rivers. North American Journal of Fisheries Management 19:406-420.

Gadomski, D. M. and J.A. Hall-Griswold. 1992. Predation by Northern Squawfish on Live and Dead Juvenile Chinook Salmon. Transactions of the American Fisheries Society 121: 680-685.

Gregory, R. S. and C.D. Levings. 1998. Turbidity Reduces Predation on Migrating Juvenile Pacific Salmon. Transactions of the American Fisheries Society 127: 275-285.

Knutsen, CJ, and DL Ward. 1999. Biological Characteristics of Northern Pikeminnow in the Lower Columbia and Snake Rivers Before and After Sustained Exploitation. Transactions of the American Fisheries Society: Vol. 128:1008-1019, 1999. 
Mesa, M. 1994. Effects of Multiple Acute Stressors on the Predator Avoidance Ability and Physiology of Juvenile Chinook Salmon. Transactions of the American Fisheries Society: Vol. 123, No. 5, pp. 786-793.

Mesa, M G. T.M. Olson. 1993. Prolonged swimming performance of northern squawfish. Transactions of the American Fisheries Society. 122:11041110.

NMFS (National Marine Fisheries Service). 2000. Biological Opinion. NMFS, Seattle Washington.

Perry, Russell W., Noah S. Adams, Dennis W. Rondorf, 2001: Buoyancy Compensation of Juvenile Chinook Salmon Implanted with Two Different Size Dummy Transmitters. Transactions of the American Fisheries Society: Vol. 130, No. 1, pp. 46-52.

Petersen, J. H. 1994. Importance of Spatial Pattern in Estimating Predation on Juvenile Salmonids in the Columbia River. Transactions of the American Fisheries Society 123: 924-930.

Petersen, J. H. and D.L. Ward. 1999. Development and Corroboration of a Bioenergetics Model for Northern Pikeminnow Feeding on Juvenile Salmonids in the Columbia River. Transactions of the American Fisheries Society 128: 784-801.

Petersen, J., C. Barfoot, and M. Sheer. 2001. Predation by northern pikeminnow on juvenile salmonids in The Dalles Dam tailrace: field, laboratory, and habitat modeling studies (FY2000). Draft report to the Portland District of the US Army Corps of Engineers, Portland, OR.

PNNL. 1997. Biological Studies to Determine the Effects of Shear and Turbulence Stresses on TurbinePassed Fish, Draft FY97 Work Plan. Submitted to Ben Rinehart, Idaho National Engineering and Environmental Laboratory, Idaho Falls, ID.

Poe, T, S. Anglea, A. Giorgi. 2001. synthesis of Radio Telemetry, Hydroacoustic, and Survival Studies of Juvenile Salmon at John Day Dam (1980 - 2000). Draft Report to the U.S. Army Corps of Engineers.

Rieman, B. E., R. C. Beamesderfer, S. Vigg, and T. P. Poe. 1991. Estimated loss of juvenile salmonids to predation by northern squawfish, walleyes, and smallmouth bass in John Day Reservoir, Columbia River. Transactions of the American Fisheries Society 120:448-458.

Steffler, P. and J. Bla ckburn. Two-Dimensional Depth Averaged Model of River Hydrodynamics and Fish Habitat. Users Manual. University of Alberta. September, 2002.

Urick, R.J. Principles of Underwater Sound. 1983. McGraw-Hill, Inc. 423 p.

Ward, D. L., and M. P. Zimmerman. 1999. Response of smallmouth bass to sustained removals of northern pikeminnow in the lower Columbia and Snake rivers. Transactions of the American Fisheries Society 128:1020-1035.

Weiland, M.A. and T.J. Carlson. In prep. Evaluation of Light Emitting Tags and Ultrasonic Technologies to Characterize Hydraulic Conditions and Fish Locations During Turbine Passage. Prepared for U.S. Department of Energy Idaho Operations Office, Idaho Falls, Idaho. 